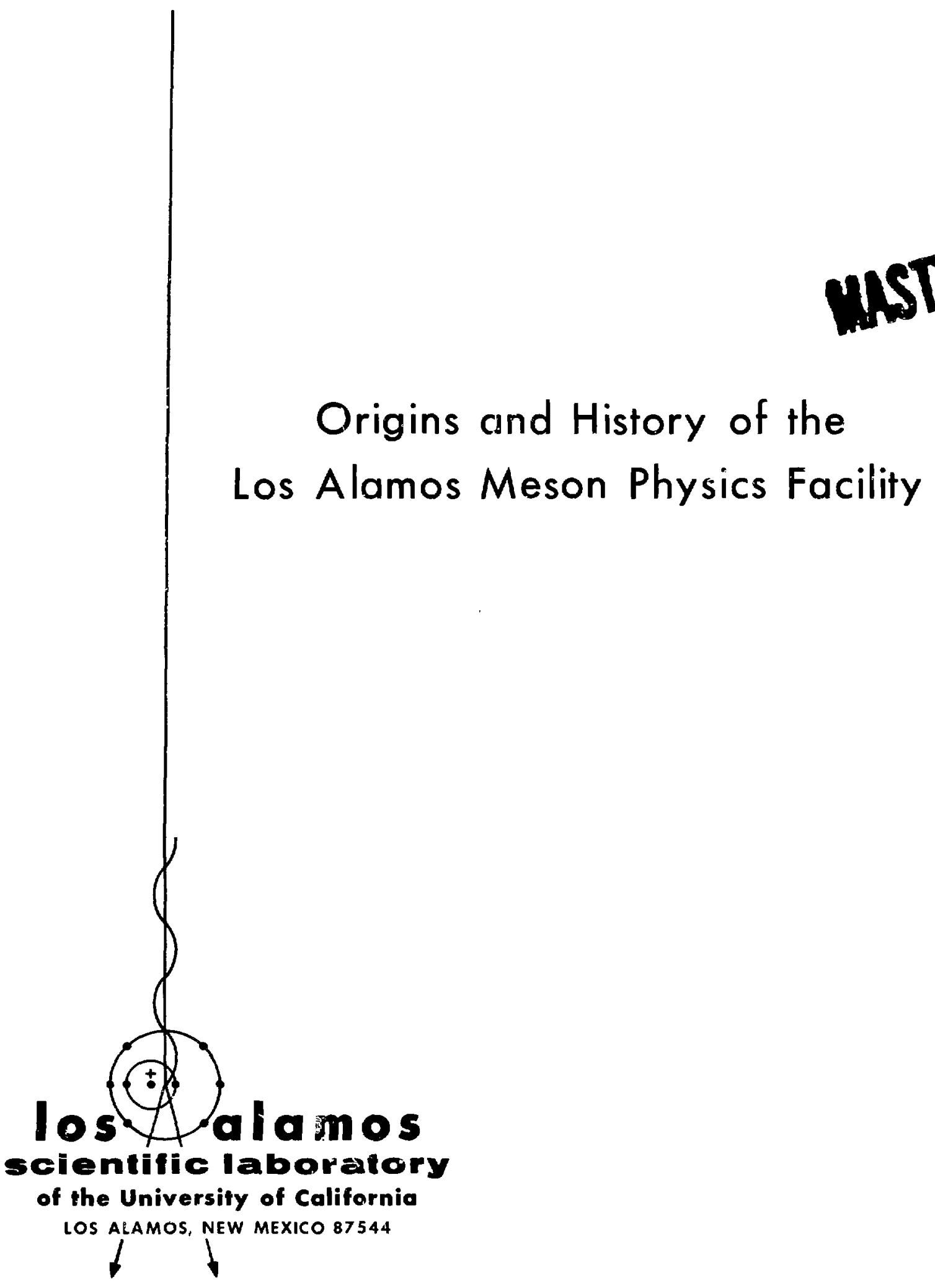


This report was prepared as an account of work sponsored by the United States Government. Neither the United States nor the United States Atomic Energy Cornmission, nor any of their employees, nor any of their contractors, subcontractors, or their employees, makes any warranty, express or implied, or assumes any legal liability or responsibility for the accuracy, completeness or usefulness of any information, apparatus, product or process disclosed, or represents that its use would not infringe privately owned rights.

Printed in the United States of America. Available from National Technical Information Service .

U. S. Department of Commerce

5285 Port Royal Road

Springfield, Virginia 22151

Price: Printed Copy \$3.00; Microfiche \$0.95 


\title{
LA-5000
}

UC-23, 28, \& 34

ISSUED: June 1972

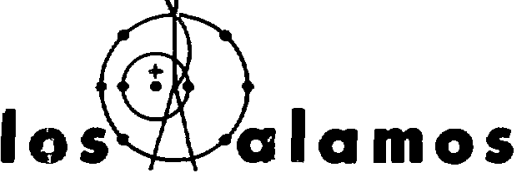

scientific laboratory

of the University of California

IOS ALAMOS, NEW MEXICO 87544

1

\section{Origins and History of the}

Los Alamos Meson Physics Facility

\author{
by
}

M. Stanley Livingston*

*Consultant to the Los Alamos Scientific Laboratory.

NOTICE

This report was prepored as $n$ account of work sponsored by the United States Government. Neither the United States nor the United States Atomic Energy Commission, nor any of their employees, nor any of their contractors, ubcontractors, or their employees, makes any warranty, express or implied, or assumes any legal linbility or responsibility for the accuracy, completeress or usefulness of uly information, apparatus, product or process disclosed, or represents that its use would not infringe privately owned rights. 


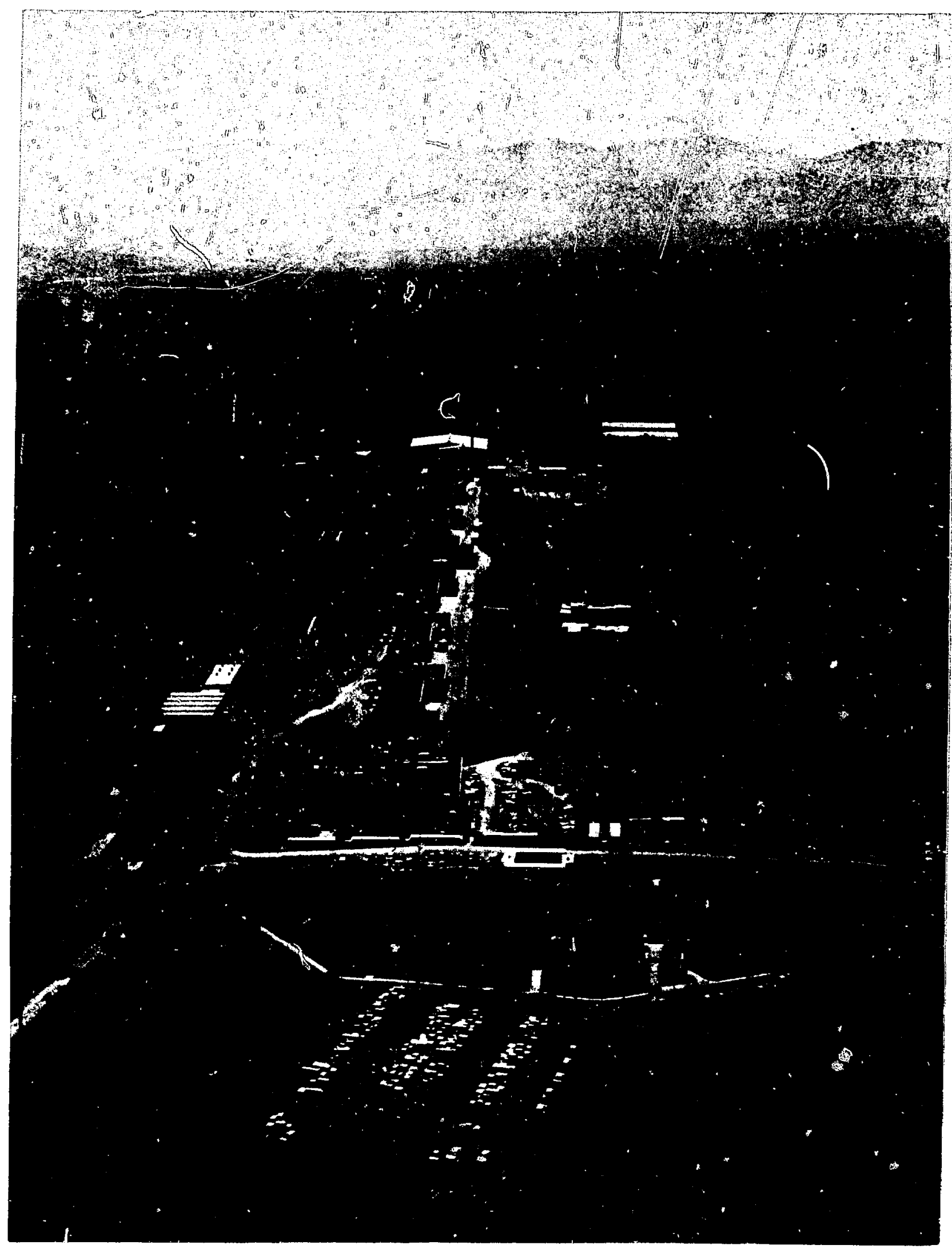




\section{CONTENTS}

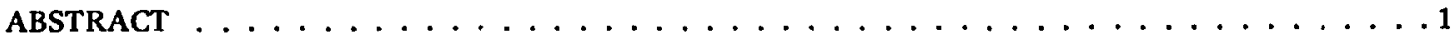

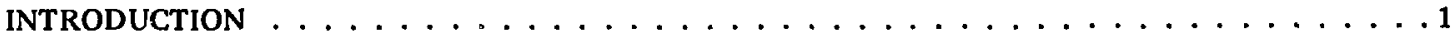

CHAPTER 1. ORIGIN OF THE LAMPF PROPOSAL $\ldots \ldots \ldots \ldots \ldots \ldots$

CHAPTER 2. AEC AND CONGRESSIONAL ACTIONS ON LAMPF FUNDING $\ldots \ldots \ldots$

CHAPTER 3. ACCELERATORS FOR MESON FACTORIES $\ldots \ldots \ldots \ldots \ldots$

A. Early Linear Accelerators $\ldots \ldots \ldots \ldots \ldots \ldots$

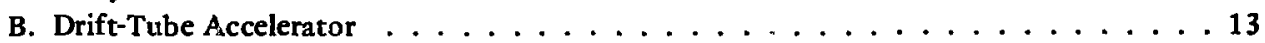

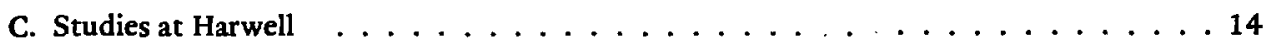

D. Studies at Yale and Brookhaven $\ldots \ldots \ldots \ldots \ldots \ldots$

E. High-Intensity Cyclotrons $\ldots \ldots \ldots \ldots \ldots$

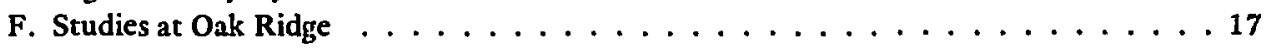

G. Studies at UCLA . . . . . . . . . . . . . . . . . . . 19

H. Low-Intensity Meson Facilites $\ldots \ldots \ldots \ldots$

I. Intense Neutron Generator . . . . . . . . . . . . . . . 21

CHAPTER 4. TECHNICAL DEVELOPMENTS AT LAMPF $\ldots \ldots \ldots \ldots \ldots \ldots$

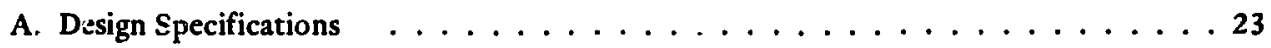

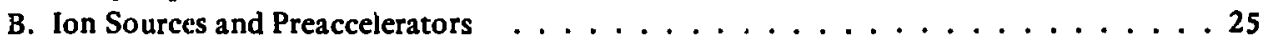

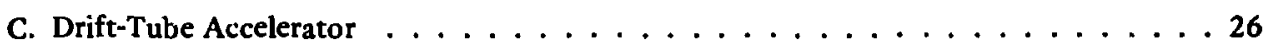

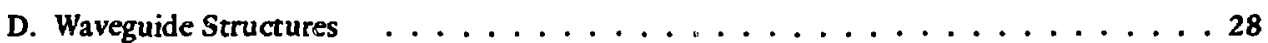

E. Radiofrequency Power Systems $\ldots \ldots \ldots \ldots \ldots$

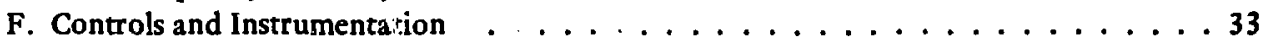

G. Beam and Target Handling . . . . . . . . . . . . . . 34

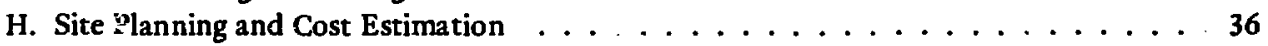

CHAPTER 5. ORGANIZATION AND ADMINISTRATION $\ldots \ldots \ldots \ldots \ldots \ldots \ldots \ldots \ldots$
A. Design Phase . . . . . . . . . . . . . . . . . . . 39

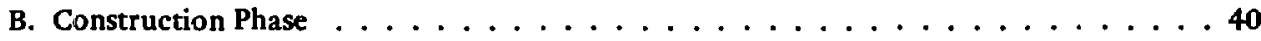
C. Operations Phase ....................... . . 41

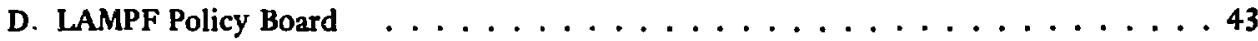

CHAPTER 6. SCIENTIFIC USE AND RESEARCH FACILITIES $\ldots \ldots \ldots \ldots \ldots \ldots$

A. LAMPF Users Group . . . . . . . . . . . . . . . . 45

B. Research Facilities . . . . . . . . . . . . . . . . 47

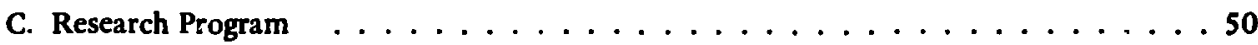

D. Program Advisory Committee $\ldots \ldots \ldots \ldots \ldots \ldots \ldots$. . . . . . . . .

E. Radioisotope Production . . . . . . . . . . . . . 51

F. Biomedical Facility $\ldots \ldots \ldots \ldots \ldots \ldots \ldots \ldots$

Appendix A: LAMPF CONSTRUCTION STAFF, JULY $1971 \ldots \ldots \ldots \ldots$ APpendix B: UNIVERSITIES AND LABORATORIES PARTICIPATING IN FIRST LAMPF USERS

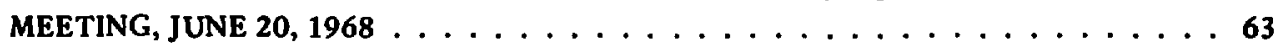

Appendix C: USERS GROUP. Los Alamos Meson Physics Facility . . . . . . . . . . . . 65

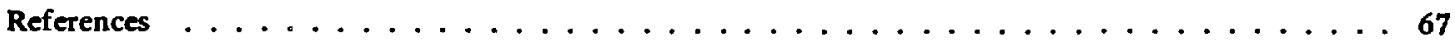


ORIGINS AND HISTORY OF THE

LOS ALAMOS MESON PHYSICS FACILITY

by

M. Stanley L.ivingston, Consultant

\begin{abstract}
This monograph presents a history of the Lus Alamos Meson Physics Facility (LAMPF) from initiation of preliminary plans and proposals in 1962 to the present. It includes the year-by-year story of the actions of the Atomic Energy Commission, the United States Congress, and the Bureau of the Budget relative to funding the project. It also discusses the discovery, subsequent interest, and proposed applications of the pi-meson.
\end{abstract}

\title{
INTRODUCTION
}

The purpose of this study is to search out the origins of the concepts inve lved in the design and development of the Los Alamos Meson Physics Facility, and to write the history of the LAMPF project. This search for historical origins quickly leads to an awareness of many facets of the story, each of which deserves a separate survey; yet each is incomplete in itself and has meaning only as a part of the whole. The procedure used here is to treat the several areas of interest in separate chapters or sections, as indicated in the Contents, although the reader will note many cross linkages.

The most pertinent historical sequence is the story of the local group that conceived and carried our the project at Los Alamos. This includes the series of preliminary plans and trial proposals that started in 1962, the responses from the Atomic Energy Commission, and the impact of the several advisory panel studies. This basic sequence is presented in Chap. 1.
A sequence of fundamental importance, but of a more formal nature, is the year-by-year story of the actions of the Atomic Energy Commission, the United States Congress, and the Bureau of the Budget relative to funding the LAMPF project. The actions of the Joint Committee on Atomic Energy are of particular significance in this sequence. These negotiations and decisions and their eventual results are described as a running story in Chap. 2.

C. F. Powell and his associates at the University of Bristol in England discovered the pi-meson (or pion) in photogaphic emulsions exposed to cosmic rays at high altitudes in 1947. Further studies showed that the pimeson was a strongly interacting particle of short lifetime $\left(2 \times 10^{-8} \mathrm{sec}\right)$ that decayed into a weakly interacting particle called the mu-meson (or muon). The muon was the original meson, discovered in 1932 in cosmic rays by Carl Anderson; it is also unstable, decaying into an 
electron (and two neutrinos) with a lifetime of $2 \times 10^{-6}$ sec.

The first observation of pi-mesons in the laboratory was by A. L. Gardner and C. M. G. Lattes, in 1948, using a $400-\mathrm{MeV}$ proton beam from the 184-in. synchrocyclotron at the University of California Radiation Laboratory. For the next ten years synchrocyclotrons in several laboratories in the United States and abroad (of several hundred $\mathrm{MeV}$ energy) were used for the study of production cross sections and basic properties of pi-mesons and their decay products. Proton intensities from synchrocyclotrons were initially low and the research was limited in scope. At an early stage, it became clear that pi-mesons were highly efficient in the production of other nuclear interactions; their use as incident projectiles for mesoninduced inieractions became a further goal. However, to exploit this field properly would require much higher intensities of mesons and so much higher intensities of accelerated protons than were available from synchrocyclotrons.

The growing awareness of the importance of the research field of meson physics was a basic contributing factor and provided the external pressure that made the LAMPF proposal successfal. Of particular interest is the story of the competition between the several laboratory groups that designed and requested support for highintensity meson-production facilities, and the reasons why the t:.sk was assigned to the Los Alamos Scientific Laboratory (LASL). This part of the story is told in Chap. 3.

Another aspect of the history of this field is the evolution of the concept of the "meson factory" as a research facility. A meson factory is a very high-intensity accelerator of intermediate energy (less than $1 \mathrm{GeV}$ ) which produces intense beams of secondary radiations, primarily pions. Such a facility is expected to provide new tools for the study of nuclear structure and to open new fields of research. Our knowledge of nuclear structure has increased steadily with the continuing study of mesonproduced interactions. The scientific motivation has also stre.ıgthened as machines have-been developed to produce ever higher intensities. Scientists in many institutions have become interested in meson research and have started planning experiments that will become possible only with really intense meson beams. An important aspect of
LAMPF history is this rapidly growing scientific interest which came from the cross-fertilization of ideas between scientists from many institutions.

Other parts of the story include the origins of the important technical features that made the LAMPF proton linac a practica! answer to the needs. This part of the history starts with basic features developed at other linacs and briefly described in Chap. 3 ; again, it shows the importance of collaboration between workers in different laboratories. Details wil! interest experts in this engineering field. For example: How were modern linac structures such as the side-coupled cavity developed from their elementary origins? And who first recognized the necessity of a change in the type of accelerating structure and the frequency of acceleration above 100 to $200 \mathrm{MeV}$ ?

Within the LAMPF laboratory, the origins of some of the technica! developments are nut always clear and assignment of individual credit may be questionable. To the extent that memories and laboratory records allow, such technical contributions are identified in this study and are described in Chap. 4. However, much of the credit still remains to be shared jointly by the entire LAMPF staff including the many engineers, technicians, and machinists. Each had his part in perfecting the thousand-andone details which haye made the completed accelerator sucressful.

The administrative and organizational practices are discussed in Chap. 5. The changing structure of the Divisions and Groups within LASL, and the responsibility assignmiants to leading members of the staff are also described. For completeness, a list of the staff involved in the construction of LAMPF during 1971 is given in Appendix A.

The planning for the scientific use of the facility, including new administrative arrangements to expedite cooperation between LAMPF and the university scientists, is treated as a separate part of the study and is discussed in Chap. 6. Included is the story of the growth of interest and support for a biomedical facility to explore opportunities for treatment of human tumors with meson beams. It is hoped that this procedure of describing the various aspects separately will result in a readable acccunt of the story of this important new research facility, LAMPF. 


\section{CHAPTER 1}

\section{DRIGIN OF THE LAMPF PROPOSAL}

Long before LAMPF was proposed and funded as a maior new research facility, the seeds from which it would grow were germinating within the Los Alamos Scientific Laboratory. Although LASL was originally established as a mission-oriented Laboratory and was funded primarily through the Division of Military Applications of the Atomic Energy Commission, a tradition had become established of the importanre of basic research to the uitimate goals of the Laboratory. The Physics Division supported many programs in basic atomic and nuclear research and in the development of instrumentation for this research. Most staff members of the Physics, Theoretical, and other scientific Divisions had advanced degrees and research training, as did many members of the applied science Divisions. Staff interest in new research fields and associated design studies were generally supported by the Administration. This readines: to support fundamental research projects at LASL vias known of and approved by AEC officials as authorized DMA policy.

One area in which Los Alamos scientists became interested was nuclear and particle physics based on highenergy accelerators. During the period 1954 to 1957 a group of LASL scientists and outside consultants made preliminary design studies for two machines: a $2-\mathrm{GeV}$ spiral-ridge $F M$ synchrocyclotron and a $12-\mathrm{GeV}$ proton synchrotron. The design effort continued at a rather low level for two to three years. The staff members most actively involved were D. Nagle, H. Argo, F. Ribe, A. McGuire, and F. B. Harrison, supported by J. M. B. Kellogg, Physics Division Leader. However, there were no strong spokesmen to argue for and to promote the projects, the LASL Administration was lukewarm, and the design studies were terminated without results. In retrospect, it seems that such highenergy machines, which are useful primarily for research in highenergy particle physics, were considered inappropriate to the Los Alamos mission by Administrative and AEC Staff. So this accelerator design program faded away into the files.
The recorded story of LAMPF started in 1962 when Louis Rosen sent a memorandum ${ }^{1}$ to Kellogg suggesting a program for future physics facilities at the Los Alamos Scientific Laboratory. The significant feature of Rosen's memorandum was its emphasis on the scientific importance and the growing feasibility of the "meson factory," a very high-intensity accelerator of energy 500 to 800 $\mathrm{MeV}$, with which a program of studies of nuclear physics could be launched using secondary beams of pi-mesons as probes. This memo pointed out the need for updating the LASL facilities and suggested that the Atomic Energy Commission be "forcefully apprised" of the potential importance of a meson facility at Los Alamos. Rosen's interest had been indicated earlier that year when he attended a Conference ${ }^{2}$ on sector-focused cyclotrons at Los Angeles in April. One of the papers, by Prof. Roy Haddock of UCLA, was on "The Role of the Pion Factory in Elementary Particle Physics." Another, by Lloyd Smith of the Lawrence Radiation Laboratory at Berkeley, was on a "Comparison of Accelerator Types" for use as meson factories.

The memorandum was only one example of the continuing urge at LASL to develop new physics opportunities. Rosen's interest was paralleled by other scientists in the Laboratory who joined with him in studies of the scientific opportunities and in the engineering design problems. Several staff members wrote letters in direct support of Rosen's proposal: Keilogg transmitted Rosen's memo to the Director, Norris Bradbury, with his enthusiactic approval; Charles Critchfield of the Theoretical Div: sion sent a supporting memo to Kellogg; Prof. Hans Bethe, an important early mrmber of LASL and a continuing consultant to $T$ Division, wrote in support to Bradbury; and Richard Taschek, Alternate P-Division Leader, indicated his interest in a letter to J. C. Severeins of the AEC Research Division. At an early stage, Leona Marshall (Libby) suggested that Rosen enlist Nagle, aiso of the Physics Division. Nagle left his studies of the 
Mossbauer effect and became Rosen's chief supporter and the first local expert on accelerator technology.

The first order of business was to decide which type of accelerator to use. Several LASL scientists, including Nagle, John Marshall, R. Taschek, E. Knapp, D. Hagerman, and others visited other laboratories in this country in which high-intensity machines were being studied. During the summer of 1962 teams of LASL staff members visited and talked with experts at Berkeley ( $R$. L. Thornton), Oak Ridge (R. Livingston), Yale (R. L. Gluckstern), MURA (D. W. Kerst), UCLA (J. R. Richardson), Argonne (A. V. Crewe), and also Stanford and Princeton. Potential scientific users at LASL and several visiting scientists were consulted. From all these investigations the conclusion was the same-that a proton linac was probably the most satisfactory type, everi though it was expected to be the most costly. The linac was favored by an impressive majority of potential users because of its superior beam quality, high intensity, and ease of extraction.

Others at Lo: Alamos joined in the effort. Knapp, Hagerman, and McGuire became active in design planning, L. Marshall studied the optimum energy range, and several members of the Theoretical Division contributed to the discussion of the scientific use. During this period of planning, the activities in accelerator design were considered a normal and proper part of the Physics Division program, and were conducted in a rather informal manner. On September 1, 1962, Taschek was named Leader of the Physics Division. However, before he left for his new assignment in the Director's Office, Kellogg made plans to organize a new Group (P-11) to formalize the growing linac design group. On this same date Rosen became Aiternate Physics Division Leader. He reduced his research activities on polarization in nuclear interacticns and became increasingly active in planning for the research use of the new facility. Rosen left the technical planning and design to others but his enthusiasm and leadership attracted other members of the Physics Division to join the design study group. The LASL Administration and the local AEC representatives were fully informed and were very helpful during this phase of planning for a meson facility.

This intense activity brought immediate visible results. By December a preliminary version of a Proposal $^{3}$ had been prepared by 19 members of the LASL staff and 3 consultants. The Proposal included a discussion of the sciertific motivation and described a proposed study program for utilizing mesons and other secondary radiations. It included design criteria of the accelerator (based in large part on Yale Report Y-6), descriptions of necessary buildings and facilities, and manpower and cost estimates. An important appendix was a report by William $\mathbf{B}$. Brobeck Associates on a comparison of particle

accelerators for meson production, which gave relative characteristics, yields, and costs. Again it was concluded that the proton linac offered the best performance, although at the highest initial cost. The basic characteristics of the linac described in the initial proposal are shown in Table 1. Many features in this list of parameters were retained, essentially unchanged, in the final design.

By the start of 1963 many members of the LASL staff had become interested or involved in the planning for a meson facility. This was recognized within the Physics Division by the formation on February 1 of a new Group, P-11, with Nagle as Group Leader, to cooruinate the planning. Among the more active members of the Group were Nagle, Knapp, Hagerman, and McGuire. They became an informal "steering committee" and met frequently to discuss the technical studies and to coordinate the engineering aspects of the planning. T. Putnam became a mernber of this steering committee when he transferred to Group P-11 in April 1964: and McGuire left the Laboratory in January 1965 . For two years after its formation, P-11 group members wrote more than 20 technical papers on various aspects of linac design; the results of their studies are also recorded in quarierly Progress Reports. ${ }^{4}$ A sampling of the topics studied illustrates the

TABLE I

LINEAR ACCE LERATOR CHARACTERISTICS

(from Preliminary Proposal, December 28, 1962)

Rate of energy gain Total peak rf power Total average if power Macroscopic duty factor Injection energy Total accelerator power Beam loading

\section{Proton energy
External average
beam current
Overall length
Radio frequency}

Drift-tube (Alvarez) design is used below $200 \mathrm{MeV}$ and iris-loaded waveguide (Hansen) design is used above this energy.

Focusing is accomplished by quadrupole magnets in the drift tubes and between waveguide sections.

Triode amplifier tubes are used at $200 \mathrm{MHz}$ and coaxitrons at $800 \mathrm{Mhz}$ or klystrons at $1200 \mathrm{MHz}$. 
coverage and identifies most of the LASL staff members active in design.

a. Beam dynamics calculations - Hagerman, Milich, and Visscher.

b Radiofrequency structures calculations - Hoyt.

c. RF structures, experimental - Hagerman, Knapp, Schlaer, and Furnish.

d. RF amplifier study - McGuire, Furnish, and Freyman.

e. Experimental area - McGuire, Whetstone, Logan, and Marshall.

f. Beam blow-up in a linac cavity - Gluckstern and Butler.

g. Acceierating structures - Potter, Knapp, and Lucas.

h. Electron analog tests - Brolley, Emigh, and Mueller.

i. An 805 Mc amplifier - Hagerman, Doss, Freyman, and Parker.

j. RF phase and amplitude control - Jameson and Turner.

k. Electrical behavior of long linac tanks - Nagle.

1. Tests on a cloverleaf cavity - Knapp, Parker, Doss, Freyman, and Schlaer.

m. Digital computer for linac control - Putnam, Jameson, and Schultheis.

n. Linac error analysis - Butler.

A presentation, in the form of an outline of the initial proposal, was given by Rosen to the High Energy Panel of the AEC General Advisory Committee and the President's Scientific Advisory Committee in January 1963 , and was later published as a LASL report. ${ }^{5}$ One of the next steps was a study of the work schedule, organization, and budget requirements ${ }^{6}$ for the project, reported in April 1963. In August, the LASL Administration submitted to the AEC a Schedule 44, Construction Project Data Sheet, entitled "Los Alamos Meson Physics Facility," estimated at a cost of $\$ 47,142,000$. Other reports followed rapidly, although some were only restatements of the basic proposal for special purposes. Two papers presented by Rosen and Nagle at a Meeting of the Association of Rocky Mountain Universities on December 18,1963 , for the purpose of discussing prospects for collaboration, were published as a LASL report. ${ }^{7}$ As of this date, the planning activity was still being referred to internally as LAMP (Los Alamos Meson Project). The acronym "LAMPF," coming from the title of the Schedule 44, came into general use during the following year.

For the record, it should be noted that this design activity was an authorized part of the Physics Division program and was supported by funds allocated by the Division of Military Applications (DMA) of the Atomic
Energy Commission. The major expenditures during the early years before AEC Research Division funds became available were for salaries of staff and technical personnel diverted into the design study. The total funds provided by the DMA during FY 196:, 1964, and 1965 were estimated to be $\$ 2,380,000$. When Research Division funds became available, most of the salary budget was transferred to the new account. However, some DMA support continued in the form of LAMPF overhead absorbed by LASL, Engineering Department support, and General Plant Projects. During FY 1966 to 1971, inclusive, such supporting funds continued at a level of approximately $\$ 900,000$ per year.

The Schedule 44 submission brought the first official response from the AEC Division of Research. A meeting that included Los Alamos representatives $\mathrm{L}$. Rosen, P. Franke, D. Hagerman, and D. Nagle was held on October 25, 1963, in Paul W. McDaniel's office to discuss the various aspects of research, development, plarining, and the associated costs and schedules for the proposed Los Alamos Meson Physics Facility. The project was tentatively included in the budget of the Division of Research for the coming fiscal year (FY 1965).

This was only nominal AEC recognition of the existence of the new program. It was clear that the Research Division required further backing by the Commissioners and general support by the scientific community before the LAMPF project could be funded. With an estimated budget of about $\$ 50,000,000$, it was the most costly scientific facility yet proposed in the field of basic nuclear research. Competing proposals for meson factories had been received by the AEC from several other institutions. The Research Division proceeded to survey the mood of leading scientists. Also, McDaniel appointed an ad hoc committee of scientists from the Southwest and Rocky Mountain areas, chaired by G. A. Kolstad of the Research Division, to study the problem of a regional scientific facility at Los Alamos for the study of mediumenergy pion physics and to advise the AEC on the scientific and te 'inical merits of the proposal.

The report ${ }^{8}$ of this "Kolstad Committee," which was issued on March 17, 1964, recognized the unique features of the proposed Meson Facility and suggested that it would make an important contribution to the scientific and educational growth of the Southwest and Rocky Mountain regions, as well as becoming a major spur to the scientific strength of the Los Alamos Scientific Laboratory. It was considered at that time to be a regicnal form of a national laboratory that would involve many local universities in a previously undeveloped form of cooperation with Los Alamos. The report was highly complimentary and recommended that funds be appropriated to implement the proposal at the earliest possible 
date. The Committee also recognized that security regulations at LASL would need to be examined and probably modified to minimize possible handicaps.

Meanwhile, in late 1962 the General Advisory Committee (GAC) to the AEC and the President's Scientific Advisory Committee (PSAC) established an Advisory Panel to "review the status of high-energy accelerator physics and to make recommendations as to the future program in this field." This joint GAC/PSAC Panel held a series of meetings and hearings during the winter and the AEC published their Report ${ }^{9}$ in April 1963. The "Ramsey Report," named for the chairman of the Panel, Prof. Norman F. Ramsey of Harvard, made several recommendations concerning high-energy accelerators, including a $200-\mathrm{GeV}$ proton synchrotron designed at the Lawrence Radiation Laboratory and a $12.5-\mathrm{GeV}$ high-intensity fixed field alternating gradient (FFAG) accelerator proposed by the MURA group at Madison. The report did not consider high-intensity machines of less than 1-GeV energy, stating that a $12.5-\mathrm{GeV}$ machine would serve most of the needs for a high-intensity accelerator in the field of elementary particle physics.

The Ramsey Panel Report did not include the needs for lower-energy accelerators to support nuclear structure physics. In addition to the AEC, the National Science Foundation and the Department of Defense supported programs in this field, and the responsible staff members were aware of the growing pressures for additional facilities. Among these pressures was the expanding interest in accelerators of very high intensity with energies below $1 \mathrm{GeV}$ - the "meson factories." By early 1963, there were four groups proposing to build such facilities: Yale (with Brookhaven), Oak Ridge National Laboratory, University of California at Los Angeles, and the Los Alamos Scieritific Laboratory.

In December 1963, the Administration made a policy decision against building the MURA very high-intensity FFAG accelerator for $12.5 \mathrm{GeV}$ protons. This decision implied that the subject of meson factories needed to be studied further.

In late 1963, Donald F. Hornig, Director of the Offic: of Science and Technology, established an Advisory Panel on Meson Factories, chaired by Professor Hans A. Bethe, to consider the usefulness of high-intensity accelerators for nuclear structure research and the needs for this tyde of facility. The Panel met on December 4-5, 1963, and at several successive times. The "Bethe Panel Report" 10 was issued in March 1964 and made a series of specific suggestions. They proposed that only one meson facility be built; it should have variable proton energy up to a maximum between 500 and $800 \mathrm{MeV}$; it should be built in a National Laboratory; and it should support the scientific needs of a well-organized group of "user" universities. The report commented on the relative merits of the several types of machines, and made it clear that the proton linac was preferable for several reasons, including intensity, variable energy, and ejection efficiency. A disadvantage of the linac was its small duty cycle. Although there was no definite choice indicated, the several specific recommendations pointed strongly toward the LASL proposal for a proton linac as the leading contender. Because of its importance in the decision-making process of awarding the meson factory to Los Alamos, the members serving on this Panel are listed in Ref. 10.

One of the administrative anomalies discussed in the Bethe Panel Report concerned the budgetary arrangements for supporting this medium-energy high-intensity research field. It was not included in the high-energy particle research budget and had not yet been recognized as part of the low-energy research field of nuclear physics. The Bethe Panel suggested that the Low-Energy Nuclear Structure budget should be substantially increased to include at least one meson factory.

At the April 2-4, 1964, meeting of the AEC General Advisory Committee, the LASL proposal for a meson factory was presentrid by Rosen, Nagle, and Taschek. The GAC also had the report of the Bethe Panel auailable and concurred with the general recommendations. However, they had not been briefed on the other meson factory proposals, and were concerned with the impact of funding such a costly proposal as LAMPF on the national program of support for low-energy nuclear physics; in consequence, they did not make a specific recommendation for LAMPF.

However, in April the AEC Research Division made $\$ 500,000$ of Construction, Planning, and Design funds available to LASL to define the scope, design the basic characteristics, and develop reliable estimates for the LAMPF project. These funds were for design planning only and carried no assurance of future support. The funding did allow LASL to increase the design effort (the personnal applied to LAMPF averaged 15 during FY 1965) and to employ an architect-engineering (A/E) firm to develop cost estimates.

A policy decision made by the AEC in May 1964 stated that medium-energy physics utilizing high-intensity radiations from particles accelerated to energies of up to $1000 \mathrm{MeV}$ constituted an important area of research that was germane to the needs and interests of the AEC. This intermediate-energy field was to be supported by a budget separate from low-energy nuclear physics and high-energy particle physics.

With the report of the Bethe Panel it had become clear to members of the Oak Ridge Accelerator Division that their proposal for an " $\mathrm{Mc}^{2}$ Cyclotron" was not filvored in the meson factory competion. A. Weinberg, Director of ORNL, wrote to McDaniei recommending consideration of a new type of accelerator, the separated 
orbit cyclotron (SOC), and urging that the AEC not commit funds for a meson factory until the SOC could be evaluated and a second ORNL proposal could be prepared.

This was the situation at the July 6-8 meeting of the GAC. McDaniel discussed the policy of dividing accelerator physics into three categories, wirh meson facilities in an intermediate-energy class. He also expressed concern with the divided opinion of the scientific community, as he had sampled it, in view of the expected funding limitations for accelerator-based physics. For these and other reasons, the GAC recommended that the meson facility not be included in the FY 1966 budget.

The engineering and cost study of the LAMPF proposal, " which had been authorized by the AEC, was completed by September 2,1964, and was transmitted to the Division of Research. In addition to supporting the local model study program, $\$ 500,000$ was used to obtain the services of several commercial firms: Radio Corporation of America and Continental Electronics performed parallel studies and made cost estimates of the radiofrequency power systems; Edgerton, Germeshausen and Grier, Inc., made a study of the control system; and Giffels and Rossetti, Inc., produced an architectengineering study of the buildings and site requirements with the help of Brobeck and Associates on the machine components. From these studies a final cost estimate was developed and presented to the AEC in a Schedule 44 dated October 30,1964 , for a total of $\$ 55,000,000$. This became the base costestimate figure during future negotiations. The time schedule for construction was estimated as six years. 


\section{CHAPTER 2}

\section{AEC AND CONGRESSIONAL ACTIONS ON LAMPF FUNDING}

The winter of 1964-65 was a period of great uncertainty regarding future prospects for funding the LAMPF proposal, or even continuing the design study. The President's budget for FY 1966 did not provide any funding to continue the meson facility program. In November 1964, Bradbury provided infoimation on the LAMPF proposal and its prospects to the Hon. Clinton P. Anderson, U.S. Senator from New Mexico. On Senator Anderson's advice, copies were sent to the other members of the Joint Committee on Atomic Energy and its staff. In January 1965, Bradbury talked with McDaniel about his concern over the future prospects for the project. Bradbury's stated first preference was for full authorization for construction by Congress in FY 1966; his second preference was for authorization for detailed design at about $\$ 4$ million plus about $\$ 2.5$ million for research and development (R\&D) in FY 1966; a third and minimal possibility was a line item of $\$ 500,000$ for further progress on Title I design plus $\$ 2.5$ million for $R \& D$. When a Santa Fe newspaper reported on January 25 that LAMPF was not in the President's budget and requested comment from LASL, Bradbury's comment was "We seem to have lost the battle, but we have not yet lost the war. ... If we do not make it this year, we will certainly increase our efforts to get it in next year."

Special open hearings were held on March 2-5, 1965, in Washington before the Subcommittee on Research, Development and Radiation of the Joint Committee on Atomic Energy (JCAE) on the subject of HighEnergy Physics Research. About 40 physicists testified and the complete testimony was published in a Congressional Report ${ }^{12}$ released June 29. Among other reports, Rosen described the purposes, plans, and status of the LAMPF project. At the conclusion of the discussion, Glenn Seaborg testified that the AEC regarded the Bethe Report as AEC Policy, and that it was only a matter of timing as to when the meson factory could be financed in competition with the numerous other items competing for the budget. In response to a question by Chairman
Holifield, he replied that there was no money for further design of the LAMPF project in the FY 1966 budget.

The Joint Committee on Atomic Energy continued hearings on the AEC Authorization Legislation for FY 1966 on March 10. The new category called Medium Energy Physics was described by McDaniel. It had a budget of $\$ 7.5$ million, but it did not include any item for LAMPF. However, when the report of the Authorization Legislation was released by the JCAE, it carried an item of $\$ 9$ million for Medium Energy. Physics, an increase of $\$ 1.5$ million. This increase was described as a reallocation of $\$ 1$ million from the weapons program and $\$ 500,000$ from High Energy Physics. The Committee specified that \$2 million of the funds for Medium Energy Physics were to be utilized for $R \& D$ in advanced design studies for the proposed LAMPF project. The Coinmittee also recommended construction funds of $\$ 1.2$ million for partial A/E work for this facility under a new plant and capital equipment authorization. The Committee stated its expectation that the FY 1967 authorization bill should include funds for construction of the LAMPF facility, currently estimated at $\$ 55,000,000$.

The House Appropriations Committee approved the $\$ 9$ million budget for Medium Energy Physics but did not approve the $\$ 1.2$ million for partial $A / E$ for the LAMPF facility; however, the Committee on Appropriations of the Senate restored this cut. The final Appropriation Bill for the AEC for FY 1966, as approved by both houses of Congress and signed by the President, provided the $\$ 1.2$ million in construction funds for LAMPF A/E work as well as the $\$ 2$ million for advanced design studies (R\&D) specified by the JCAE.

In November 1965, an article published in the LASL magazine, The Atom, described the progress in the linac design. In particular, it reported the new accelerator cavity scheme which had been developed - the sidecoupled cavity - and which promised to increase efficicncy and reduce tuning troubles. It was reported to be a significant advance in the evolution of linacs and was 
expected to reduce future linac costs. This article was noted by a member of the Joint Committee staff, Colonel Jack Rosen, who inquired of the AEC whether this might reduce the cost estimate for the LAMPF facility. This caused some confusion for the AEC budget planners and required a letter from Bradbury to the JCAE explaining that the new devclopment would make a better machine and allow the duty cycle to be increased, but would probably not reduce the cost. Incidentally, it may be noted that later utilization of the idea by commercial firms did demonstrate the advantages of side-coupled structures for electron linacs of 4- to $12-\mathrm{MeV}$ energy.

At this point it might be assumed by an inexperienced observer that the battle over the funding for LAMPF had been won and that construction support was assured. This was not the case, as the story told in the remainder of this chapter will attest. There was also a disconcertingly long delay (to the LAMPF staff) in the authorization for spending of the funds that had been appropriated. The Congressional Appropriation Bill for the AEC for FY 1966 was nor passed and signed by the start of the fiscal year, but, as has become common in recent years, was delayed by pressure of Congressional business until September. Next, a financial plan for disbursement of the appropriated funds had to be prepar. ed by the AEC and approved by the Bureau of the Budget (BoB).

From information received later from AEC representatives, $^{13}$ it seens that questions concerning the justification for the LAMPF project had arisen within the Bureau of the Budget. Charles L. Schultz, Director of the BoB, was concerned with the construction funding of \$SS million planned for the FY 1967 budget. He had noted the $\$ 4$ million authorization by the National Science Foundation to Columbia University for increasing the intensity of the Nevis synchrocyclotron, and wondered whether this might provide an acceptable substitute for LAMPF. He questioned the necessity for the $800-M e V$ energy of LAMPF, having been informed that $\$ 10$ million could be saved by reducing energy to $500 \mathrm{MeV}$. with only minor changes in scope. He also questioned the need for the continued support for design of the ORNL Separated Orbit Cyclotron. Answers to these and other questions were provided by the Division of Research and by Chairman Seaborg, who strongly supported the prograin for LAMPF. The authorized funds of $\$ 1.2$ million in construction funds for $A / E$ work and $\$ 2$ miltion in operating funds for FY 1966 were finally allocated to LASL in January 1966. Although these funds were restricted to design activities and no assurance was given of full construction funding, this date is generally taken to be the start of the definitive design phase of the LAMPF project.
Meanwhile, design activities had not been allowed to lose momentum at LASL. A new Division of Medium Energy Physics (MP Division) was formed in July 1965 with Rosen as Division Leader and Nagle and Tesche as Associate Division Leaders. A primary purpose was to continue with the design and development of the meson facility. With the Congressional authorization, the AEC felt justified in allowing LASL to anticipate funding to maintain progress. By February 1966, a contract had been negotiated with Giffels and Rossetti, Inc., of Detroit, for the A/E work on the major pertion of the LAMPF building complex. A 6000 square foot "mock-up" addition to the P-Division building was nearing enmpletion to house waveguide prototypes, an $800-\mathrm{MHz}$ power amplifier, controls and other components of a test system. A 40-cell piototype of the waveguide (Model B) was in progress. The of systems were also in an advanced stage of development. By February the MP Division had a staff of 61 with 18 persons from other LASL divisions contributing to the effor General agreement existed within the project that the desired beam quality could be achieved throughout the linac without requiring unduly severe electrical and mechanical tolerances.

The President's Budget for FY 1963, when submitred to Congress, included $\$ 3$ million of construction funds to continue $A / E$ work, and $\$ 2.9$ million in operating funds under Medium Energy Physics for continued R\&D for LAMPF. The JCAE agreed to this continuation of support for design and again postponed full authorization for construction to the following year. In due course these budget items were acted upon favorably by the Appropriations Committecs, passed by the Congress, signed by the President, and allocated by the Bureau of the Budget.

During the remainder of calendar 1966 and on into 1967, the design activities for LAMPF continued. The limitation to design activities only was liberally interpreted by the AEC to include full-power prototype development, site clearance, and many other related activities that could only be justified on the assumption that authorization of constnuction would follow. This was clearly the intent of the Joint Committee and of the AEC. For example, the site preparation was extended to include bulldozer excavation of the entire linac tunnel and experiniental area region, and was included within the $\$ 3$ million of $\Lambda / E$ work.

On Septcmber 10, 1966, Vice.President Humphrey visited Los Alamos and was given a briefing about the meson facility. It became known that President Johnson had indicated his support for the LAMPF project. In October 1966, LASL was host to the International Conference on Linear Accelerators, which brought togerher many of the world's foremost experts in the field. 
In preparing the FY 1968 budget, the AEC Research Division requested funding of $\$ \mathbf{5 0 . 3}$ million for the remainder of the construction cost. However, the final version of the AEC budget request to the BoB did not include any construction funds for LAMPF and the item did not appear in the President's Budget submitted to Congress. Hearings on the AEC Authorization Legislation for FY 1968 were held by the JCAE in February 1967, at which Rosen was again invited to testi: $y$. Rosen informed the Cornmittee of the status of LAMPF design progress and of the increasing scientific interest. He also discussed the potential use of negative pion beams for radiation therapy of deep-seated tumors. In the report by the JCAE on these hearings there is stated: "The Committee recommends approval of the full amounts requested by the Cummission for operating expenses and plant and capital equipment obligations proposed for this subprogram (Medium Energy Physics) in the coming fiscal year.' This included the authorization of new obligations of $\mathbf{\$ 5 0 . 3}$ million for the meson physics facility at Los Alamos.

However, the House Appropriations Committee, in its report to the Congress, recommended a reduction of $\$ 39.9$ million in the request for LAMPF to convert the fiuancing to an annual appropriation basis instead of the full funding proposed in the budget estimates. This represented a major change in Congressional policy regarding the inding of line items of this type. All previous accelerator installations had I:ad construction costs authorized in full. The Appropriations Committee stated that because of the large construction cost involved, it would be desirable for Congress to review construction cost and progress annually. This recommendation was accepted by the House and the Senate and the bill was approved by the President. So the LAMPF budget authcrized for FY 1968 included only $\$ 10.4$ million for construction.

Physical construction (Titic III) actually began in the carly spring of 1968 . Acting on the expectation of a $\$ 10.4$ milion construction budget, the LAMPF staff had obtained bids for several of the buildings on the site and for several long-delivery items of materials and equipment. Then in November 1967, the Bureau of the Budget requested from the AEC an analysis of the impact of a nine-nonth deferral in the stari of construction. This was in anticipation of the FY 1968 Public Works Appropriation Bill, which was awaiting the President's signature and which called for a frecze on spending of new construction funds. With heavy hearts, a reduced program of construction was prepared and submitted by LAMPF planners. After considerable discussion and negotiations, a revised total of $\$ 3.7$ million was allowed and allocated for the fiscal yenr.

An important event in this year was the first operation of the Electron Prototype Acceleratot on: December 21. 1967. which operated as planned and confirmed the validity of basic concepts and design criteria for the 800-MHz waveguide system. A long-delivery order was placed for copper-clad steel for the tanks of the Alvareztype linac to provide the first $100 \mathrm{MeV}$. A contract was awarded in January 1968 to J. R. Brennand Co. for construction of the Equipment Test Laboratory, the first building on the LAMPF site.

The groundbreaking for this first building of the LAMPF complex was held on February 15. Due to inclement weather the ceremony was transferred on short notice to the platform of the auditorium in the LASL Administration Building. Senator Clinton P. Anderson, Chairman Glenn Seaborg of the AEC, and Louis Rosen wielded gold-plated shovels in a box of earth brought from the site. Also present at the ceremonies were Congressman Thomas Morris; AEC Commissioners James T. Ramey and Gerald Tape; and General Manager R. E. Hollingsworth, President Charles J. Hitch, and Vice President Emeritus Robert Underhill of the University of California; University of California Regents Edwin Pauley, Elinor R. Heller, John Canady, and Theodore Meyer; Dr. A. Ray Chamberlain of Colorado State University representing Associated Western Universities, Inc., and from LASL the Director, Norris Bradbury, and many membels of the staff.

The authorization for FY 1969 followed a pattern similar to earlier years. The final action of Congress, with the approval of the President, resulted in an appropriation of $\mathbf{\$ 1 8 . 7}$ million in construction funds. In summary, by June 30,1968 , approximately $\$ 7$ million in construction funds had been committed and another $\$ 7$ million of authorized funds was being held in reserve by the BoB. The new funds for FY 1969 raised the authorized total to about $\$ 33$ million, or $60 \%$ of the estimated cost.

Then in September 1968, a serious threat occurred when the Bureau of the Budget withheld $\$ 26$ million of capital funds (authorized for LAMPF by Congress and requested by the AEC) that had not yet been allocated. Later information shows that Mr. Charles J. Zwick, Director of the BoB, acting under restrictive orders from President Johnson, was concerned about continuing the LAMPF project in future years and questioned whether or not construction could be pursued of both LAMPF and the $200-\mathrm{BeV}$ accelerator in Illinois. This action by the BoB soon became known in Los Alamos where it caused acute dismay at the administrative level. Bradbury protested strongly to the AEC. The Commissioners were also seriously concerned and requested reconsideration by the BoB. Fortunately, this effort was successful and the BoB agreed to release the FY 1969 funds for LAMPF. The good news was received at LASL on October 10, 1968. Bradbury and Rosen and others concerned were greatly relieved and heartened. 
LASL requested $\$ 15.3$ million for FY 1970 to maintain the construction scheduls. However, the President's Budget allowed only $\$ 5$ million for LAMPF. On request, Rosen estimated the impact on the project of a one-year deferment of $\$ 10.3$ million of construction funds to be a six-month postponement of completion date and an increase in cost of about $\$ 1$ million. Strong letters of protest from Bradbury and the LAMPF Policy Board were transmitted to the AEC. The JCAE held hearings on the AEC Authorizing Legislation for FY 1970 in April 1969, where McDaniel testified and gave a status report on LAMPF. Rosen was present at the hearings and was again asked by Chairman Hoiifield to comment. Despite all efforts, the final action by Congress and the President was to provide only $\$ 5$ million in construction funds for FY 1970.

This result called for a restudy of LAMPF priorities and schedules, with the purpose of trying to maintain the date of June 30, 1972, for initial operation of the accelerator, even though some of the research support facilities might be delayed. It was found that some of the funds allocated to contingency had not been required and could be reassigned to construction. It still seemed possible to meet the initial operation date under revised priorities, although less essential items would be postponed and the total cost for completion would be increased by $\$ 1$ million.

The President's Budget to Congress for FY 1971 included $\$ 10.5$ million in construction funds, leaving a balance of $\$ 6.7$ million to reach the revised total estimate of $\$ 56$ million. In the JCAE hearings on the AEC Authorizing Legislation for FY 1971, McDaniel testified that these amounts would, hopefully, enable the LAMPF staff to produce an initial beam by the summer of 1972 and to complete all construction by the summer of 1973. Rosen was in attendance and discussed the LAMPF status and plans for a Biomedical Facility. The final action by Congress and the President was for $\$ 10.5$ million in construction funds for FY 1971.

Rolling with the punches had become so customary that there was a feeling of great relief at LASL when the FY 1972 construction budget for LAMPF of $\$ 6.7$ million was arnounced - sufficient to complete construction of the facility. This amount was listed in the President's budget announced in late 1970; by late 1971 it was passed by Congress and signed into law. The $\$ 56$ million total included a $\$ 1$ million increase due to postponement of scheduled needs for FY 1971, but otherwise was the same amount estimated at the start of the project in 1965 - an admirable record. By early 1971 the most important unfunded items were the Biomedical Facility and housing for the beam assigned to classified weapon's research, neither of which had been included at the start.

This period of political promotion and financial juggling was in retrospect an exciting and successful one. The record related above will change some preconceived ideas about the monolithic momentum of the Atomic Energy Commission.

The importance of the Joint Committee in influencing the funding process stands out over that of any other arm of government, including the Congress. Certain individuals contributed significantly to forwarding the LAMPF project over its successive hurdles. The iwo members of the Joint Committee from New Mexico, Senator Clinton Anderson and Representative Thomas Morris, served as watchdogs to guard the LAMPF budget time after time. Senator Anderson used his high prestige for direct approaches to the President on several occasions. Representative Morris was influential through his membership on the House Appropriations Committee. The Chairman of the JCAE for several terms during the period of LAMPF funding was Representative "Chet" Hollifield, and he proved a gond friend and supporter. Two members of the JCAE staff were also extremely helpful in expediting approvals of LAMPF budget items and in keeping the LASL staff informed: Mr. Jonn Conway had a legal background and Col. Jack Rosen was a military officer with a Master's Degree in Physics who handled the technical problems. Later, Col. Rosen transferred to the AEC as assistant to Commissioner Tape where he continued his activities in support of LAMPF until his untimely death in 1970 . The JCAE really took an interest in the fate of the Los Alamos meson project; they rescued it from Congressional and Bureau of the Budget attacks year af ter year. In a speech at the National Accelerator Conference in 1969, Representative Hosmer of the JCAE spoke of "forcing the meson on a reluctant administration." In recalling the history of LAMPF, it is well to re cognize the understanding and foresight of those dedicated members of the Joint Committee and their staff who watched and cared for the fledgling LAMPF and brought it through to full stature. 


\section{CHAPTER 3}

\section{ACCELERATORS FOR MESON FACTORIES}

\section{A. Early Linear Accelerators}

The linear accelerator provides a method of obtaining high-energy particies by use of repeated small pushes. The concept is as old as the child's swing and must have occurred to many inventors in the days before the technology that was required to implement it was developed. The earliest written proposal was by Ising $^{14}$ in 1924 , but it was premature due to the rudimentary state of the electrical art, and did not result in a wroking model.

The concept that made the linear accelerator a practical possibility was resonance of the moving particles with an alternating radio-frequency electric field. In 1928, Wideröe* described $^{15}$ the resonance principle and a working prototype of a two-step linear accelerator. A ridiofrequency voltage was applied to an arrangement of tiree cylindrical electrodes in line such that the particles were accelerated on crossing each of two successive gaps between electrodes, emerging with an energy equivalent to twice the applied voltage. The length of the tubular electrode, the voltage and frequency of the applied if and the type of ions $\left(\mathrm{Na}^{+}, \mathrm{K}^{+}\right.$) were chosen to allow the ions to be accelerated while crossing each gap, and to be shielded by the central "drift tube" during the decelerating half cycle of the radio frequency ( $r f$ ).

Ernest $O$. Lawrence of the University of California was inspired by Wideröe's paper to invent, in 1929 , the magnetic resonance accelerator that later gained fame under the name "cyclotron." While the cyclotron was being developed, David H. Sloan, a student working under Lawrence's direction, constructed a much improved version of Wideröe's linear accelerator for mercury ions. A set of 30 drift tubes of increasing length (to match the

*In 1972 Rolph Wideröe, this ingenious and versatile inventor, is still active in the laboratory of the Brown-Boveri Company in Zurich. increasing ion velocity) were connected alternately to two bus bars. The capacitance of the drift tubes was resonated with an inductive coil at a frequency of $7 \mathrm{MHz}$ and powered by a homemade $20-\mathrm{kW}$ power oscillator tube. The limitations of the drift-tube system and oscillator and the low frequency restricted the type of particles in resonance to heavy ions. With this arrangement, Sloan and Lawrence ${ }^{16}$ were able to accelerate $\mathrm{Hg}^{*}$ ions to 1.26 $\mathrm{MeV}$ in 1931. Later, Sloan and Coates ${ }^{17}$ accelerated $\mathrm{Hg}^{+}$ ions to $2.85 \mathrm{MeV}$ using an improved apparatus and bombarded a number of targets; no nuclear events were observed, only $x$ rays characteristic of the materials. Still later. Kinsey ${ }^{18}$ built a linear accelerator for $\mathrm{Li}^{+}$ions at energies up to $1 \mathrm{MeV}$, also with negligible scientific results.

These early resonance accelerators were not able to accelerate protons, or other light ions, due to the limitations of the rf technology of the time. As a resuit, they were not useful for nuclear studies or disintegrations and were abandoned in favor of the cyclotron.

\section{B. Drift-Tube Accelerator}

At LAMPF the first $100 \mathrm{MeV}$ of acceleration is produced in a drift-tube-type linear accelerator, similar in many respects to other linacs presently used as inje:-tors for high-energy accelerators such as AG proton synchrotrons.

Luis W. Alvarez of the University of California Radiation Laboratory proposed, in 1946, to build a linear proton accelerator to be driven by existing if power oscillator tubes developed for radar systems and designed to operate at about $200 \mathrm{MHz}$, which were then available as war surplus. The accelerator consisted of a long cylinder resonant at this frequency, with an array of $\mathbf{4 5}$ drift tubes of increasing length (to match particle velocity) 
mounted along its axis. The loaded cavity operated in the $2 \pi$ mode, a modification of the $\mathbf{T M}_{010}$ mode. Protons were preaccelerated to $4 \mathrm{MeV}$ in a horizontal electrostatic generator before injection into the linac. The resunant cylinder was formed of shaped copper sheet mounted within a steel vacuum chamber and was water cooled; both the copper cylinder and the enclosing vacuum chamber were formed in two halves that were split along a horizontal center line and could be opened to service and align the drift tubes. The first linear accelerator ${ }^{19}$ of this type was completed at Berkeley and protons were accelerated to $32 \mathrm{MeV}$ in October 1948. The Alvarez linac has been described as the successful fusion of the resonant acceleration principle (Ising, 1924; Wideröe, 1928; Sloan and Lawrence, 1931) with the high-power of techniques developed for radar during World War II.

In the ensuing 20 years there have been major improvements in the engineering techniques used for construction, and the output energy has been increased to $200 \mathrm{MeV}$. But the basic principle of the drift-tube linac and the basic arrangement of structures for acceleration have been retained without significant modification except for the addition of post couplers. Engineering improvements have been the result of work in many laboratories and have involved a great deal of consultation and cooperative effort in which individuai credit is difficult to assign. The most significant of thest modifications are listed.

a. Improvement of mechanical tolerances in construction.

b. Improvement of of properties of materials and joints.

c. Use of improved pumps, seals, and vacuumconditioning techniques.

d. Use of automatic temperature controls to stabilize frequency.

e. Use of quadrupole lenses in drift tubes for focusing.

f. Use of copper-clad steel in iank construction.

g. Use of post couplers to change operation from $2 \pi$ to $\pi / 2$ mode.

b. Radiation "hardening" with ceramic insulation.

A listing ${ }^{20}$ of the major Alvatez-type linacs built or under construction by 1971 is given in Table $I 1$.

\section{Studies at Harwell}

There seems to be no doubt that the first recorded plans for a medium-energy, high-intensity proton linac intended to produce quantities of pi-mesons were developed in England in the early 1950's by a group of scientists and accelerator experts mostly from the fatomic
Energy Research Establishment (AERE) at Harwell. ${ }^{21}$ The earliest record of interest in this field is a letter ${ }^{22}$ dated November 21,1950 , from T. G. Pickavance at Harwell to W. Walkinshaw (then at T.R.E.j requesting consideration of a proton linac to boost the energy of the extracted beam of the Harwell synchrocylotron $(175 \mathrm{MeV})$ by $100 \mathrm{MeV}$ to be able to produce pi-mesons through the $p+p$ interaction. Walkinshaw's answer raised the difficult problem of adequately focusing the diverging emergent beam from the synchrocyclotron.

Pickavance continued his interest in a mesonproducing linear accelerator for the Harwell accelerator program. For example, he wrote to D. W. Fry at Harwell on September 5, 1951, citing the meson yields expected from a $400-\mathrm{MeV}$ proton linac with $1-\mu \mathrm{A}$ intensity, and describing some of the possible meson physics studies. ${ }^{23}$ This letter stimulated Fry to call a meeting ${ }^{24}$ on October 23 to discuss alternative possibilities for future accelerators in England. The conceptual design of a $450-\mathrm{MeV}$ proton linac and the techniques available for focusing the beam in the linac were also discussed.

This activity by the Harwell accelerator experts resulted in a meeting if top British physicists from AERE and the Universities, called by Sir John Cockcroft in June 1952, to discuss British accelerator policy and the possibility of joining in the European effort (which was to become CERN). British policy was formed from this and subsequent meetings. Initially the policy was to join the European program to build a multi-GeV proton synchrotron at Geneva, and also to build a 600-Mey piston linac at Harwell to provide pi-mesons for British scientists. A memorandum ${ }^{25}$ prepared in early 1953 describes the status of Pritish accelerator policy at that time and gives staff requirements and cost estimates.

The first design study ${ }^{26}$ for the Harwell proton linear accelerator (PLA) was prepared by L. B. Mullett in April 1953; the first engineering drawings were dated December 1953. Many of the early technical studies involved focusing problems, including use of grids, foils, electrostatic lenses, axial conductors, and magnetic focusing with solersoids. Another series of studies was on the use of dielectric disk loading for waveguides to match par-icle velocity. By 1953 it became clear that "strong focusing" by the use of quadrupole magnetic lenses of alternating polarity, as discovered and published ${ }^{27}$ in the United States in hte 1952, would allow much higher beam currents, some hundreds of times more inter,se than those available from synchrocyclotrons.

By 1954 there were 50 persons working on the PLA at Harwell. A decision was made to construct a $50-\mathrm{MeV}$ first section of the Alvarez design as a prototype and to gain experience. Design efforts weie then turned to studies of structures for linacs at higher energies. Detailed design on the PLA continued until 1956, when a decision 
TABLE II

\section{LISTING OF ALVAREZ-TYPE PROTON LINACS ${ }^{\star}$}

\begin{tabular}{|c|c|c|c|c|c|c|}
\hline Machine & $\begin{array}{c}\text { Year } \\
\text { Completed } \\
\end{array}$ & $\begin{array}{l}\text { Output } \\
\text { Energy } \\
\text { (MeV) }\end{array}$ & $\begin{array}{c}\text { Frequenicy } \\
\text { (MHz) }\end{array}$ & Focusing & $\begin{array}{c}\text { Mo. ỗ } \\
\text { Drift Tuhes }\end{array}$ & $\begin{array}{l}\text { No. and Type } \\
\text { of Tanks }\end{array}$ \\
\hline Alvarez, Berkeley & 1948 & $3 ?$ & 202.5 & grids & 45 & 1-liner \\
\hline Kharkov 1, USSR & 1950 & 20.5 & 139.4 & grids & 50 & 1-liner \\
\hline Bevatron, Inject 1 & 1953 & 10 & 202.5 & grids & 42 & 1-liner \\
\hline \multirow[t]{3}{*}{ Univ. Minnesota } & 1955 & 10 & 202.55 & grids & 41 & 3-liner \\
\hline & & 40 & & & 37 & \\
\hline & & 68 & & & 24 & \\
\hline \multirow[t]{3}{*}{ PLA, Harwell } & 1959 & 10 & 2.02 .56 & grids & 41 & 3-liner \\
\hline & & 30 & & quads & 40 & \\
\hline & & 50 & & quads & 26 & \\
\hline \multirow[t]{3}{*}{ CERN-PS, Inject } & 1959 & 10 & 202.56 & quads & 41 & 3-liner \\
\hline & & 30 & & & 40 & \\
\hline & & 50 & & & 26 & \\
\hline AGS, Inject I & 1960 & 50 & 201.06 & quads & 124 & 1-copper clad \\
\hline Nimrod, Inject & 1961 & 15 & 115 & Guavis & 48 & 1-liner \\
\hline Bevatron, Inject II & 1962 & 19.3 & 199.3 & quads & 73 & 1-copper clad \\
\hline ZGS, Inject & 1963 & 50 & 200 & quizds & 124 & 1-copper clad \\
\hline \multirow[t]{2}{*}{ ITEP-PS, Inject } & 1966 & 6 & 148.5 & quads & 18 & 2-liner \\
\hline & & 24 & & & 33 & \\
\hline \multirow[t]{3}{*}{ Serpukhov, Inject } & 1967 & 38 & 148.5 & quads & 93 & 3-liner \\
\hline & & 73 & & & 41 & \\
\hline & & 100 & & & 26 & \\
\hline AGS, Inject II & 1971 & 200 & 201.25 & quzads & 295 & 9-copper clad \\
\hline $200 \mathrm{GeV}$, Inject & 1971 & 200 & 201.25 & quards & 295 & 9-copper clad \\
\hline LAMPF, Inject & 1971 & 100 & 201.25 & quads & 165 & 4-copper clad \\
\hline
\end{tabular}

${ }^{2}$ Taken in part from Linear Accelerators, ${ }^{20}$ Nerth Holland Publishing Company, Amsterdam, 1970.

was made to terminate the PLA at $50 \mathrm{MeV}$ and to cancel the plans for $600 \mathrm{MeV}$. This action was taken when it was dc ided to build a proton synchrotron for $7 \mathrm{GeV}$ (Nimrod) at Harwell. A final design teport ${ }^{28}$ on the 600-MeV linac was published in 1957.

Walkinshaw first pointed out that the shunt resistance of the Alvarez-type drift-tube linac decreased with increasing particle velocity, requiring ex:cessively high if power. It was expected that a different structure would be more suitable for high energies. One type of structure suggested at Harwell was an iris-loaded waveguide, another was a series of coupled resonant cavities.

One of the most significant contributions of this Harwell study was made by Peter Dunn on resonant loop coupling between cavities. He appreciated the significance of a double-periodic system, i.e., pillbox cavities and resonant coupling loops, and worked out equivalent circuit equations. ${ }^{29}$ Also, Adlam ${ }^{30}$ worked on an external coupled cavity that: might be considered the precursor of the present I.AMLPF side-coupled cavity. However, at that time the costs ot waveguide fabrication were a cause of concern, and thunn's loop coupling was favored as prebably less costly. Later, Alan Carne did some work on $\mathrm{X}$-bar ard Clover-leaf structures for waveguides, which was also krownt and utilizea during the design of LAMPF.

\section{Studies at: tale and Brookhaven}

Activity dinected toward the design of a highintensity protion accelerator at $Y_{\text {ale }}$ was initiated by Professm: V'urnon Hughes in early $19599^{31}$ On his recommeradation, in the late iummer of 1959, the Physics Departmsint woted in favor of 2 high-intensity accelerator 
to be used for meson physics. The facility was to be locaced at Yaic and was intended to complement rather than compete with the facilities at Brookhaven National Laboratory. A small design effort was immediately started in the Physics Department and included the services of $R$. L. Gluckstern, F. R. Beringer, M. S. Malkin, and G. Wheeler, all having just completed the Heavy Ion Linac at Yale. It is hardly surprising that they showed small enthusiasm for cyclotrons and quickly turned their attention to the proton linac. The Yale designers were also strongly encouraged toward a linac by John P. Blewett of Brookhaven, who had designed the 50-MeV linac injector for the Alternaring Gradient Synchrotron (AGS). They chose an initial goal of $750-\mathrm{MeV}$ energy and $100-\mu \mathrm{A}$ average current. Their studies soon showed that the linac had an inherent capability of even higher current, and they raised the announced goal to 1-mA average. This caused a frantic cffort by the cyclotron proponents at ORNL and UCLA to show that cyclotrons could also produce a $1-\mathrm{mA}$ external beam.

At the Second International Conference on Sector Focused Cyclotrons, held at UCI.A in April 1962, the battle between cyclotrons and linacs was formally joined, with a survey report by Lloy'd Smith that discussed the relative nerits of different machines. Smith concluded that the proton linac was the strongest candidate (although it was the most costly). By 1963, at the Third International Conference of Scctor Focused Cyclotrons and Meson Factories, in Geneva, the linac occupied a significant place on the program.

Meanwhile, the Yale studies matured and the first formal design report of the linac meson facility, ${ }^{32}$ known as "Y-6," was issued in 1962. This proposed to use an Alvarez-type linac with shaped drifc tubes operating at $200 \mathrm{MH} /$ for the first $200 \mathrm{MeV}$, and an iris-loaded waveguide at 800 or $1200 \mathrm{MH} z$ to accelerate from this energy to $750 \mathrm{MeV}$. The total length was $550 \mathrm{~m}$. This report was used as the basis for the initial Yale request for support from the Atomic Energy Commission. It is also fair to say that the first LASL proposal for a linac meson factory (December 1962) was based largely on Yale Report Y-6.

By the end of 1962, there were four meson factory proposals receiving serious attention from the U.S. Atomic Energy Commission. These were: ORNL $\left(\mathrm{H}^{+}\right.$ cyclotron); UCLA (H cyclotron); Yalc (linac) and LASL (linac). Yale thought it wise to strengthen their relative position in the competition by combining forces with Brookhaven. At Brookhaven, John Blewett was strongly urging a new injector of much higher intensity and higher energy for the AGS. For a time, the Brookhaven and Yale groups considered a facility at the AGS in Brookhaven that would provide a high-intensity beam for injection during the short injection pulse and would serve as a meson factory for the remainder of the time $(95 \%)$. This effort failed to become a praciical proposal, largely due to lack: of official support from the Brookhaven Administration and the AEC.

By 1964, following publication of the "Bethe Panel" study of meson factories for the Office of Science and Technology, it was clear that there would be no meson facility at Yale. The AEC instructed the Yale design group to terminate its work by September 1964. The final report ${ }^{33}$ of the design study is Yale Internal Report Y-12; the estimated cost was $\$ 59.3$ million.

The Yale group made a major contribution toward establishing the linac as the most suitable accelerator for a meson factory. Had it not been for their efforts a cyclotron might have been built. When a LASL group visited Yale in 1962, the Yale staff were extremely helpful with their information and advice. Substantial technical contributions also came from the Yale group. They made the first calculations showing the feasibility of very high currents in a linac. They justified the separation of the linac into two structurally different components as early as November 1960, one with drift tubes operating at $200 \mathrm{MHz}$ and the other with a waveguide structure resonant at 800 (or 1200 ) $\mathrm{MHz}$. Yale followed Harwell's lead in developing the $\pi$-mode standing-wave waveguide instead of a traveling-wave waveguide. Much of the early thinking which led LAMPF to the choice of a linac was done at Yale. Many features of the eventual LAMPF machine design bear a striking resemblance to Yale Report Y-12. It is well to recognize the debt owed by the LAMPF project to this earlier work of the Yale linac study group and to their generosity in advice.

\section{E. High-Intensity Cyclotrons}

The invention of the cyclotron by Lrnest Lawrence in 1930 was followed bv a decade of standard cyclotron development (with uniform magnetic field) at Berkeley and many other laboratories. This stage is best represented by the classic " 60 -in." cyclotron that attained the relativistic energy limit (for protons and deuterons) of 20-25 MeV. This size of machine was widely copied and used for nuclear studies up to this energy. In 1938 , Thomas $^{34}$ pointed out a method of increasing the relativistic energy limit based on the use of azimuthal variations in the magnetic field to maintain axial focusing; for various reasons his proposal was not utilized at that time.

The next phase $w$ as the rapid development of the synchrocyclotron following the end of World War II, proposed independently oy E.M. McMillan at Berkeley and $V$. Veksler in Moscow. The synchrocyclotron was based on the synchronous stability available with frequency modulation, which provided much higher proton 
energies, but at quite low intensities $(0.1-$ to $1.0-\mu \mathrm{A}$ average). About 10 large machines were built, mostly for energies of 400 to $700 \mathrm{MeV}$.

During 1950-1952, the Thomas cyclotron concept was revived by McMillan at Berkeley, and the theoretical aspects analyzed by $\mathrm{D}$. Judd, as part of the Materials Testing Accelerator (MTA) program of the AECsupported Radiation Laboratory of the University of California, to develop a source of very high-intensity protons. This work was done under security restrictions with potential for the production of fissionable material in the event the U.S. were denied foreign sources of uranium. Supporting theoretical work and model studies were carried on at the Oak Ridge National Laboratory, and were also classified. Then in 1952 the principle of "strong focusing" using alternating magnetic gradients was discovered at Brookhaven. ${ }^{27}$ The AG principle was extended to fixed-field alternating gradients (FFAG) by the Midwest University Research Association (MURA) group at Wisconsin, where an important concept was the spiral-ridge synchrotron. The generalization of this concept to cyclotrons was straightforward, and it became clear that the spiral-ridge cyclotron was essentially an extension of the Thomas radial-sector machine.

Design studies for conversion of existing cyclotrons to azimuthally varying field (AVF) were undertaken from 1953 onward at several laboratories, including LASL, ORNL, and UCLA. For the next decade, a great deal of effort was applied to the development of AVF cyclotrons, also ca!led isochronous or sector-focused (SF) cyclotrons, with much higher intensities than were available from synchrocyclotrons, although generally at lower energies. In a conference on sector-focused cyclotrons held at Sea Island, Georgia, early in $1959^{35}$ a tabulation by R. J. Burleigh in the Conference Proceedings lists 15 machines either operating, under construction, or in the design stage. Most were for proton energies below $100 \mathrm{MeV}_{\mathrm{i}}$ one was a design study (at AERE Harwell) for $240 \mathrm{MeV}$; another was a very preliminary engineering study for a 400-MeV size machine sponsored by the University of Florida.

\section{F. Studies at Oak Ridge}

The first accelerator group to apply serious design efforts to high-intensity cyclotrons of the medium-energy range ( 0.5 to $1 \mathrm{GeV}$ ) was at the Oak Ridge National Laboratory, led by Robert S. Livingston. This interest followed directly from their earlier classified studies of the Thomas cyclotron. It also utilized their experience with electromagnetic separators for uranium isotopes (Calutrons) and with two large standard cyclotrons: the "86-in." cyclotron was brought into operation in late
1950 and became an effective tool for basic nuclear research and for isotope production, operatin; at proton energies up to $23 \mathrm{MeV}$; the "63-in." cyclotrn- was designed expressly to accelerate heavy ions $\left(\mathrm{N}^{3+}, \mathrm{N}^{4+}\right.$, etc.) and opened this new field of research.

Active interest and extensive theoretical design studies on an AVF cyclotron of very high intensity started at ORNL in late 1954. The initial design ${ }^{36}$ took the form of a three-spiral-sector magnet of 76-in.-diam pole capable of accelerating protons to $75 \mathrm{MeV}$ and heavier ions to other appropriate energies. The scientific motivation for the development of the 75-MeV "ORIC" was for basic research in nuclear physics and chemistry, the production of neutrons and induced radioactivities, and the study of heavy ion atomic physics; there could be no expectation of the production of mesons at this energy. However, early ORNL studies also included two electron analogue models, one to study the resonance behavior of particles in AVF magnetic fields, and an ambitious model (Electron Analogue II) for a possible $850-\mathrm{MeV}$ cyclotron. Note that this analogue study for $850 \mathrm{MeV}$ was first described in 1954.

With the completion of ORIC in 1960, the major design effort went to the "Mc ${ }^{2}$ Isochronous Cyclotron." This effort was based on the desire to build a highintensity cyclotron of the highest practical energy, which was conceived to be for an energy ( $900 \mathrm{MeV}$ ) just below the proton rest-mass equivalent; the rest-mass energy was believed to be a technical limit. It was for this purpose that Electron Analogue II was built and studied; these studies showed that all resonances could be avoided or crossed up to the $\mathrm{mc}^{2}$ limit (for electrons). With this favorable prediction, design and engineering studies on the $\mathrm{Mc}^{2}$ Cyclotron continued, with a status report in 1962 and a formal proposal ${ }^{37}$ in 1963 . The magnet was to be an eight-sector spiral-ridge type, with four fixedfrequency of cavities lucated in valleys between the ridges. The design intensity of the $810-\mathrm{MeV}$ external beam was $100 \mu \mathrm{A}$. The expected yields of pions, neutrons, neutrinos, etc., were calculated and a typical program of research was described. The total budget for construction was estimated to be $\$ 42,7000,000$.

Robert Livingston and his staff organized the first of a series of conferences on sector-focused cyclotrons held at Sea Island, Georgia, on February 2-4, 1959. At this conference, most of the papers dealt with machines having energies below $100 \mathrm{MeV}$, and there was no mention of linacs as potential competitors to highintensity cyclotrons. A second conference ${ }^{38}$ on sector. focused cyclotrons was held at UCLA, Los Angeles, in April 1962. By this date (three years later) the goals had changed. Several multihundred-MeV machines were described; the term "mesur factory" had been invented and was used in the titles of several papers presented at 
the conference. A paper by Lloyd Smith compared the merits of the several accelerator types as meson factoiles; he concluded that the best accelerator seemed to be the proton linac, but admitted that laboratories with cyclotron experience would probably still argue for a cyclotron. The stage was set for LASL to enter the scene.

By 1964, with the report of the "Bethe Panel" on meson factories, it seemed probable that the $\mathrm{Mc}^{2}$ Isochronous Cyclotron Proposal was in difficulties and was not the obvious front runner. A major criticism was the known beam loss during acceleration and ejection and the risk of buildup of unacceptable levels of radioactivity in the chamber. The ORNL group offered a counterproposal of a Separated Orbit Cyclotron (SOC) following the design ${ }^{39}$ developed by F. M. Russell in 1962 while present at Oak Ridge as a visiting scientist from the Rutherford Laboratory. The SOC was to be formed of a helical spiral of magnets in which the beams were spatially separated on each turn. It might be described as a linac wrapped up into a spiral having the advantage of easy ejection of an emergent beam. The engineering design of the SOC was not yet as well developed as that for the $\mathrm{Mc}^{2}$ Cyclotron, and the proposal was informal. The initial proposal was a letter from A. Weinberg, Director, ORNL to Paul McDaniel in June 1964 claiming advantages for the SOC and asking for postponement of a decision on the LAMPF meson factory until the SOC could be evaluated. (The SOC had not been considered by the Bethe Panel.) However, this second ORNL proposal came too late to be considered, and the AEC support for LASL was not diverted.

It is of interest to observe some of the comparative material developed during this neriod of competition for a meson factory. As an example, Table III, published in the

TABLE III

\section{THREE TYPES OF HIGH-INTENSITY ACCELERATORS (MESON FACTORIES) BRIEFLY COMPARED ${ }^{\text {a }}$}

\begin{tabular}{|c|c|c|c|}
\hline & SOC (ORNL) & Yale Linac & $\mathrm{Mc}^{2}$ Cyclotron (ORNL) \\
\hline Proposed final & & & \\
\hline $\begin{array}{l}\text { energy } \\
\text { Upper limit }\end{array}$ & $1,000 \mathrm{MeV}$ & $750 \mathrm{MeV}$ & $810 \mathrm{MeV}$ \\
\hline Upper limit & $>10 \mathrm{GeV}$ & $>10 \mathrm{GeV}$ & $810 \mathrm{MeV}$ \\
\hline $\begin{array}{l}\text { Proposed mean } \\
\text { current }\end{array}$ & $1.0 \mathrm{~mA}$ & $1.0 \mathrm{~mA}$ & $100 \mu \mathrm{A}$ \\
\hline Upper limit & $10 \mathrm{~mA}$ & $1.0 \mathrm{~mA}$ & $1.0 \mathrm{~mA}$ \\
\hline $\begin{array}{l}\text { Extraction } \\
\text { efficiency }\end{array}$ & $100 \%$ & $100 \%$ & $80 \%$ \\
\hline $\begin{array}{l}\text { Exuacted beam } \\
\text { quality }\end{array}$ & Good & Good & Probably good \\
\hline $\begin{array}{l}\text { Microscopic } \\
\text { beam structure }\end{array}$ & $5 \%$ & $1.4 \%$ & $5 \%$ \\
\hline $\begin{array}{l}\text { Macroscopic } \\
\text { beam structure }\end{array}$ & $100 \%$ & $5 \%$ & $100 \%$ \\
\hline $\begin{array}{l}\text { Energy spread } \\
\text { in beam }\end{array}$ & $0.1 \%$ & $0.1 \%$ & $0.1 \%$ \\
\hline $\begin{array}{l}\text { Cost of machine per } \\
\text { watt of beam }\end{array}$ & $\$ 16$ & $\$ 24$ & $\$ 120$ \\
\hline $\begin{array}{l}\text { Machine cost for } \\
1 \mathrm{GeV} \text { at } 1 \mathrm{~mA}\end{array}$ & $\$ 16 \times 10^{6}$ & $\begin{array}{l}\text { Extrapolated to } \\
\$ 24.2 \times 10^{6}\end{array}$ & Not possible \\
\hline $\begin{array}{l}\text { Machine cost for } \\
810 \mathrm{MeV} \text {, curre:.: } \\
\text { as proposed }\end{array}$ & $\begin{array}{l}\text { Interpolated } \\
\text { to } \\
\$ 13.8 \times 10^{6}\end{array}$ & $\$ 18.5 \times 10^{6}$ & $\$ 14.5 \times 10^{6}$ \\
\hline $\begin{array}{l}\text { Variable energy } \\
\text { capability }\end{array}$ & Yes & Yes & Ne \\
\hline
\end{tabular}


ORNL Report, reproduces the characteristics of three machines. Note the claims (not well justified) for a much higher beam intensity (10 $\mathrm{mA})$ for the SOC than for the linac or the $\mathrm{Mc}^{2}$ Cyclotron. Also note that the cost estimate for the SOC is lower than for the other types, although no significant engineering design effort had been applied.

\section{G. Studies at UCLA ${ }^{40}$}

Another group to study the design problems of cyclotrons of the high-intensity medium-energ.' range, specifically aimed at the production of mesons, was at the University of California, Los Angeles, under the direction of Prof. J. Reginald Richardson. This interest was stimulated by earlier experiences in the Marerials Tesring Accelerator (MTA) group at the Radiation Laboratory in Berkeley, including work on the "Thomas" cyclotron under security restrictions. Richardson, along with Kenneth MacKenzie and Byron Wright, had brilt and operated electron models of the Thomas cyclotion and developed extraction efficiencies of up to $90 \%$.

When Richardson left Berkeley and went to UCLA, he considered plans for a relativistic cyclotron of energy up to $250 \mathrm{MeV}$ and approached the Atomic Energy Commission for design support as early as 1952. This approach was discouraged because the MTA project was still classified. The matter was dropped until after the Thomas cyclotron work was declassified in 1955, in time for the Geneva Conferenc: on the Peaceful Uses of Atomic Energy. Also, by this time the MURA group had introduced spiral-ridge focusing for fixed-field accelerators as an extension of the concept of alternating gradient focusing.

The UCLA group decided in 1957 to build a $50-\mathrm{MeV}$ proton cyclotron of the spiral-ridge design, which o. :ipied much of their efforts for the next four years. Husvever, they continued their interest in a higher-energy cyclotron to be used primarily as a source of pions for high-energy particle research. By the summer of 1958, thes had formulated plans for a design study aimed an energy of $400 \mathrm{MeV}$ (thought at that time to be limited by the $\nu_{r}=3 / 2$ resonance) and with high intensity $(10 \mu \mathrm{A})$ compared with the output of existing synchrocyclotrons.

In the fall of 1958. Richardson and his associates (including Mackencic and Wright) made the first of a series of proposals to the Research Division of the AEC for support of a design study. The ALC was interested, as indicated by the late Commissioner John Williams in the spring of 1959 when he said that he favored "the best damn pion producer that it is possible to build." Howcver, a serics of delays ensued in funding the propused study of the design for a meson factory. The official proposal $^{41}$ from UCLA was dated July 1960, but support funds were not allocated until June 1, 1962.

The laboratory at UCLA was host to the second "Conference on Sector-Focused Cyclotrons" in April 1962, which was attended by many of the most experienced and able accelerator designers in the U.S. and abroad. Most of the papers dealt with technical problems of isochronous cyclotrons that included several design studies for machines in the multihundred-MeV energy 1ange which could produce mesons. Prof. Roy Haddock of UCLA presented a paper on "The Role of the Pion Factory in Elementary Particle Physics." Incidentally, it seems that Prof. Richardson initiated the use of the term "meson factory" for high-intensity machines in the multihundred-MeV energy range, and it was used frequently in discussions at this conference.

In 1963, Richardson conceived and suggested the use of $\mathrm{H}$ ions in a sector-focused cyclotron for a meson factory and reported the concept in a UCLA report. ${ }^{42}$ The advantage of accelerating $\mathrm{H}$ ions in a cyclotron is that it solves the problem of beam extraction; stripping foils can be used to produce $\mathrm{H}^{+}$ions (protons) that then emerge from the magnetic field. Also, the energy of the extracted proton beam can be varied by changing the position of the stripping foil. The major limitation is electric dissociation of the If ions in the magnetic field, which increases with magnetic field and with beam energy. Beam loss due to dissociation produces radioactivity in the accelerator that could result in serious maintenance problems for energies above about $500 \mathrm{MeV}$. After further study and demonstration of $\mathrm{H}$ ion acceleration in the $50-\mathrm{MeV}$ machine, Richardson made a revised proposal ${ }^{43}$ to the AEC in 1964. Tlis proposal was one of the competitors for support considered by the Bethe Panel to have some significant advantages, primarily variable energy, a high duty cycle, and relatively low cost. However, the Bethe Panel recommended that government support go to a facility at a National Laboratory, so the UCLA proposal was discounted. Richardson shifted his interest to assist in the design of the TRIUMF facility, which is described in the following section, at the University of British Columbia. He is presently Director of that facility.

\section{H. Low Intensity Meson Facilitics}

Three laboratories have been funded to build meson-proutucing accelerators in the medium-energy range with considerably lower bean intensities $(0.03$ to $0.1 \mathrm{~m} \Lambda$ ) than the design intensity of the LAMPF machine. These arc located at Vancouver, in Zurich, Switzerland, and at Columbia University. 


\section{TRIUMF}

The Tri-University Meson Facility (TRIUMF) is a research facility for medium-energy nuclear physics under construction at the University of British Columbia, Vancouver, for nuclear scientists in three West Coast universities in British Columbia and the University of Alberta. The accelerator is a $500-\mathrm{MeV} \mathrm{H}^{\top}$ ion cyclotron with an ejected proton beam of $0.1-\mathrm{mA}$ average, based on designs initiated and developed by J. R. Richardson at UCLA. The proposal ${ }^{44}$ was accepted and approved by the
Canadian Atomic Energy Control Board in 1967 and the scheduled completion date is 1972 .

A tabular listing of parameters included in the proposal is reproduced in Table IV, and compares the TRIUMF chazacteristics with those of other meson factory proposals as of 1966 . Note that the average current is less than $10 \%$ of that listed for LAMPF, and the energy is $500 \mathrm{MeV}$ compared with $800 \mathrm{MeV}$. These parameters were chosen to reduce cost and operational radioactivity hazards in order to achieve a meson "workshop" at an early date.

TABLE IV

\section{COMPARISON OF MESON FACTORIES AND WORKSHOPS ${ }^{a}$}

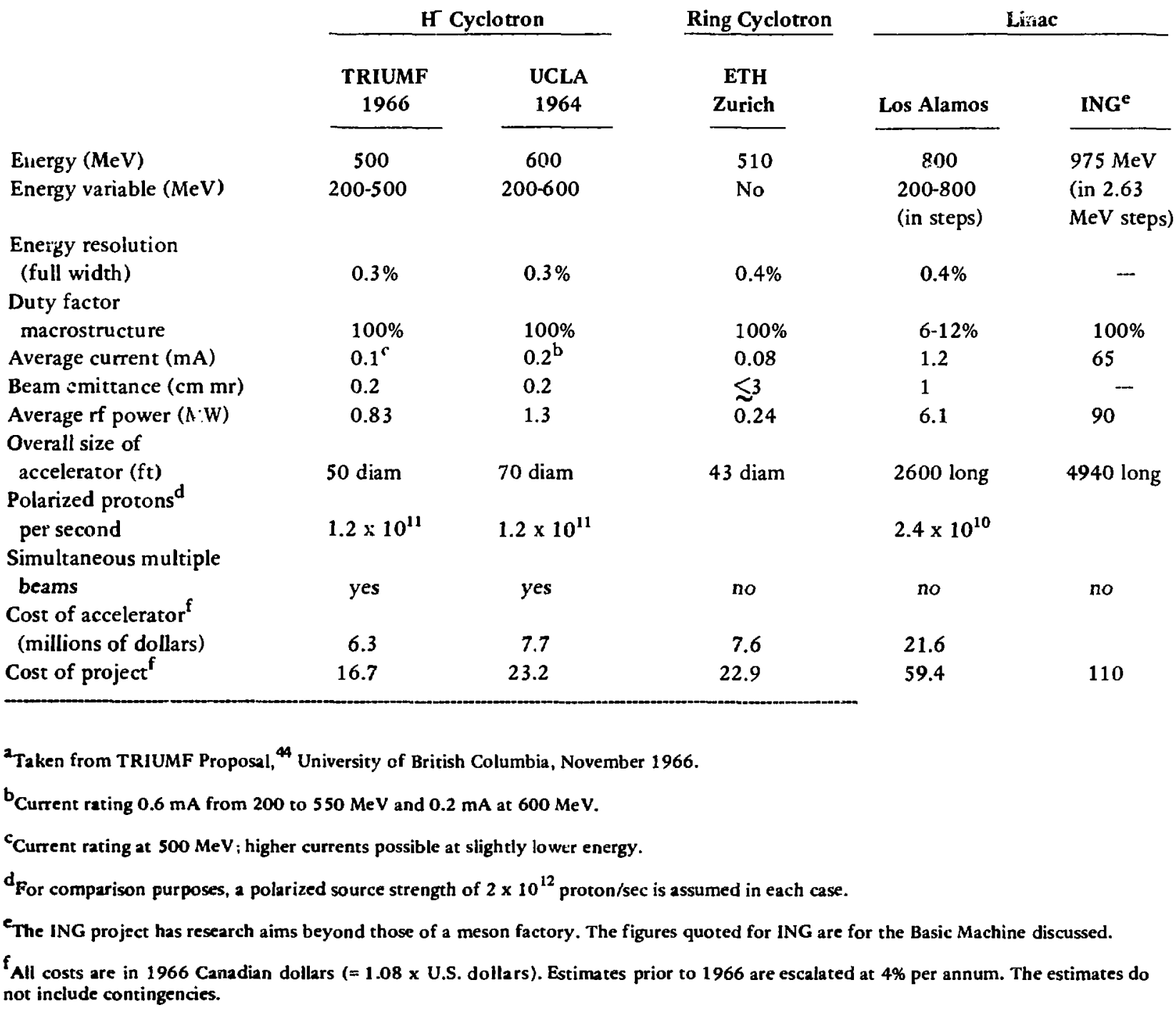




\section{Swiss Institute for Nuclear Research}

Another medium-energy meson research facility under construction is the "ring-cyclotron" at the Swiss Institute for Nuclear Research (SIN) in Zurich. Design studies and plans have been in process at the Electro Teknical Hochschule ${ }^{45}$ for several years. The new laboratory is being built at the nearby village of Villigen and is planned for completion in 1973. A recent status report is given in the CERN Courier. ${ }^{46}$

The significant feature of the design is the use of a low-energy injector cyclotron to produce $100 \mu \mathrm{A}$ of protons at $72 \mathrm{MeV}$. This injector is a spiral-sector isochronous cyclotron provided by Philips of Eindhoven. The major advantage is separation of the chief beam-loss region (at low energies) from the main high-energy machine and hence the reduction of radioactivity buildup. The emergent beam from the injector is focused and deflected through a shielding wall into the main ring accelerator; injection and capture efficiency approaches $100 \%$.

The isochronous ring accelerator developed at Zurich will accelerate protons trom $72-$ to $585-\mathrm{MeV}$ energy. It consists of eight spiral-sector magnets arranged in a ring with a $2-\mathrm{m}$ inner radius at injection and a $4.5-\mathrm{m}$ outer radius. Four of cavities resonant at $50 \mathrm{MHz}$ provide acceleration at a rate of over $2 \mathrm{MeV}$ per turn; this gives an orbit separation of $8 \mathrm{~mm}$ at peak energy. An emergent beam is ejected between sectors. Tests on a prototype and calculations predict 90 to $95 \%$ ejection efficiency. A major problem of a positive ion cyclotron is the low efficiency of ejection and production of undesirable radioactivity by the spilled beam. At the modest intensities planned for this machine, the radioactivity buildup is expected to be kept within manageable values.

The emergent beam is brought to an experimental hall to feed two primary target stations. One will have a thin target serving as the source of three pion beams and a nucleon beam; the other will have a thick target and will be the source of four pion beams (one to be used for medical purposes) and a muon beam using a 10-m superconducting solenoid channel. A polarized ion source and a polarized target are also planned.

\section{Columbia University}

The $385-\mathrm{MeV}$ synchrocyclotron at the Nevis Laboratory of the Columbia University Physics Department has been used for research on medium-energy physics since 1950 with an internal circulating beam of about $0.4 \mu \mathrm{A}$. Ten or more other synchrocyclotrons throughout the world, of 300 - to $700-\mathrm{MeV}$ energy and similar intensities, have also explored this research field. In recent years, significant new research results in this field have been increasingly difficult to obtain due to low intensities. Funds for support are in short supply and several synchrocyclotrons have been closed down.

At Columbia, a proposal ${ }^{47}$ for rebuilding the cyclotron as a sector-focused machine of 10 to 100 limes higher beam intensity and higher energy was approved and funded by the National Science Foundation (NSF) in FY 1966, and reconstruction is in progress. The status was reported at the Particle Accelerator Conferences ${ }^{48}$ in 1969 and 1971. Two modifications combine to raise the space charge limit that had restricted intensities in the early synchrocyclotrons: strong focusing and a high vertical oscillation frequency $\left(\nu_{z}\right)$ are obtained by using spiral-sector focusing with three-fold symmetry; and the frequency of modulation is increased to $300 \mathrm{~Hz}$, which involves higher of voltage and increases the macro duty cycle to $50 \%$. Additional excitation coils near the magnet gap and shorter pole separation at the periphery provide the higher energy. The expanded facility should be in operation in 1972 at $550-\mathrm{MeV}$ energy with an average emergent beam of up to $30 \mu \mathrm{A}$, capable of producing meson intensities sufficient to exiend research into $a$ variety of new programs.

\section{Intense Neutron Generator}

The most ambitious plan to date for a mediumenergy very high-intensity accelerator was the Intense Neutron Generator (ING) proposal ot the Chalk River Laboratory of the Atomic Energy of Canada, Limited (AECL), for a proton iinac of $975-\mathrm{MeV}$ energy operating on a $100 \%$ duty cycle at an average current of $65 \mathrm{~mA}$. This major research facility was intended to provide a source of secondary neutrons with an intensity $\left(10^{16} / \mathrm{cm}^{2}\right)$ exceeding that of any available nuclear reactor. It would also have been the world's highest intensity source of pions, muons and neutrinos, although its purpose was much broader than that of a meson factory. A technical proposal ${ }^{49}$ was published in 1966 , and was under study for two years by committees of the Canadian Science Council and government officials. The proposal was turned down by the Government of Canada in the spring of 1968 , and the project is now in abeyance.

The ING project had its origin ${ }^{50}$ in the long-term interest of $W$. B. Lewis in the use of nuclear spallation reactions for the production of energy. Preliminary studies of the yield of neutrons from high-energy protons were made at Chalk River as early as 1952 (when the MTA project was being started at Berkeley). The problem was revived in 1963 by the late Lloyd Elliott, who initiated a study of the physics of neutron production. The first studies were performed by G. A. Bartholomew, J. D. 
C. Milton, and E. W. Vogt, who concluded that spallation by high-energy protons should be an effective technique.

Various accelcrators were considered initially, with primary intercst in the Stparated Orbit Cyclotron (SOC) proposed by Russell ${ }^{39}$ of the Rucherford Laboratory. Design studies continued at Chalk River through 1966. with increasing concern over the escalating cost cstimates for the SOC. The technical problems of the ING proposal were largely associared with the very large of power requitements and with the anticipated high levels of radioactivity.

In 1266, a delegation visited Los Alamos and was impressed with the potentialities of the LAMP!: developments. and from that date the planning was changed to a linac based largely on LAMPF designs but operating on a 100\% macro-duty-cycle. The detaikd development was curtailed by limitation of design funds. so the enginecring design has not been completed. 


\section{CHAPTEK +}

\section{TECHNICAL DEVELOPMEN TS AT LAMPF}

\section{A. Design Specifications}

The group of 1.ASL. staff members who were atracted, in the summer of 1962, by the dream of a moron factory at i.os Alamos had one thing in common a desire to renew the quality and vitality of nuclear physicx rescarch at Los Alamos. The initial goal was to define the scope and criteria of the project and to prepare a preliminary propossl. Most of the aroup were research scientists and theoretical pliysicists, intrigued with the new fields of researcli that would be opened by the very high-intensity beams of mesons and other radiations: some contributed by planning new experiments and cstimating yields. Teams from LASL visited existing accelerator laboratories and studied the porentialities of the several possible types of accelerators as meson producerxi they quickly chose the proton linac as the most desirable machinz. Still others with engineering experience studied problems of site development, buildings. facilitics, and power requirenients, and then prepared plans and cost cstimates. An ad boc "steering committec" organized this interest into a study program that produced the Preliminany Proposal ${ }^{3}$ of Decenber 28, 1962. In the following year a Schedule 44 was submitced to the Al:C as the officiti request for support.

There were no linac experts at Los Alamos in 1962 and only a few who had experience with other accelcrators. It is not surprising that the technical characterisucs of the linac presented in their Preliminary Proposal were taken directly from Yale Report Y-6. But this situation was to change remarkably in the next few years. The small I.ASL. design group entered at full speed into a program of basic analysis, model studics, and protorype development that brought them to equivalence with more experienced linac laboratorics within a relatively short tine.

At the tine the LASL group entered the linac design competition, they found general agreement on the techniques to be used fos proton energies of up to $100 \mathrm{McV}$. The "classical" Alvarez drift-tube structure operating in the $2 \pi$ mode at $200 \mathrm{MHz}$ was by far the most efficien: structure and had adequately high shunt impedance. There was aiso generai agreement that triode power amplificr tubes were acceptable as powe: sources at 200-Milz frequency. For example, the RCA 7835 tube had been used successfully with the $50-\mathrm{MeV}$ injectur linac at the Argonne ZGS Iaboratory to provide 5-MW pulses to thi linac tank. Others had used triodes of lower pulse power ratings, in paralkel.

The area of design that was in a state of flux in 1962, with no clear indication of the direction of furure developinent, was the higher frequency $(800 \mathrm{MHz})$ structure required for protons of energy above $100 \mathrm{MeV}$. Both the type of structure for thrise higher frequencies and the power sources to excite the system were uncertain and required further development before decisions could be made. The starting point was the Yale design which proposed a set of iris-loaded wateguide cavities operating at either 800 or 1200 MHe. The first Yale design report called for 142 cavitics, wach $2.5 \mathrm{~m}$ long and operating at gos MIlz to produce $600 \mathrm{McV}$. Although this system was the ititial LASI. reference design, it was fully expected that major changes would come with further development. It was also believed that if power amplifier tubes suitable for cavitics at this frequency would become avaitable in the near future from commercial developments.

The decision to usce a frequency of about $800 \mathrm{MHz}$ for the major portion of the linac came from analyses similar to those ar Yale. Wheeler and others in the Yale group had calculated the longitudinal dynamics of procons accelerated in a $200-\mathrm{MH} / \mathrm{z}$ drift-tube linac to an energy of $100 \mathrm{MeV}$ or higher. They found that during acceleration the phase spread damps to about $1 / 4$ of the phase aceeptance at injection. This reduced phase spread can fit into the phase acceptance bucket of another linac having a frequency of 4 times $200 \mathrm{MHz}$. The LASL 
designers recalculated the dynamics of phase motion and arrived at the same conclusion. So the frequency of the high-energy portion of the linac $(805 \mathrm{MHz})$ was chosen to be the fourth harmonic of the drift-tube linac frequency of $201.25 \mathrm{MHz}$.

The first opportunity for the LASL staff to demonstrate their new-found expertise was at the Linac Conference $^{51}$ held at Yale in October 1963. Sixteen LASL representatives attended. The LASL staff had no real experience with a linac as yet, but Nagle had become a capable systems analyst, Knapp was an expert on rf structures, and others had become accomplished in other fields. The iris-loaded waveguide described in Yale Report Y- 6 was studied in some detail and was found to be limited by severe phase shifts and amplitude distortions during turnon and in the beam-loaded state. Computer analyses, calculations, and model studies made at LASL, verified this limitation. These self-made experts submitted several papers for the Conference; papers were presented by

D. E. Nagic and E. A. Knapp - Behavior of Coupled Circuits.

E. A. Knapp - Accelerating Structure Rescarch 2t LASL.

M. Jakobson - Standing vs Traveling Waveguides.

D. C. Hageiman - RF Power Scurces,

A. D. MeGuire - Experimental Target Area Design, and

H. G. Worstell - Hydrogen Purging Technique.

Bact: at LASL, a model program for testing accelerating structures was under way. In tern, the known types were theoretically analyzed and dimensions calculated. Each sype was first tested with lightweight models at low power to measure the basic parameters and then with working prototypes at high if power. They investigated the standard Alvarez-type drift tubes for 200-MHz operation. But most of the effort was in studying 800-MHz structures such as the "iris-loaded" waveguide, the "crossbar," and the "sloverleaf" $\pi$-mode cavities.

The most important progress during 1963 was the start of a development program on resonant coupled structures, first described by Dunn. Sable, and Thompson at Harwell, which eventually led to the LAMPF sid-coupled cavity system. Coupled resonator analyses noiz made by Nagle and Knapp. Models were built and tested in which the coupling structures were various resonant devices attached to the outside of the array of accelerating cavitics, with each coupling derice viewing two successive cavities. Properties improved with continued development of shapus of cavities and coupling structures. Eventualiy, it became evident that the sidecoupled cavity was a new and different linac structure with greater stability and higher if efficiency than any of the structures considered previously.

The next Linear Accelerator Conference ${ }^{52}$ was held at the MURA laboratory in Madison on July 20-24, 1964. By this time the LAMPF design group was much more experienced and in certain respects they were leading the ficld. At this conference, the germs of all basic ideas to be used in the LAMPF lina: were available for presentation and most of the theoretical calculations had been made. Some of the new ideas had yet to be tested and proven in the laboratory, but the ess-ntia! principles were understood and the important decisions had been made. Sir teen members attended the conference and eight pap..rs were presented.

D. E. Nagle - Coupled Resonator Model of Linac Tanks.

E. A. Knapp- 805 MeV RF Structure.

$M$. Rich and W. M. Visschet - Green's Function Catculation of Drift Tube Cavities.

H. C. Hoyt - Drift Tube Calculations.

M. Jakobson and W. M. Visscher - Partucle Dynamics at High Energy.

M. Rich - Beam Dynamics Calculations for Alvarez Linac.

R. A. Jameson - RF Phase and Amplitude Control.

Another important event for LAMPF was the Summer Study Session beld during July and August 1964. A number of prominent scientists sttended and discussed tise future experimental program with the LASL staff. Among the visitors were H. Fechter, A, Goldtraber, A. Kerman, H. Frauenfelder, M. Ebel, and E. Henkey. This summer study initiated the planning activity that culminated in the formation of a LAMPF Users Group in June 1968.

In the Theoretical Division, Itarry Hoyt deveioped a computer code for analyzing the of efficiency and the field patterns of three-dimensional cavities; this "LALA" code has been widely used by other linac design groups.

The experimental program that paralked the pianning effort was carried on in the "mock-up building" adjacent to the Physits Division laboratory. One of the coply important jobs was to build and test an ekctron analogue 53 of the cloverleaf type of resomant-cavity accelerator $\$ 53 t c m$. This was the first structure seriousily studied to be used for proton acceleration. Knapp designed the cloverleaf structures, which were built in the I.ASI. Shops Department, SD-5. Hagerman developed and built the if power system needed for the model. The staff member primarily responsible for the tests was K. Emigh. assisted by D. Mueller and J. Brolley. For the tests, a 20-cell section of the cloverk. f-type cavity resonating at 
$805 \mathrm{MHz}$ was installed within a cylindrical vacuum chamber. Electrons were accelerated to $189 \mathrm{keV}$ by a dc power supply and then given an additional few keV energy by if power applied to the cavities. The efficiency of the resonant rf system was determined using stopping potentials of 1 to $2 \mathrm{kV}$ applied to a grid at the beam exit. Because the velocity of $189 \cdot \mathrm{kcV}$ electrons is the same as that for 347-MeV protons, the properties of the accelernting structure for high-energy protons could be tested with this much simplir electron source.

The design phase culminated in a ser of systen parameiers that defined the goals to be achicved. These are described in the first Quarterly Report of the newly established MP Division, as of July 1, 1965. They provided basic specifications for further detailed development and were nor significantly modified as studies proceeded.

The unique characteristics of the proposed LAMPF linac were its long duty cycle and its very high average intensity. Beam loss in the accelerator structures, beam handling, and targeting rook on a much greater significance than in any previous accelerator. The cumulative harmful effects of small crrors and misalignments, or of noise in clectrical systems, required more carcful analysis and precision of construction than had previously been needed for proton linacs. As a consequence, the engineering involved in the detailed design and construction required a high level of quality and perfection of detail. Continuing development of cooling procedures to maintain physical dimensions was needed to meer the special demands coming from those high potver requirements. By carly 1965, the design specifications were complete, model tests had been made, and most of the special features needed to meet the high-intensity gonls were basically understood.

\section{B. Ion Sources and Preacecleretors}

A favorable feature of the linac as an accelerator is that several birds of partick beams can be accelerated simultaneously (or sequentially) in each pulse and can be analyzed into separate beans at the target station to supply independent research experiments. It is desirable to have separate ion sources and preaccelcraturs for each of the different particle beams. At 1.AMPF this flexibility vas recognized and plans were made at an early date to ireate three preaccelerators at the input end of the linac. It: the earliest plans, one was the primary high-inzensity prutan beam injector, a second was a spare in the event of injecin failure, and the third was for a future polarized beam vjector. At a later date a negative hydrogen ion beam tyector was substituted for the spare proton injector ta give still greater flexibility.
The injector system consists of three separaie ion source and preaccelerator units, capable of operating either independentiy or at the same time. The three beams go into a beam transport area which directs each one into the entry end of the drift-tube linac without interference with the others. The pulsed beains are timed to enter at preselected instants during the if accelerating cycle. Each preaccelerator unit is housed in a large ioomsized enclosure formed of aluminum sheet, insulated, and grounded at one point. The purpose of this Faraday cage type of enclosure is to minimize the effects of sparks from th: high-voltage terminal of the preaccelerator on external electrical apparatus. The enclosures are made 20\% larger than would be required at sea level to avoid sparking in the reduced atmospheric pressure at the Los Alamos elevation. Dimensions and specifications were provided to the architect-engineers at the time the building design was revised in 1956 by Robert Emigh, who was responsible for most of the preaccelerator and ion source development and was Associate tiroup Leader of MP-4 (Injector Systems) from the time it was organized in 1965 until it was reorganized in 1971.

Two 750-k V high-voltage generators of the Cockcroft-Walton voltage multiplier type, designed by the Injector Systems Group, were contracted to Hactely, Inc. of Basel, Switzerland. The Hacfely Company has also supplied high-voltage sets of this type to other linac laboratoric: in this country in recent years. The voltage multiplier circuit is basically simple; it uses solid-state recrifiers supplied by $5-k H z$ transformers to chatge capacitors in paralkel and discharge in series. The high-voltage terminals are enclosed in smoothly finished aluminum housings supported on insulating columns. The units ordered for LAMPF are rated for $1.0 \mathrm{MV}$ at sea level but operate at 0.75 MY at Los Alamos.

From the start of design planning. a primary concern has been the deveiopnent of proton sources capable of providing very high-intensity beams with lange duty factors. Earlier proton linacs did not have such rigorous specifications. Mueller iniciated the LAMPF ion source program in the spring of 1966 when he visited Brookhaven to study their developments. For a highintensity proton suurce he picked the Brookhaven design. a Von Ardenne duoplasmatron source with expansion cup. After further development at LASL, including design assistance by Emigh, this source has produced peak currents of over $100 \mathrm{~mA}$ during pulses of over $500-\mu \mathrm{sec}$ duration and with a time duty factor of up tes $12 \%$.

Onc of the most persistent problems has been the development of a modulator circuit for the duoplasmatron are that will give constant current anc/ voltage during a very long pulse. The modulator output of about $200 \mathrm{~V}$ is applied to the cathode of the son source. After three to 
four years of development, a circuit has been evolved that provides reasonably stable long pulses of 50 : to $10(1-\mathrm{mA}$ output; nevertheless, further improvements are still considered desirable. Another technical problem las been the developm:nt of a satisfactory plasma aperture. The solution achicved at LAMPI: is a 30-mil aperture in a septum formed as a sandivich of iron (for magnetic focusing) and copper (to conduct heat) sheets welded together. Mueller and Fimigh have been jointly iesponsible for most of these source developments.

An importane advantage of the LAMPF aceelerator over other types of proton accelerators is that beam losses can be very small, reducing the otherwise serious radiation problems. To take advantage of this inherent capability, the quality of tive injected beam must be extremely good (low emittance). Theoretical work on the design of an accelersting column to cxtract protons from the duoplasmatron source and maintain a low enittance in the column was begun in $1966 . .^{\text {s4 }} \wedge$ 200-keV partial prototype was built and successfully tested in 1967. A full 750-keV accelerating column was built by Earl Meyer. who joined MP-4 in 1967, and was operational in 1970.

The possibility of accelerating negative hydrogen ions (IF) during the reverse phase of of potential in a proton linac has been recognized by several designers. If ions have the significant advantage of being magnetically separable from the pruton beam following acceleration to high energy. They can then be transformed into $\mathrm{H}^{\circ}$ or $\mathrm{H}^{*}$ particles on traversing "charge-stripping" foils. The need for a separately controlled ion source for the High Resolution Spectrometer was discussed in a Users Summer Study in 1968, and led to the suggestion that a If beam be used for the purpose. The advantager of a negative-ion beam at LAMPF were first presented by Allison and lemigh ${ }^{\text {s5 }}$ in 1968. It was an casy decision for the LAMPF planners to adapt the available spare proton injector system to this purpose.

A If ion source of the charge-transfer type has been developed by Allison who joined the Injector Group in 1966. The souree which Allison buile and bench tested at LAMPI: directs a 100-mA beam of $\mathrm{H}^{+}$ions at $15 \mathrm{kV}$ from a standard duoplasmatron proton source through a channel filled with $\mathrm{H}_{2}$ gas at low pressure, and yields a $\mathrm{It}$ ion beam of 1 to $2 \mathrm{~mA}$. The development started in 1969 and the sccond Cockcroft-Walton preaccelerator was ordered from llacfely. Inc., at that time. A larger ion source enclosure was specified to house the if source. The system was installed in the Injector Building in 1971 and was ready for use after preliminary $800-\mathrm{MlCV}$ operations.

A third bay in the Injector Building is reserved for another Cockeroft-Walton preaccelerator having a polarized hydrogen ion source. Plans are made, and support funds have been requested, to procute this third preaccelerator in FY 1973. A polarized $H$ ion source has been developed ${ }^{\text {s6 }}$ by Mickibben and associates in Group P-9 of I.ASI.'s Physics Division, and is used for research experiments with the Van de Graaff generator. Ralph Stcvens joined Group MP-4 in 1966 and is in the process (1971) of adapting the polarized source to fit within the dome of a Cockerof $t$-Walton set. Progress toward achieving such a polarized source is consistent with plans for procuring the third preaccelerator unit described above. Meanwhile, the original polarized $\mathbf{H}$ ion source: is being used by McKibben and his associates in P Division.

\section{Drift-Tubc Accelerator}

As mentioned earlier, the type of acoelerator used for the first $100 \mathrm{MI} \cdot \mathrm{V}$ was accepted from the start to be the Alvarcz drift-tube linac developed in nuany iaboratories over a period of 10 to 15 years. The most advanced design in progress during 1962-1964 was at the MURA latoratorics in Madison, by a team consisting of $F$. Mills. D. Sivenson, J. Von Bladel and D. Ycuing. The geomein of the MCRA drift-tribe and tank structire was based on the MESSYMESII computer program developed by R. Christian, formerly of Los Alamos, which solved the electromagnetic field equations within the linac tank. If the input to this program is the geametry of the drift tubes and the external tank, the compater output will give the resonant frequency, impedances, fields, and power losses. It was the first linac program to include the effect of the axial holes in the drift tubes. The LASL planners talked with MURA staff members at an early date and decided to base their 100-Me' section on the MURA design. It was sufficiently well understood that its specifications were accepted and used in the first LASL. proposal without modification. Thereforc, only a minor effort was applied to the drif t-tule linac at L.ASL for the first two years, while more difficult problems were being worked out.

Swenson, who had done much of the particke dynamics calculations at MURA, joined the Los Alamos project in December 1964 and was assigned responsibility for the detailed design oi the drift-tube linac. He utilized the same MESSYMESH compitter program, developed geometrical shapes and dimensions, and made particle dynamics analyses. Earlier, Visseher and Rich of T Division had done some basic dynamics calculations sufficient to prove feasibility of the two-element linac system for the original proposal. From the time of his amival, Swenson took over the drift-tube linac at LAMPF. Ilis assignment was as Associate Group Leader of MP-3, Accekrato: Structures. Swensori's sunclusive dimensional analysis is contained in an internal LASL Report. ${ }^{57}$ 
In 1966, Swenson and $K$. Trandalì made space charge calculations for the drift-tube linac and did the beam-loading analysis, with the important guidance of $\mathbf{R}$. L. Glucksiern as Consultant. Gluckstern had done most of the original analytical calculations at Yale; Crandall handled the detailed numerical calculations for the LAMPF machine. Incidentaliy, Crandall also made the basic parzicle dynamics calculations for the side-coupled cavity linac, working clusely with Swensun.

The early beam loading studies at Yale made it seem probable that a drift-tube linac could accelerate very high proton beam currents, of $100 \mathrm{~mA}$ peak intensicy or higher. Such an extremely high poak current was fiund not to be necessary at L.AMPF. Rather, design planning at LAMPF was directed tuward a very lange duty factor, initially $6 \%$ and ultimately $12 \%$ of total time, to provide a long operating cycle for experiments using electronic detection equipment. So the significant paramenter at LAMPF became the arerage current, which was chosen to be $1.0 \mathrm{~mA}$. With a $6 \%$ duty factor, the peak current requirement is only $17 \mathrm{~mA}$, welt below the maximum achicvatile. However, the large duty factor and the large average current of $1 . \mathrm{cmA}$ result in a bearı power of $100 \mathrm{~kW}$. This average power is ten times greater than whs achicved in previous linacs of comparible tnergy with duty factors of less than $1 \%$. As a resulr, all hardware in the linac has been designed for a considerably higher average power level than for any previously designed linac. This feature has required some significant changes in the structural design of the dift tubes and the enclosing cavities. For example, water cooling passages are provided in the noses of drift tubes, and the enclosure tanks are surrounded with water jackets.

The LAMFF drift-tube linac development has been aided by paralleling civelopments in two other laboratories: the Mark 11 200-MeV injector linac for the ACS at Brookhaven, and a 200-MeV injector linac for the 200-GeV machine at the National Accelerator Laboratory in Batavia, Illinois. These three new linacs were in process of design and construction during the same peried between 1966 and 1970. Consultations betwen the three groups were so frequent and complete that each group benefited significantly from design improvements of the others. The three laboratories chose essentially the same basic design features, including the use of copper-ciad steel tanks, quadrupole magnets mounted withir dritt tubes for focusing, and the same frequency of about $200 \mathrm{MHz}$.

One significant difference at LAMPF is that the design energy is only $100 \mathrm{MeV}$, utilizing the cconomic advantage of the side-coupled cavity structure for energies above $100 \mathrm{MeV}$. The design energy of the drif -tube linac has changed several times as the plans and designs for higher frequency cavities proceeded: from $200 \mathrm{MeV}$ in
1962 , to $160 \mathrm{MeV}$ in 1964 , and back to $200 \mathrm{MeV}$ in 1967 in Swenson': first dimensional analysis. The decision to reduce eneryly to 1 (10 MeV was made in 1968 with the experimental successi of a side-coupled cavity model and revised cost analyse'; which showed the economic breakpoint to be lower than previously expected.

A 4-ft-long rank that could be equipped with fullsize drift tubes was built in early 1967 for model studies. 1t was used for full power tesis at $200-\mathrm{MHz}$ frequency and to study the cooling requirements with long pulse lengths (6\%). It was also used in develaping a ceramic window for inserting an of ccupling loop.

The mrost: significant improvement originating at LASL was the discovery by Knapp and Swenson in June 1967 of the "post coupler" for tuning and stabilizing the drift-tube structure; it has improved the stability by a factor of 100 or better. Knapp had noted that tile excellent stability of the side-coupled cavity system at $800-M I / z$ frequency was due to the $\pi / 2$ resonant side cavities used for coupling, and hoped to stabilize the 200-MHz drift-tube structurc by a similar technique. He suggesied the first structural arrangement. Swenson sugpested a second teclinique using $\mathrm{T}$-bars along the inside of the tank enclosure. They combined their ideas to conceive and develop a system using a set of resonant stems along the rank wall opposite each drift tube, with eccentric nosepieces on the stems to adjust the tuning of the tank. They recognized that such a stem coupler was excited $\pi / 2$ out of phase and did not dissipate power, in a manner similar to the $\pi / 2$ resonant side cavity used for coupling in the 800-NiHz system.

When LAMPF reforted their post-coupler concept, the Brookhaven design was too far along for BNL to utilize the idea; they had earlier developed a multistem system that provided many of the same properties. However, the NAL designers recognized this feature as an important improvernent and did incorporate it in the design of the NAL 200-MeV linac.

The final design of the drift-tube linac at LAMPF consists of four tanks: one short tank accepting protons from the source at $0.75 \mathrm{MeV}$ and accelerating to $5 \mathrm{MeV}$. and three longer tanks producing terminal energies of $4 \mathbf{i}$, 73 , and $100 \mathrm{MeV}$. The total length including intertank spacings is $202-1 / 2 \mathrm{ft}$. Final parameters of the drift-tube linac are given in T:tble $\mathrm{V}$.

The first step in constructing the drift-tube linac was to build and test the short 5-MeV tank. Because this included the shortest drift tubes with internal quadrupole magnets and had the most congested spacings, it represented the most critical part of the linac. To braze drift tubes and quadrupoles at elevated teinperatures, the quadrupole windings ware constructed with ceramic insuiation. This feature has proved to be a valuable asser during high-power operation and as protection against radiatior: 
TABLE V

\section{DRIFT-TUBE LINAC PARAMETERS}

\begin{tabular}{|c|c|c|c|c|c|}
\hline \multirow[b]{2}{*}{ Cell No. } & Tank I & \multicolumn{2}{|c|}{ Tank 2} & \multirow{2}{*}{$\frac{\operatorname{Tank} 3}{98 \text { to } 135}$} & \multirow{2}{*}{$\frac{\operatorname{Tank}}{136 \text { to }} \frac{4}{165}$} \\
\hline & 1 to 31 & 32 to 59 & 60 to 97 & & \\
\hline Encrgy in (MeV) & 0.75 & \multicolumn{2}{|c|}{5.39} & 41.33 & 72.72 \\
\hline Fnergy out (MeV) & 5.39 & \multicolumn{2}{|c|}{41.33} & 72.72 & 100.00 \\
\hline$\Delta$ energy $(M c V)$ & 4.64 & \multicolumn{2}{|c|}{35.94} & 31.39 & 27.28 \\
\hline Tank length (cm) & 326.0 & \multicolumn{2}{|c|}{1968.8} & 1875.0 & 1792.0 \\
\hline Tank dianeter (cm) & 94.0 & \multicolumn{2}{|c|}{90.0} & 88.0 & 88.0 \\
\hline D. T. diameter $(\mathrm{cm})$ & 18.0 & \multicolumn{2}{|c|}{16.0} & i6.0 & 16.0 \\
\hline D. T. corner radius (cm) & .0 & \multicolumn{2}{|c|}{4.0} & 4.0 & 4.0 \\
\hline Bork radius $(\mathrm{cm})$ & 0.75 & 1.0 & 1.5 & 1.5 & 1.5 \\
\hline Bore corner radius (cm) & 0.5 & \multicolumn{2}{|c|}{1.0} & 1.0 & 1.0 \\
\hline G/L & $0.21-0.27$ & \multicolumn{2}{|c|}{$0.16-0.32$} & $0.30-0.37$ & $0.37-0.41$ \\
\hline Number of cetls & 31 & \multicolumn{2}{|c|}{66} & 38 & 30 \\
\hline Number of yuacis & 32 & 29 & 38 & 20 & 16 \\
\hline Quac gradient $(\mathrm{kG} / \mathrm{cm})$ & $8.3+2.36$ & $2.4+1.89$ & $1.01-0.87$ & $0.90-0.84$ & $0.84-0.83$ \\
\hline Qund length (cm) & $2,62-7.88$ & 7.88 & 16.29 & 16.29 & 16.29 \\
\hline$E_{u}(M V / m)$ & $1.60-2.30$ & \multicolumn{2}{|c|}{2.40} & 2.40 & 2.40 \\
\hline$\vartheta_{s}($ deg $)$ & $-26^{\circ}$ & \multicolumn{2}{|c|}{$-26^{\circ}$} & $-26^{\circ}$ & $-26^{\circ}$ \\
\hline Power (AIW) & 0.305 & \multicolumn{2}{|c|}{2.697} & 2.745 & 2.674 \\
\hline Intertank space (cm) & 15.90 & \multicolumn{2}{|c|}{85.62} & 110.95 & - \\
\hline
\end{tabular}

Total length including intertank spaces $=6174.281 \mathrm{~cm}(202 \mathrm{ft} 6.819 \mathrm{in}$.

damage. The 5-NeV unit was installed in the drift-tabe scction of the linas tunncl in carly 1970 and was operated for the first time on July 1, 1970.

Assimbly of the remaining threc tanks of the driftsule linac was completed in carly 1971, and first operation al 1000-110V energ! and 1-mis curreat intensity cocurred on junc 21, 1971. Tune-up and uperational performance tests continued intermittently for the following year, resulting in routine uperations before July 1. 1972.

\section{Wavequick Structures}

A linac is a liniear array of coupled resonant cavitics or circuits in which the of whtage across stecessive gaps is in phase to accelerate the aloving particles. In proton linaes the standing wave set up must have identical phases across the accelerating gaps even though the spacing letween gaps increases with particle velocity. Power is fed in eo compensate for resistive lesses and beam loading effetts, preferably at only a few points alorig the waveguide. The problem is to cortrol both amplitude and phase and to keep the acielerating electric fictds constant along the successive gaps as beam loading is increased.
This was a recognized difficulty in the carly drift-tube yype linacs and led to severe beam current limitations. It was also a known limitation in the designs proposed at Hanwell and $Y a l e$ for higher frequencies.

In electron linacs such as St.AC the particles travel at essentially the velocity of light. The waveguide is irislonded with a uniform iris spacing that produces a group velocity equal to that of light, and it propagates a traveling waive in the $\pi$-mode. Electrons ride the front of the traveling wave much as a surf board rides a water wave. The acelerating electric fields can decrease along the waveguide without affecting the phase as beam loading increases. The simultaneuus control of both amplitude and plase is not needed for slich relativistic particles, and the points wher: power is fed into the waveguide are not critica!.

Early experimental studies of structures for highenergy proton linacs were based on the developments at llanvell ard Yale. The cloverlcaf-type cavity initially showed the best promise and was the first to be modeled and studived in detail at LASL. It had good if characteristics but was difficult and costly to build. Nevertheless, a full-scale 40-cell unit was built and tested at high power. Mciasurements on cloverleaf́ models continued for several 
ycars, until the side-coupled system had been thoroughly developed and proven.

Dunn, Sable, and Thompson of Harwell first proposed $^{29}$ the use of resonant coupling structures between successive accelerating cavities in a high-energy proton linac; however, they did not find an efficient coupling device. Fro:n the start, it was recognized that a standing wave system was more suitable than traveling waves for a proton linac, and that both amplitude and phase must be controlled and corrected for beam loading along the full length of the linac. This required a sequence of resonant cavities producing accelerating if fields. To keep such resonant systems in phase the cavities must be tightly coupled. The Harwell scientists suggested that these coupling systems should also be resonant, and experimented both with loop couplers and with resonant slots.

The development at LAMPF that led to the sidecoupled cavity system started from the early Harwell concepts and was improved in a series of steps starting in 1963. The persons chiefly concerned with the analysis were Knapp and Nagle. The technical development was accomplished by a team led by $\mathbf{E}$. Knapp consisting of $\mathbf{B}$. Knapp. W. Shlaer, and J. Potter. It was recognized that the resonant coupling system should operate in the standing wave $\pi / 2$-mode which has no power loss except for resistive losses due to transmitted power. To transmit power for the beam and to make up losses, a trayeling wave component must also be present; this requires phase shifts that involve higher-mode terms. The first resonantcoupling model used at Los Alamos had external $\lambda / 4$-wave coaxial lines with coupling slots opening into two adjacent accelerating cavities. Experiments with this model showed excellent response to tuning the coaxial lines and good control of phase along a multicell model. In fact, this early model later led to the concept of tuned $\lambda$ 4-wave resonant posts applied to the Alvarez-type drifttube accelerator.

Next, an external resonant cavity operating in the $\pi / 2$-mode, coupled by slots viewing each of two successive accelerating cavities, was found to be an even more efficient system to provide the necessary phase shifts. Continued studies with experimental models led to major improvements (increases) in the shunt impedance of the system. The shape of the resonant accelerating cavity was modified by rounding the inner wall surfaces, which fuwered resistive losses and reduad the volume of magnetic field. Nose cones were added that raised the shunt impedance due to the transit-time effect. The result of the several shape modifications was to raise the shunt impedance by about a factor of three above that of the equivalent iris-loaded waveguide; the power needed to prouluce a given electric field for acceleration was reduced by the same factor.
The resonant side-coupling cavity was also modified in shape to reduce resistive losses, to minimize construction costs and errors, and to provide a mechanism for Frecision fine-tuning af ter installation. Still another experimental study was to determine the most efficient size and shape of the coupling slots between the coupling units and the accelerating cavities.

The resulting coupled system operates at the center of the pass-band where the slope is steepest and so gives maximum mode separation and is least sensitive to coupling errors or tuning errors. Field amplitudes in the accelerating cavities are independent of frequency errors to the first order. It was observed that the side-coupled cavity system had greater stability and higher if efficiency than any previously considered structure for proton linacs.

A movie was made to demonstrate the coupledcircuit theory, which explains and interprets the performance. To illustrate, a computer program deveioped the amplitude and phase response with time of each cavity in the system, and the response is shown in the film. The movie has been shown to interested audiences at several recent linac conferences.

The first report of the side-coupled cavity and its tuning system was made to the 1964 Linac Conference $^{52}$ in Madison. Step-by-step developments were reported in a sequence of other conferences during the next few years. As a result, the principle was never patented and became available to all. One consequerice was that commercial firms manufacturing clectron linacs for $x$-ray applications have adopted the side-coupled cavity for their electron linacs that produce multi-MeV x rays for hospitals, medical centers, and industrial plants. With this structure, unusually high field gradients are possible, of over $4 \mathrm{MeV} / \mathrm{ft}$. The short physical length of linac allows gimbel-mounting of $x$-ray units, a distinct advantage for therapy applications. By 1971, Varian had markered 48-, and 12-MeV units, SHM 4-MeV, Arco 12-MeV, Nippon Electric 4-MeV, and Mitsibishi Elestric 6-MeV units.

In October 1968, a 4-ft model of an early sidecoupled cavity design was installed as the resonant load on the test stand, and considerable time was spent making measurements of gradients and fields at high if power levels. Shapes for the final protorype and the production units were determined from these studies. A decision was made about this time to perform the final machining and assembly steps of the linac construction at LAMPF in the Equipment Test Laboratory, and suitable machine tools and furnaces were installed.

An important part of the waveguide story concerns the development of the technical expertise to build and assemble the complicated structures. This program was aided by the transfer to MP Division of experienced 
engineers and technical staff having previous experience with vacuum systems, pumps, precision-made chambers, alignmeni supports, cte., from the Physics Division, GMX Division (the PHERMEX program), and other LASL Divisions.

The engineering design of the waveguide structures was initiated by E. Knapp and D. Nagle. Mechanical enginecring and supervision of construction was provided by Hairston (Spike) Worstell and his technical staff. Worstell came to Group P-11 in September 1963 as their first mechanical engineer to work on the model program. He had previous experience in the PHERMEX program, which involved linac-type cavitics and vacuum systems. When the MP Division was formed in July 1965, Worstell became Associate Group Leader of MP-3 (design, development, models), and chief mechanical engineer for accelerator structures. During the design phase, the MP-3 enginecring staff reporting to Worstell included most of the mechanical engineers, draftsmen, machinists, and technicians employed in the model program. A variety of waveguide modals were designed, installed, and operated by this group; this included several cloverlsaf cavity systems, one of which was installed in a vacuum chamber and operated with clectrons, by Emigh and his associates, to gain experience with of systems. The culmination of the model program in 1968 was the Elcctron Prototype Accelerator (EPA), which was the first practical test of the side-coupled cavity system. Construction of the waveguides for the EPA was carried out at CMB-6, the LASL. meiallurgical group.

An carly technical decision was to subcontract as much as possible of the casting, forging, crude machining. shaping, etc., to outside firms, but to Jo all the critical work of finishing, final assembly, and precision tuning of the waveguides in the Equipment Test Laboratory (ETL) at LAMPF. Many factors were involved in making this decision, including problems of transportation, engineering supervision, and the special brazing treatments required. For example, there were 352 separate accelerating tank sections built for the $805-\mathrm{MHz}$ waveguides. each with aifferent dimensions. Few commercial firms were equipped with brazing furnaces capable of assembling full-length tank sections. One of Worstell's first assignments was to design and procure electric-heated. hydrogen-purged furnaces to perform the great varicty of brazing operations; these were installed in a special high bay in the ETL Building. Lathes were procured for the precision rurning jobs required for cavity tuning; test stands designed by the rf group were installed to life-test the klystrons provided by commercial firms; and cleanrooms with filtered air were installed to handle assembiy procedures requiring a dust-free environment. Another reason for iocal assembly was to minimize the initial stock of spares and to be able to replace units rapidly if necessary.

During the accelerator design phase, the nechanical engineers and draftsmen on the LAMIPF staff produced about 2000 drawings, most of which were used to specify production contracts. More than 80 vendors and contractors used these designs to fabricate accelerator components. Procurement of the materials for the waveguides and other machine components was greatly aided by the Supply and Property Department of LASL, particularly by R. J. VanGemert and D. Bryson.

Other LASL divisions and shops have contributed to the total local effort: CMB-6 makes the ceramies for insulators; SD-5 does many specialty machining jobs and provides experienced machinists for the LAMPF shops; the inspection department of SD-4 provides engineering inspection services; the SP (Supply and Property) Depart* ment does the buying, keeps records, makes payments, and controls shipping; the Personnel Department supplics new staff needs. In summary, it is ckar that the experienced staff and the technological expertise existing at LASL provided much of the know-how needed to build the I.AMPF accelerator.

\section{E. Radiofrequency Power Systems}

The type of of power amplifer most suitable for excitation of the high-frequency $800-\mathrm{AHz}$ smuctures needed for the major portion of the linac was a source of argument between experts for several years. George Wheeler and his collaborators at Yale did exploratory design studies for a linac meson factory and telieved strongly that a triode power tube would be best, using the "coaxitron" design then under development at KCA which had been successful at lower fiequencies and lower peak power. Blewett at Brookhaven also favored triodes; his 50-MeV injector linac for the AGS used 200-Mitz triodes built by the CSF Company in France.

In 1962, most linac experts strongly disilked klystrons, probably due to unfavorable experiences with klystrons during the development program at Brookhaven. Furthermore, no klystrons had yet been built for 1-NW peak power desired for the linac application at $800 \mathrm{MHz}$. Still another possibility was the "amplitron" being developed at Raytheon, a crossed-field amplifier using a secondary emission cathode theoretically capable of long tube life and high rf efficiency. This was the existing situation when LASL entered the field in 1962, and it continued without much change until late 1964 when the definitive LAMPF proposal was submitted to the AEC.

The original team considering the technical problems of linae design a: LASL consisted of D. Nagle, E. 
Knapp, D. I Iagerman, and $\boldsymbol{A}$. MeGuire. As the design study intensified, llagerman becams individually responsible for the planning and supervision of the of power problems and the other members specialized on other aspects. The 1.ASL staff at that time had no applicable rexpericnce in if power systems to help them make a choice between the three potential types of power tubes. It semed that their only recourse was to sponsor the development of suitable tubes by manufacturers, and to build a test facility at LASL to observe the comparative performance.

RCA made a proposal to LASL in August 1963 to develop a 1-1/4-MW peak power tube of the "coaxitron" design for 800-M11z frequency, with $50 \%$ of efficiency and a duty factor of up to $5 \%$. This fited the needs, so LASL placed a development contract with RCA for five tubes on the basis of their proposal. Meanwhite, a negotiation for a joint LASL-Yale-Brookhaven development order with RCA was started, but pi-gress was slow duc to limited funds. In September 1963, Kaytheon sent a proposal for a 1-MW amplitron operating at $200 \mathrm{MHIz}$; however, this proposal was for the wrong frequency and was tnot acceptable.

The first technical step at LASL was the construction of a power cube test stand which was mosxly built of surplus equipment from a discontinued Nike-Zcus radar installation at White Sands. The first tube to be tested was a $100 \cdot \mathrm{kW}$ cekrode to be used as an intermediate power amplifier (IPA). The first RCA coaxizon for 1-1/4-MW peak powet at $800 \mathrm{MHz}$ was received and put under test in December 1964. The last tube of this fist orde: from RCA came in June 1965. During this testing period many unpleasant surprises occurred: the cube characteristies failed to meet the ancicipated specifications in many ways. A major limitation was the short liferime and short duty cycle; a typical result was so-h life at $1 \%$ duty factor. The state of progress was reported ${ }^{\text {sal }}$ to the National Accelerator Conference in carly 1965.

Thomas Turnex, who had previous experiener with of power systems at SLAC (Stanford) joined Group P-11 in 1964. His first assignment was to develop a lob-kw driver sage for the RCA coaxitron. This development ultimately succeeded, using a klystron built for the television industry by Eimac (4KM7OLH), and was used as the driver in the rest station during the 1965 testing of RCA triodes on resonant loads. This was LASL's first success with a klystron; later the unit was permanenty installed in the LAMPF sysrem. Tu!ner played a leading role in the of development until his untimely death in 1970.

This first suscess with a klystron srimulated furthes studies. R. Jameson, who had joined LASL in 1963 and did a PhD thesis at LASL for the University of Colorado in RF Controls Engineering, continued his studies on controls and transfer functions of triodes and klystrons. ${ }^{\text {3n }}$
He found the klysirion tractable for controls and acceptable as a resonant circuit driver. This was a major step forward. Iirum this time (mid-1965) on, the klystron replaced the tetrode for drive applications.

A second contract was placed with RCA in late 1965 for further development of a $6 \%$ duty factor triode. Studies of these RCA 1-1/4-MW triodes continued on the test stand during 1966.

During 1966, the desire to have a still higher duty factor (12\%) and higher average power grew to become a firm demand. It was increasingly obvious that the RCA triodes could not meet this additional specification. But klystrons showed promise. They had been suceessful in producing both high peak and high average power at SLAC at 3000 Allz, and experience was accumulating at several tube plants in the $800-\mathrm{MHz}$ frequency tange. In October 1966, developmene ordens for five tubes each for 1-1/4-AW klystrons capable ultimately of a $12 \%$ duty factor were pizced with Lirton and with Varian (which had absorbed Bimac). At this same time, an order was placed with Raytheon for two 1-1/4-MW implitrons at $800 \mathrm{MHz}$, also for $\$ 12 \%$ duty factor.

This duplicution of development contraces was considered necessary to obtuin a successful power tube in time to meet th- MMPF schedule. Meanwhile, the original RCA contract for triodes was rerminated by nejotiatiors started in April 1967, and the 100-kW etrode (IPA) was abandoned as the driver stage. During 1966-1968, the type of power tube that would prove capable of excixing the $800-\mathrm{Mt}$ tz portion of the linac was uncertain. This uncertainty coused much concern to members of the staff and became a major bottleneek to mecting the desired schedule for completion.

The first 1-1/4MW amplitron was received from Raytheon in April 1967 (utilizing two units in series). Under test, the amplitron had serious fead-back problems and was almost impostible to control. Nevertheless, testing of Raytheon amplitrons continued to November 1968 when the contract was terminated. The first 1-1/4-MW kJystron was received from Litron in June 1967, but was found to have many unsatisfactory features; it was noisy and had low of efficiency. Nevertheless, the experience with this tube uftimately led to the decision to use klystrons as the power source.

The first good tube to be tested was a Varian klysuron (VA-862) received in November 1968; it performet well ${ }^{60}$ at over $50 \%$ efficiency. This tube was still in service in the LAMPF system in 1971 after operating for over $2000 \mathrm{~h}$. The Varian five-tube contract was completed by July 1969. However, Litton productivity was less setisfactory, with no deliveries of acceptable tubes until Octoi 1969. By this time, LAMPF took the specifications and parameters of the successful Varian tube and applied them to the Litton contract. 
The 'nads used on the test stand were both resistive and resonant. The resistive load was a water cell that could dissipate the full 1-1/4 MW. A multicell section of the water-cooled cloverleaf-type waveguide was the first resonant system to utilize full power from the klystrons under test: !ater an early model of the side-coupled savity was used, also water cooled. By early 1970, a 40-cell unit of the production design side-coupled cavity was tested in LASL's Equipment Test Laboratory. Three power test stands were installed in this building for testing production klystrons.

A production arder for 45 klystrons (44 total required) was placed with Varian in March 1970, for completion July 1972. For those delivered up to the date of writing this report, the record has been good - only one failure and this only after over $6000 \mathrm{~h}$ of service. An order for 25 tubes with essentially identical specifications was placed with Litton in May 1971 ; these will become available as spares. The question is still open as to whether. LAMPF will develop its own klystron repair and rebuilding shop for long-term maintenance needs.

One of the major technical advances in the $f^{\prime}$ system for the LAMPF accelerator is the control system of phase and amplitude. This system has several novel features that have not been used on other linacs. A simplified description of the amplitude contcol process might be: a pick-up loop samples the if field in the accelerator tank; this is compared with a reference voltage (coming from a battery) that generates an error signal, which is fed back to the driving amplifier. A similar picl-up, reference phase voltage, error signal, and feedback is used for phase control. Developing the control system required a wide band width and absolute standards for amplitude and phase. The person primarily responsible for this development was R. Jameson, who was the originator and continuing supervisor to the step-bystep process.

In the absence of absolute standards of field strength, a method was devised to obtain the precise tuning conditions from the behavior of the accelerator beam. This development involved $R$. Jameson, $K$. Crandall, and D. Swenson. The resulting system is sufficiently unique to be known by the special name of the "At curn-on;" in this process the power units are turned on one by one from the entry end of the linac, and each one is carefully tuned for precise amplitude and phase before going on to the next unit. A disadvantage of the size of the powering units for this puppose is that each unit is about one phase oscillation in length (about $16 \mathrm{MeV}$ at 100 to $200 \mathrm{MeV}$.

The Electron Prototype Accelerator (EPA) was designed and built in 1967 to test the operation and performance of the side-coupled cavity. It also served an exential function in providing a working system on which to study the rf control problems at the designed frequency of the main linac ( $805 \mathrm{MHz})$. The EPA was completed and operated for the first time in December 1967. During 1968-1969, Jameson studied the if control problems. Initially he was unable to make the power balance between the four if power units (tanks) as the duty factor and average power were increased. This was due to lack of adequate cooling; but more importantly, it was clear that there was inadequate understanding of the coupling and tuning errors. During this study, Jameson further developed the basic concepts of the "phase-amplitude control" system described above. By late 1969 these problems were satisfactorily solved. For example, the EPA was operated many times for 10 to $20 \mathrm{~h}$ with a measured variation in beam energy of about $0.1 \%$. This development led to significant changes in cooling design and in tuning techniques and produced a much better understanding of the precision and quality control problems of the if structure. The result was a successful completion of the phase and amplitude control system that has proven essential to the efficient performance of the linac.

It should be noted that in August 1971, Jameson was placed in charge of testing, etc., of the side-coupled structure by the Construction Steering Committee.

We now go back to 1966 to describe the parallel development of the if power system for the $100-\mathrm{MeV}$ drift-tube linac operating at $200-\mathrm{MHz}$ frequency. As mentioned above, the RCA 7835 triode was known to be satisfactory as a power tube capable of delivering short pulses at up to 5-MW peak power. The problem was to develop an intermediate power amplifier (IPA) and modulator for the much larger (12\%) duty factor and higher average power needed at LAMPF. Again, Hagerman was the group leader and Boyd was a prime mover.

In January 1966, the tube and associated equipment for a standard IPA unit at $200 \mathrm{MHz}$ was put on order. Meanwhile, a modulator was needed to handle the large duty factor and,as a first try, two RCA 8618's were used in parallel. Difficulties occurred in the modulator development at this high average power level, and also in the IPA when it was received in October, largely due to if leakage in the containment hardware supplied by Continental Electronics Corporation. Tests continued, with frequent modifications, until early 1967 , and by this time many of the problems were resolved. The first operation of a complete driver system with a 7835 power tube at 6\% duty factor occurred on April 30. As the goal was pushed toward $12 \%$ duty factor, still other limitations showed top in the 7835 cavity provided by Continental and in the blocking capacitors, which continued for another year of development. Continued engincering improvements led to firm specifications by mid-1969. Funds became available at this date to place orders for the operational units. 
Module 1, which powers the first 5-MeV tank, was installed in its permanent location and became operational in March 1970. It was used to obtain the first $5-\mathrm{MeV}$ beam on July 1 , on schedule. Module 2 became operational in April and by November installation of all four modules was complete and system improvement tests were under way. Successful operation at $100 \mathrm{MeV}$ was achieved in June 1971. All evidence suggests that the major problems are solved and that the complete power system for the $200-\mathrm{MHz}$ linac will operate as designed.

\section{F. Controls and Instrumentation}

The concept of a control system organized about an on-line digital computer appeared very early in the history of LAMPF. The idea was first proposed at a P-11 group meeting in September 1963. The importance of computer control was also noted in a letter from Kolstad of the AEC dated September 26. A preliminary study ${ }^{61}$ of the feasibility of a central computer control system was prepared by R. A. Jameson and H. S. Butler in October. It argued that a computerized system offered greater flexibility, higher reliability, and more uniform operation than a conventional hard-wired system and was well worth the possible higher capital costs.

The matter lay dormant until February 1964 when T. M. Putnam transferred to P-11, from the Sherwood Project, where he was group leader of the Engineering Group. Putnam became a member of the P-11 "Steering Committee" and accepted responsibility for the control system. His first act was to develop the design goals against which any approach to a control system could be evaluated. During the summer of 1964, Putnam directed EG\&G in an intensive study of the controls problem, aided by T. M. Schultheis and Jameson. The conclusion of this study is contained in the following sentence.

\section{“...E.G\&G recommends the use of a control digital computer installation for accelerator status monitoring, beam program establish- ment, and direct digital control at LAMPF..."}

With this recommendation as a starting point, $s$-ious consideration was given to the design of a computer-based control system for LAMPF. A conceptual design for the system and the tasks to be performed by the computer were presented in a pape ${ }^{62}$ by Putnam, Schultheis, and Jameson at the first Particle Accelerator Conference. The design reflected the modular arrangeinent of equipment along the length of the accelerator. A typical module included an $\mathrm{rf}$ power amplifier, one to four accelerating cavities, radiation monitors, water and vacuum systems, beam-monitoring equipment, several magnets, and beam-steering controls. In all, about 100 data and control signals were associated with each of the 60 modules, giving a total of 6000 channels on the accelerator.

The controls for each module were consolidated at a central location. This module control point served two essential functions. First, it provided the controls for operating the equipmcnt locally during installation, checkout, and maintenance. Second, it served as a remote terminal for all data and control signals going to and from the control room. Each module control point was linked to the Central Control Room (CCR) by transmission lines. These lines terminated in a special multiplexer connected to the computer. A functional design for the complete interface system between the computer and the accelerator was published in November 1965 by Butler and Smith. ${ }^{63}$

In spite of the compelling arguments for compurer control, it was necessary to justify so distinct a departure from accelerator technology. This justification took the form of a prototype computer control system for the 24-MeV Elactron Prototype Accelerator (EPA). The computer for the prototype system, an SEL-810A costing $\$ 2000,000$, was delivered in March 1967. The linac was first operated from a manual control system during December 1967. Development of these manual controls was supervised by Putnam and R. A. Gore. The responsibility for the computer interface hardware lay with $D$. T. Van Buren and, later, with D. R. Machen. Computer control of the EPA, from turn-on through beam steering, was demonstrated in the spring of 1968. The programming effort was supervised by Butler and R. F. Thomas. About 12 man-years were invested in the programming system.

In parallel with the development of the prototype control system, an effort was made to evolve a control philosophy for LAMPF. A summary of the overall control system design philosophy was made by Putnam in November $1967 .^{64}$ The principles set forth in that report became the guidelines for developing the LAMPF control system. Subsequently, a committee of nine senior staff members met weekly between January and May of 1968 to discuss various facets of the subject. Minutes of these meetings were distributed, but never summarized in a single document. A few of the major points are listed below.

a. The accelerator, switchyard, and permanent portions of the beam lines will be operated from CCR through a centralized control system.

b. Sufficient manual controls will be provided at each module for equipment installation, checkout, and maintenance. 
c. These manual controls will be designed so that parameters can be set locally and then sivitehed to remote control without any interruption in operation.

d. Data and control signals will be transmitted tir serially between CCR and each module over a digital multiplexer system involving very few cables.

e. In general, the only control loops to be closed through CCR will be those requiring considerable analysis, such as for beam oprimization.

f. "Operation by exception" will be the rule in the design, with a human operator standing by to handle the exceptions.

g. Equipment will be self-protecting; all eircuits related to personnel and machine protection will be hardsired and interlocked locally.

h. The system design will be modular to speed maintenarice and reduce the spare parts inventory. The module designs will minimize the number of circuits and components consistent with system requirements.

i. Personnel safety will be of prime importance in all phases of the design.

Work on the prototype control system continued through the fall of 1968 . At that time the PERT chart for LAMPF indicated that a choice had to be made between conventional and computer control. On the basis of the success achieved with the EPA system, it was proposed by Butler $^{65}$ that an SEL-840MP computer be purchased as the core of the LAMPF control system. This cuurse of action was approved first by the Steering Committee and later by the entire Technical Committee of LAMPF.

With that fundamental decision made, the tempo of work on the control system increased markedly. Prototyping activities were brought to a conclusion. The designs for all systems were reviewed to ensure their compatibility with computer control. Procurement actions reached a peak in 1969. Essentially all of the equipment was built commercially from designs developed by the controls and instrumentation group.

The installation and checkout of the control system was started in 1970 and picked up momentum all through 1971. The control computer was delivered in March 1970. Five months later it was installed permanently in CCR. The interface system between the accelerator and the computer was connected in the fall of 1970 . The programming system evolved all during that year. In December 1970, an operator seated at the console in CCR used the computer controls to bring up a beam in the Injector and stecr it through the low-energy transport region to the drift-tube linac. During the $211-$ MeV beam test in August 1971, the CCR was the center of operations.

Although this history has cmphasized the computer-related aspects of the control system, a comparable effort went into developing the operational systems. The distributed operational systems extend over the length of the facility and are essential to the operation of the accelerator. Included in this category are the timing, fastprotect, run-permissive, personnel safery, and radiation-safery systems. The TV, communications, and video (pulse-viewing) systems comprise the auxiliary opcrational systems. The local control systems were all developed from a set of nine standard control modules packaged in NIM bins. This approach greatly reduced the spare parts inventory and the time to effect repairs.

Throughout the entire development, Putnam was Group Leader of MP-1 and coordinated the controls system development. In parallel with this, he also served as the LAMPF Safety Officer, and by 1971 he assumed continuing responsibility for the safery program, which will become an increasingly important activity as operations and the experimental program start. As this load increases Gore will take over as MP-1 Group leader to guide completion of the accelerator instrumentation and control work, and to develop the capabilities within the group to provide electronic support for the experimental program. In addition, MP-1 has been given the responsibility for developing the LAMPF data-acquisition system for the Experimental Area. In both these activities, Gore will be assisted by Butler, Machen, and Thomas.

\section{G. Beam and Target Handling}

The radiation effects of the unusually large beam power of the LAMPF accelerator were also anticipated from the siart of planning. It was known that the large fluxes of mesons and neutrons from targets would require massive shielding, and that the induced radioactivity near targets following beam turn-off might reach intensity levels of tens of kilocuries. Remote handling from behind shields was known to be essential for all targets and equipment exposed to the primary beam. One of the strong arguments in favor of Los Alamos as a location for a meson factory was their experience in handling high levels of radioactivity.

To plan research experiments (as well as to design shielding) it was necessary to determine the radiation flux with soine precision at an early date. Several members of the Physics and Theoretical Divisions contributed to the calculations of the nuclear cascade in targets and in shielding materia!s, and to predictions of the fluxes of secondary radiations. These included R. Bivens, J. Wooten, 
D. Cochran, D. Mueller, and S. Whetstone. An early goal was to determine basic shielding requirements to provide data to prepare cost estimates for the proposal to the

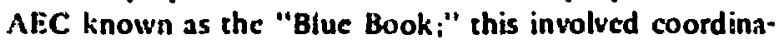
tion with McGuire and others preparing building specifications. The set of Monte Carlo calculations of the intranuclear cascade shar were made were based on a revised version of the Monte Carlo code of Metropolis et al. from I Division. Using the sophisticated transport codes of Kaye Lathrop and Forrest Brinkley of T Division and the Monte Carlo resuits as input data, Harvey Isracl. of II Division, and Cochran calculated the required proton beam line shielding. One major report ${ }^{6 s}$ on the status of the cascade calculations during P-1 1 days was written by S. Whetstune in December $196 \mathrm{t}$.

So it became possible so calculate meson and neutron fluxes with good precision at an cariy stage, and so to define the shiclding requirements atound targets and other portions of the beam run. This allowed the design of the beam runs, target systems and experimental arrangements to proceed. This "first-cut" design was intended to provide sufficient detrii to allow responsible enginecring cost estimates of the experimental building. McGuire did much of this initial planning and supervised the enginecring cost estimating.

To obtain minimum volumx iron was chosen for the shielding around tanget stations. Light material was also nreded to reduce fast neutrons emerging from iron to acceptable low intensity, which implied an outer sheathing of concrete. Calculations showed that $13 \mathrm{ft}$ of iron and 3 ft of concrete might be needed around each target. Shielding was designed to provide maximum persunnel acess around taxgets, even though it increased shiclding cost. A sequence of four to six target stations along the beam run was yisualized, each shielded for maximum beam loss. Shielding was specified as mobile, stacked, and close-fitting - a fairly expensive construction option. An experimental building to house these :arget stations, with overhead crane to handle shielding, roughly resembles the present "Area $\boldsymbol{A}$." In the iisitial plans, the crane operator was to be placed in a fixed control room with remote viewing and manipulators. Another important activity in 1963-1964 was the design of magnets and other devices for the beam-handling channels for pion and muon heams. done primarily by Butler; engineering cost estimates of these squipment items were aiso prepared. The result of these early studies was a cost estimate of the experimental building and its equipment which, fortunately, has remained valid through many subsequent revisions. McGuire left LASL. (temporarily) in January 1965 and F. Tesche assumed responsibility for subsequent revisions.

This was the state of planning when Mahlon Wilson transferred to LAMPF in May 1967. Wilson had previous experience with radioactive hot cells and remote handling problems in CMB Division and had recently completed his Doctorate in Mechanical Engineering with a thesis on 2 problem in cryogenies. He was assigned to the MP-6 Group (Experimental Rreas) under Cochmn, where he became Associate Group Leader. One of his first acts was to propose ${ }^{67}$ a new approach to the concept of shielding and remote handling that led to the system known as "Merrimac."

The concept of Merrimac is that of art iron-clad movable vchicle (hence the name) that can service all targe: stations along the main bcam, and transport radioactively hot items within a shielded box to a hot lacoratory for handling or replecement. The Merrimac vehicle rides on top of the pile of iron and soncrete shieiding along the main beam. It can service Experimental Aru A (threc targets), the radioactive isotope production area. the biomedical area, and the beam stop. Metrimac alse includes a unified system of connect-disconnects for vacuum chambers, electrical power, and cooline water sysiems for the magnets and other beam-handling equipment along tht beam run. A major virtue is its flexibility to solve unanticipated problems of remote handling and manipulaticn. It can remsotely remove rargets and transport them to the hor lab within a box having 16-in. steel walls (adequate protection for $4000 \mathrm{C}$ in the handling time required). It can carry 30 tons of weight (an ironcopper magnet of 4 by 4 by $4 \mathrm{ft}$ ) within its shictded box (10 by 10 by $6 \mathrm{ft}$ internal dimensions). The loaded carricr weighs $\mathbf{2 0 0}$ tons. It rums on tour aircraft landing gear units obrained as surplus from carly-model B-52 bombers.

The operating technique used with Merrimac is summarized.

2. Roll Merrimac over target area on aireraft landing gear wheels.

b. Open top shielding doors over target area horizontally on rollers to form a top opening.

c. Lower shielded box (open bottom) into hole using four screw jacks.

d. Use remote-control manipulators within shielded box to make a target change of disconnect faulty equipment.

c. Lift target or faulty component up into shiclded box by winch.

f. Raise shielded box up into Merrimac chassis by screw jacks. 


\section{target. \\ g. Close rop door on shielding srack over the}

h. Transport component to hot cells.

The entire operation is directed and controlled by an operator riding in a cab on the side of the Mcrrime chassis, who is protected from radiation by a 16 in. stecl shicld.

Development of the engincering concepts for moving and handling the heavy shirlding and large loads involved several inembers of Group AtP-6. Wilson cunceived the basic system for a rolling vehicle carrying heavy loads. After studying the limitations on loading of railroadtype mils and whecls, Pati Franke suggested the use of very large pneumatis rubbet eires. Linas Thorn studied Janes' "All the World's Aircrafe" and found that four b-52 landing gear units would carn the load. An availability study located sonve obsolcte carly-model B-52 landing gear assemblies that could be obtained from salvage. Six aseemblics were obtained from which the fust units were assembled for vicrimnc.

The stecl needed for the dieriime: shiplded box was also procured quite cheaply, utilizing rejected slabs from v.S. Steel ( $20 \mathrm{ft}$ by $6 \mathrm{ft}$ by $6 \mathrm{in.}$ ) and surplus counterweights ( 20 ft by 3 ft by 6 in.) from Atlas missile silos. The enginecring design of the Merrimac system and mechanisms was supervised by Wilson and dawn by Group MP-6. The cotal cost of Merrimac, including the loading gantry crane, the landing gear units, shiclded box, and all gearing and electric drive systems was about $\mathbf{\$ 3 0 0 , 0 0 0}$. This was lest than the cost of a singke taget station as originally estimated and made a much more extensive system of arget stations possible within the budget. In fact, it is possible to conclude that the most important feature of Merrimac was the bargain basement cost that allowed this cxtension of target arrangernents within the strictly limited budget for experimental areas.

The target changing system may urilize the shielding and fast access provided by Merrimac, if desired. A target changing mechanism built into a "bottom entry" cask can be carried in the shielded box. The target : "sconnected by remote handling devices and is raised up into the portable eask which is then transported to the hot hab. oratory for chemical processing. A fresh targei is inserted with the same handling devices. Other target systems (for uncooled tangets) utilize pneumatictube delivery to the hot laberatory.

Targets for bem intensities up to $0.5 \mathrm{~mA}$ average can be mude of graphite of water-eosiled copper. For highest intensity and smallest spot size $\left(0.1 \times 1 \mathrm{~cm}^{2}\right)$ a molybienum wheel target that conminuously spins to expose = fresh cooled surface is planned. The maximum mdiosetive intensity anticipated on thick copper target is $40 \mathrm{kCi}$. For the final beam stop beyond all tagets, the beam will be spread uver $a$ G-in. diam and will be absorbed in a tlick water-cooled iron slug. Cooling water will be recirculated tlirough a heat exchanger within the shielding and the gasems $11^{3}$ radioactivity induced in the water will be locally trapped and concentrated for removal.

Group MP-6 has a wide range of responsibilitics related to the primary beam. They design and develop all components used in the target areas and beam switchyards up to and past the "first bend." This includes bending magnets, quadrupoles, beam diagnostic equipment, vacuum chambers, targets, etc. Of special interest is the nineral-insulated magnet coils that provide major rediation hardening developed by Alex Harvey. MP-6 works cloxely with Group MP-7, which has responsibility for developing. constructing, and cheching out all the secondary beam tines. MP-6 and MP-7 atsist scientists to plan experiments and cooperate in designing tbe equipnient. They develop instrumentation for measuring pion and neutron fluxes as radiation backgrounds.

\section{Sife Ptensing and Cost Estimetion}

The site elected for LAMPF is on "Mesita de Los Alarnos" paralleling the main Los Alamos mesa on the south, but separated by decp canyon. In the fall of 1962, the LASL Enginecring Denartment made a study of possible sites within Laboratory boundaries that were sufficiently fat and straight enough for a half-mile-long linac. The sfudy included an acrial survey of the mare promising sites. The chosen site has a subsoil of soit ruff rock favorable for machine cxcavation yet providins firm foundations. Access to LAMPF is from the East Jemex road (the Los Alamos truck route) which not only makes it convenient to orher LASL facilities, but saved raad construstion costs. The site was tentatively chosen in time to be included in the Preliminary Proposal ${ }^{3}$ dated December 28, 1962, and was later approved and authoriaed by the Director and by ABC representatives.

The carliest reasunably complete plans for the buildings and site amangement were made by Austin McGuite, in consultation with ocher planners and with assistance from the LASL Engineerity Departinnnt, in time to be included in the definitive Proposal "known as the "Blue Buok." dated September 1964. These plans proposed an underground tunnel for the linac housing. with 20 to $30 \mathrm{ft}$ of earth to provide thr: basic overhend shiclding from radiation during operations. Buildings for the injector system and fer an extended eazet eumplex were at extreme ends of the tunnel; housing for if power. cooling systems, and controls extendexl aling the halfmile tunnel above gruund: and structures for laboratory and office use and for equipmeni assembly were amanged 
nearb; : These building requirements were used by Ciffels ani Rossetri to obtain the initial cost estimaics for constructing the physical plant. MeGuire left the linac design group for other intereses soun after the Proposal was completed.

As designs maxured, nany changes were made in the site arrangeirents and in the decalled plans for auxiliary buildings, but were kept within the original total construction cost cstimate. Perhaps the most extensive changes were made in the experimental areas; the final arrangements are irdicated in Fig. 1 in Chap. 6.B. Another major changs uis to use the funds originally assigned for equipment asscmbly in the Target Building complex to constrset a separate fiquipment Test Lab. oratory (ETL) remuved frors the main buildings. Ground was broken for the ETL in Febraary 1968.

Various other problems were identified and rewohed during this redesign plase. A natural hollow actoss the mesa would have reguired major earth moving to provide shielding; so the longitudinal location of the accelerator cunnel $\cdot 2$ s shifted to locate the injector building, which did not require thick shiclding, into this hollow. The risk of earthquake damage was raised by the AEC. staff and resulied in an asi-nment to Giffels and Rossetri to analyze the natural resonances of the linac machine and building structures on the tuff foundation. The result showed negligible carthquake risk. A detailed study ked to a choice of $26.5 \mathrm{ft}$ for the earthful shielding ove the highenergy end of the line tunnel: in practice, it was found that this same thickness could be extended ovet the full kngth of tunnel wishout increased cost.

The person chicfy responsible for courdinating these modifications was Paul Edwards, who joined the P-11 design gruup in May 1965 and transferred to Group MP.5 when LAMPF was formed in July 1965. The Group Leader at that time was F. Tesche, who joined LAAPF in July 1965 and continued in this capacity until he kft che project in June 1954. During this period, the final forms of the reviced building arrangements touk shape. Fdwards beeame Group Leader when Tesche left. One of Edwards" major accomplishincres has becn to pry realistic builings criteria out of the several Groups in time to incorporate them in construction cuntracts.

The philosuphy used in develuping the building spevifications was to conceritase on the detailed desizns sequentially following the predictions of a Program Evalustion Review Technique (PERT) cost and rime analysis. As a result, the various parts of the project were designed and cunstructed serially. For example, the cuncepss of the beam switchyard in the carget area and of the Merrimac iandling system eame at a late date in 1969, and were quite different from the original coneepts. The major items or packages put under cortract during site conaruction in the date sequence when the items were started ste listed here.
4/64- Preliminary design contract with Giffels and Rossetri.

1/66 - Basic architectengineer contract with Giffels and Rossctri

2/67 - Site and Utilities, 1 $\sim \$ 0.6$ million (incl cut for linac tunnel)

2/68 - Construction of ETL. Building $\sim 50.8$ million

$5 / 68$ - Injector Building and $100 \mathrm{McV} \sim \$ 2.2$ million Facility

5i68 - Sitc and Utilities, II

$\sim \$ 0.3$ million

$7 / 68-115-k V$ Substatiols

$\sim \$ 0.7$ million

12,68 - Laboratory-Office Building

$\sim 51.4$ million

1/69- 805-MII Ix Facility

$\sim \$ 5.56$ mition

4/69 - Design Conract with Giffels and Resereni for Experinental Area

6/69 - Opcrations Buildiny $\sim 9.6$ million (controls)

9/69- Experimeneal Area, I — $\mathbf{S 2 . 9}$ million (main targer building)

$10 / 70$ - Experinental Area, II -34.2 million (experimental areas)

6/7l - Experimental Ars, IIt

$\sim \$ 1.5$ million (extension ro beam stop)

6/71 - Site and Utilitics, III

$\sim \mathbf{3 0 . 1}$ million

The rirst cost cstimate inaluded in the Preliminary Proposal was taken from two sourecs: (1) an exrimate of cquipanent and babor custs for construce ion of a 750 MeV protun line with 1 mA average beam prepared by Witliam il. Brobeck and Assuciates, based on specifications for such a linac given in Yile Report ${ }^{32} Y-6$ of October 1962. and (2) initial estimates for building construction and sitefelated costs prepared by the LASL Enginecring Department. The total extimated project cost given in the Pteliminary Proposal was \$2,137,000. This same ctimate was detailed and repesed in the Schedule 44 , Constrtiction Project Data Shect, presented to the AEC in August 1963.

In an Appendix to the Preliminang Proposal. $R$. Emigh presented an. Iternate csimate obtained by scalin: up the costs of the PIIERMEX project recently completed 
at Los Alamos to the higher power and higer magnet, vacuum and cooling requirements of LAWIPF. The estinate obtained by this sealing process wat $\$ 55,500,000$. It is interesting to note how cluse this was to the final estimatc.

Enginecring and cost studies were continued during the following yers with the assistance of other commercial firms. The of power sysfems were studied and cost estimates were made by Radio Corparation of America at. I by Cortinental Electronics; Edgerton. Germeshausen Ind Grier made a study of the control system: Brobeck and Assuciates continued studies of the linac components: and Giffels and Russetri analyzed the revised buildings ard site reguirements. Giffels and Rosstzi made an ineependent extimte of the rotal project cost as $\$ 60$ million, wich sumehow became knuwn to the news media and was reported in a New York Times arricle by John Firnsy on September 14, 1964, entitled "AEC Consideril.; Meson Factory 21 Les ilamos" The LASL Administra ion was concerned that this high cost estimate might detra: : from the chances of success. On September 22. Rosen stivt a memo to Bradbury indicating that the cstimate coulo be reduced by a minor rescoping of the project. On Set:ember 30, Bradbury informed McDaniel of the AEC of tya: confidence that LASL could build the proposed facility fur $\$ 5 \$, 000,000$ (including escalarion and contingency).

This round number of 555 milion beame the official LASI. cost csimate. The reports from the cunsulting enginecring firm were slightly rescoped and reesrimated to bring the total of the cost esximates to this desired figure. The dena is were repored to the AF.C in a Schedule 44 dated Catober 30, 1964. This figure remained firm throughout the carly construction period, up to late 1969, when the FY 1970 budget was reduced by $\$ 10.3$ million below that scheduled and requested by IASL. As a consequence of this postponement of construction funds, costs were increased by $\$ 1,000,000$ and the total cost-to-complerion was revised to $\$ 56,000,000$. At this lime (1972!) construction is approaching completion ard the current estimate of total cost is $\$ 56,985,000$.

LAMPF management decided to act 25 its own gencral planner and to employ separate architect/enginecring firms to develop designs and cost estimates for competitive bidding. William M. Brobeck and Associates were commissioned to prepare the initial cost estimates for construction of the accelerator and its associnted equipment. The detailed design and rest estimating for buildings, site, and facilities was contracted (cost plus fixed $(e x)$ to Giffels and Rossetti. who also prepared specificaxions for biúding and supervised conseructicn performanec. MAP Division staff provided supervisory contral over the $A / E$ firms, by permission of the $A E C$ contracting officer, and also supervised some of the vendors of really critical cumponents. Hiwever, most of the supervisury duties for building construction were performed by the LASI. Engineering Department staff and other service gioaps assigned and attached temporarily to LAMEF. This procedure has been successful in maintaining high-quality performance on contrazs and has minimized costs that would otherwise acerue to a general architect/enginecr. 


\section{CHAPTER 5}

\section{ORGANIZATION AND ADMINISTRATION}

\section{A. Design Phase}

The administrative organization for LAMPF grew from the experience and practice at LASL Technically, LAMPF leaned heavily on the support and service structure of the Laboratory. During the early planning and design phase, all activities were part of the Physics Division, as described in Chap. 1. Beginning in 1962, L. Rosen acted as coordinator of planning for the meson facility. He was named Alternate Division Leader of P Division on September 1, 1962. Rosen was the shief spokesman for the local planning group, both within LASI. and in Washington, as the project moved into the proposal phase. He crganized and wrote much of the material in the proposals on the scientific justification for a meson facility, and continuously emphasized its scientific importance. ${ }^{63}$ One of Rosen's most valuable functions was to find and cultivate channels of political influence within the Atomic Energy Commission and the Joint Committee on Atomic Energy, and to use them to promote the meson project. An important eatly activity of the design group was a modeistudy program to test if suructures and power sysems, led jointly by Nagle, knapp, and Hagerman. Austin McGuire was responsible for supervising the activities of subcontractors such as ahe Willian B. Brebeck Associates in their engineering and cost amalyses. During this initial phase, the planning staff came chiefiy from P Division, which was then headed by J. M. B. Kellogg, and support came primarily from the P Divi sion budgex. The Preliminary Proposal ${ }^{2}$ for a Meson Faciliry. dated Decenbet 28, 1962, was propared by 19 members of the LASL staff and three consultants.

Technical studies and consolidation of phans continued for several years under the administracive umbrella of P Division and was supported by DMLA funds. Planning and design activities for the meson facility were handkst through a new group. P-11, organized in February 19:53. with Darragh Nagle as Group Leader. The prime purpose was to firm up tecinical decisions and prepare an authoritative proposal. The first formal action was the submission to the AEC of a Schedule 44, Construction Project Data Sheet, complete with manpower and cost estimates, in August 1963. These technical and engineering studies continued into the next year. The P-11 Progress Reports ${ }^{4}$ give details of the design progress.

In April 1954, the AEC Division of Research made available a fund of $\$ \$ 00,000$ to prepare a definitive design proposal, which allowed LASL to increase the design effort and to employ more professional assistance. This phase culminateo in the preparation of the definitive Proposal" for LAMPF and its submission to the AEC in Septembar 1964. The full-time staff applied to the óssign effort during 1964 averaged 15, but the total number of LASL staff involved was much greater. For example, the Proposal tists 68 LASL staff and 14 consultants as concributors.

The LASL Bulletin for October 3, 1964, announced that Rosen had heen appointed Acting Project Dinector for LAMIPF. With the availability of special funds to support the design, and an official responsibility, Fisen increased and expanded the design eifort. From thes time on the reduced his research activities in P Division and devoted increasing time to the administration, phnning, and promotion of LAMPF. A new 6000-sq-ft building (the so-called "Mockup" building) was added to P Division to house experimental waveguide tanks, if power systens, and corteji system protony pes. Later, a wing was added to provide a site for the Electron Prototype Accelerator (EPA) built to test the efficiency of the new side-coupled envity waveguide system. This additional space was complezed and occupied in early 1966.

Recognition of the maturing sratus of LANIPF within the Laborator $\mathrm{j}^{\prime}$ came with the formation of the new division for Mledium Enetgy Physics (MP Division) in July 
1965. Rosen was named Division l.eader, and Group P.1 1 was discontinued. (Note that the symools MP describe the general fieló of medium-energy physics, not meson physics as is frequently assumed.) Within the MP Lrivision the organiagrion of the !.A.MPl: staff wis similar to the practice in the Physics Division: areas of responsibility were assigned to several Ciroup Laders, each with Associatc or Alernate Ciroup lecaders. A listing of the major assignments and activitics during $19.55 \cdot 1966$ incluste

\section{ISF-DO}

Luuis Russ'n

lirederick R. Tesche

$M P-1$

Thomas M. Puenam

Haroid S. Butler

MP-2

Donaid C. Magerman

Thomis Boyd

Robert A. Jameson

$M P-3$

Edward A. Knapp

Hairston G. Worstel!

Donald A. Swenson

MP-4

Darragh E. Naglc:
MP Division leader (also) Acting Project Difector of LA.IIPl:)

Associate Division Leader Systems Planning. Linac Characteristics, Aceelerator Physics

Associate Division Leader Admin istrative Services

Group Leader, Controls and Instrunicutation

Aitcrnate Group L.cader Beam Transport

Group Lcad:r - RF Systems

Alternate Group Leader RF Systenus

Alternate Group Leader RF Phase and Amplitude Control

Group Leader - Accelerator Strucrutes

Assuciate: Group Leader Mechanical Enginecring

Associate Group Leader $200 \mathrm{MH}$ Accelerator

Group Leader - Injector System (also Associate Division Lea ter)

\section{Robert limigh Assistant Group Leader}

311?-5

Frederick R. Tesche Group Leader-Building. Budgets, PE,RT. Scheduling (also Associate Division Leader)

Paul D. lidwards

Site and Building Requirements

Also:

George A. Cowan Radiochemistry

John li. Brolley. Jr. Flectron Analog Experiment

In the summer of 1966, George Koistad of the Washington Office of the AFC Rescarch Division spent several weeks in Los Alamos and produced a document ${ }^{69}$ describing a possible organizational structure for the opcrating phase of L.AMPF with suitable functions and responsibilitics. Although this was not an official doc unsent, it did cail attention to many potential problems and policy questions beiore they became critical, and so served a most useful purpose. It recommended a structure of advisory and working commitees and indicated theit functions. It discussed the factors to be considered in the approval of propossls for experiments and in scheduling experimental ope:ations.

\section{H. Construction Phase}

The organization described above, a Division Office and five Groups, continued with little change following authorization of the first funds for construction in early 1966. Group Leaders and their professional staff eitlanged their actiaritics by specifying ecrnstruction items as required and spending construction funds. Nagle was named Alternate Division Leader and given authority to make technical decisions and sign major orders. Nagle and the other Group Leaders became an informal executive comnitrec to advise Rosen on decisions involving priorities and budget allocations. Two new groups were added as new needs developed: MP-6. Experimental Areas, was formed in 1968, first with Rosen and then with Cochran as Group Leider; and MP-7, Secondary Beam Lines and Spectrometers, was formed in 1970 with Lewis Agnew as Group Leader.

The availability of construction funds added a new kind of money to LAMPF. Each year funds were allocated from the Research and Development (R\&D) budget of the AEC. These funds were used to pay staff salaries and to support the design and development 
activities. When construction funds became available they were used for all outside contracts and matcrials and for all inside activiticts resulting in equipmient or products used in the meson facility, including the salaries and wages of those employees engaged in specifying and spending such funds. The construction budget was referred to locally as the A/E (architect/engineer) budget.

This existence of two kinds of money required that employees be paid from R\&D or A/E Funds repending on the kind of work they were assigned. New administrative procedures at LASL were needed to solve the problem. The $A / E$ suff were, in principle, expeck:d to be employed only for the duration of construction. However, certain exceptions to the temporary nature of employees paid from the $A / E$ account might be noted: MP-3 included a nuanber of permaient LASL employees transferted to LAMPF from other Divisions to utilize their technical and nechanical skills, and a group of $\mathbf{2 0}$ or more LASL staff from tne Engineering Department were attached to MP-5. who were used as engineers, designers, and inspectors. Furthermore, cmployment levels and skills in the $A / E$ staff were planned to enable MP Division to move from construction to installation to operation and maintenance with a minimum crange in numbers and maximum continuity of employment. It is expected that most $A / E$ stoff will be shifted to Operations or become technical assistants to zcsearch groups following completion of construction.

A listing of the staff members and other emplsyees involved in the construction of LAMPF is given in Appendix $A$ to retain a record for future reference. The list gives the staff as of June 1971, but also includes a few who terminated before that date. The names are listed under headings of the Division Offuce and the seven technical groups; employees paid from the construction budget are included in separatc listings. The job title lor job description) is given for each person, the professional training or background is indicated, and the date he entered either Group P-I 1 or MP Division. The administrative and supervisory staff, with their titles, are listed at the head of each group.

Two commitres have stecred the course of design and construction, and have coordinated the efforts of the several groups involved. The MP Technical Committee was started in July 1967 for the "discussion of outstanding technical problems and to srimulate ideas for their soluticn." Membership initially included Group Leaders and Alternate or Associate Croup Leaders, totaling 15 persons. During the following year, mectings were called at approximately two-sweek intervals. The agenda broadened to include not only the more important technical matters, but also budgetary planning, schedules, personnel requirements, and many minor administrative problems. As the staff grew, membership increased to 24 or more and the

meetings became more and more just information meetings to kecp the Division staff informed. B $y$ the end of 1969 the Technical Commitrec was no longer a useful working centity.

$\boldsymbol{A}$ true working committec with only three members was formud in Misy 1968 and was called the Design Review Committec. It had the authority "to delve into all aspects of accelerator construction and to make decisions on the scope, direction, and implementation of all MP Division activitics related thereto." The members of this Commitece werc Don liagerman, Paul Edwards, and Edward Knapp (rotating chairmanship). In August 1970 the group was expanded to include Rober Warner and renamed the Construction Steering Committee, with essentially the same terms of reference and authority.

This system of using a committec for making construction policy decisions has worked well. In spite of strikes, deferred construction funds, and difficulties in developing critcria, thic "bricks and mortar" pant of the project has gone well. Installation has rarely been delayed by building construction, and the amount of rebuilding after construction was completed has been very small.

\section{Operations Phase}

Plans for an orderly move from Construstion to Operations and Research Support were prepared well in advance of completing the Accelerator. A rearganization of the Group structure with some reassignments of responsibilities will be implemented as soon after January 1, 1972, 25 is feasibic without cusing unacceptable distuption to construction setivities. The revised organization is summarized here.

\section{MP.DO}

$\begin{array}{ll}\text { L. Rosen. Division } & \text { Medium Energy } \\ \text { Leader } & \text { Physies Division }\end{array}$

\section{Nagle, Alternate Division Leader}

\section{Hagerman, Associate Division Leader}

\section{E. Knapp, Associate Division Leader}

\section{r. Putnam, Assistant Division Leader}

P. D. Edwards, Assistant Division Leader
Operations and Chief of Operations

Prsctical ispplications

Safety

Facility Planning and Budget Control 
E. Dunn, Administrative Assistant

MP-1

R. Gore, Group Leadet Instrumentation and Computer Systems
H. Butler, Alternate Group Leader

D. Machen, Assistant Group Leader

R. Thomas, Assistant Group Leader

Electronic Instrumentation and computer-based data acquisition systcms. Support all grcups, including LAMPF Users.

MP-2
D. Hagerman, Acting
Group Leader
Accelerator
Operations

\section{R. Warner, Alternate Group \\ Leader}

Accelerator operations and lighe maintenance.

\section{MP-3}

$\begin{array}{ll}\text { E. Knapp. Group Leader } & \text { Practical } \\ \text { Applications }\end{array}$

Practical Applications of LAMPF and LAMPF technologies.

MP-4
D. Nagle, Group Leader
Nuclear and Particle
Physics

Basic research responsibility fur all juch research in MP Division and for coordinating the MP program with all othet users.

\section{MP-5}

To be disbanded. Scheduling, construction planning, and budget control activities to move into MP-DO.
MP-6
D. Cochran, Group
Experimental Arc.ss

Leader

R. Macek, Alternate Group

Leader

M. Wilson, Associate Group

Leader

P. Franke, Assistant Group

Leader

Maintain and manage experimental area, including remote handling, targets, beam dumps, effluent control, isotope production, and cryogenic operations.

MP-7

L. Agnew, Group Secondary Beam Lines Leader

H. A. Thiessen, Alternate Group

Leader

Maintain and improve secondary beam lines.

MP-8

T. Boyd, Group Leader Engineering Support

H. Worstell, Alternate Group

Leader

Electrical and mechanical engineering, including drafting, metronics laboratory, klystron repair, and improvemenis to accelerator.

MP-9

R. Jameson, Group Systems Development
Leader

D. Swenson, Associate Grrup

irader

C. R. Emigh, Associate Group

Leader

Development of advanced concepts for improvement of accelerator reliability and capability. 


\section{LAMPF Policy Board}

In early 1968, Bradbury established a Policy Bard composed of senior members of the national scientific community to advise him on the overall policy, progress, and effectiveness of the LAMPF program. In his letter of invitation he indicateo the national character of the facility and the magnitude of the administrative responsibility. Initially, the function of the Board was to review the technical design and the construction schedule and to consider matters of policy having to do with personncl, administration, fiscal arrangements, and plans for experimental facilities.

The following nine individuals accepted membership: Herbert L. Anderson, George A. Cowan, Herman Feshbach, Clark Goodman, Robert Hofstadter, Vernon Hughes, M. Stanlcy Livingston, E. Gerald Meyer, and R. Ronald Rau. Vernon Hughes was named Chairman at the first meeting; two years later he was succeeded by Herbert Anderson. Meetings were held at approximately sixmonth intervals until the construction phase was complete; dates were: October 12, 1968; January 17-18, 1969 ; June $12-13,1969$; January 23-24, 1970; June 5-6, 1970; January 22-23. 1971 ; and June 24-25, 1971.

At the first and most subsequent meetings, detailed presentations were made by Rosen and his staff on the status of accelerator construction and plans for research facilities. Tours of the site were arranged to dernonstrate progress. At almost every meeting, the threat of a cutback in construction funds was a major concern. A: several of the more critical times the Board wrote strongly worded letters to the Director (at his request), describing the damaging consequences of such reductions, to assist him in his effort to have the cut-backs restored.

The Board noted the LASL interest in conducting some classified research with the LAMPF beams, which might conceivably interfere with other research activities. They urged that the beam arrangements be revised to achieve physical separation of the beams to be used for weapon's research. This was accomplished successfully by the staff by redesigning the beams areas and diverting a beam into a security area called the "Weapons Neutron Facility." With this arrangement, short beam pulses can be diverted out of ihc crperimentai building through ain underground channel to a special guarded laboratory where weapons research can be conducted with a negligible effect on the beams in other channels used for research and without introducing any significant personnel security problems.

There was extensive discussion of the itaffing plans for MP Division on the assumption that LASL staff would not only maintain and operate LAMPF but would use about half of the machine beam time for research. The importance of developing a I.ASL staff having high quality and creativity was recognized, including the need for a group of first-rate theorists. Procedures for acbieving this happy goal were discussed at length with Bradbury and Rosen. In several instances, Board members used their personal influences to locate and persuade high-quality candidates.

The Board was inforned of the plans for producing a beam of negative pions to be used in a biomedical program aimed at developing techniques of pion radiation therapy for the clinical treatment of human cancerous tumors. Members were impressed and pleased with these plans and strongly supported Rosen and the other sponsors of the Biomedical program.

The Policy Board continuousiy emphasized the National Facility aspect of LAMPF and took a strong interest in the LAMPF Users Group and its zeeds. The Board studied the technical plans for the experimental areas and major experimental facilities and certain members joined personally with design task forces to plan experimental facilities. They recognized that the major problem was obtaining funds to support the needs of the Users, including staff, technical developments, and computer services, and urged the Users to develop more reliable estimates of these needs.

The Board early' rccognized that housing non-LASL users of LAMPF might constitute a severe problem, and urged Bradbury and later Agnew to take necessary steps to avoid a serious and embarrassing situation. The housing problem has in fact been the main task the Board asked the Director of LASL to resolve.

The Board took a strong stand for having a totally open laboratory at LAMPF, with no security restrictions; the Director of LASL was urged to strive for simplified security procedures and for prompt authorization of visitors. Of particular interest was the process of approval for visits to Los Alamos of non-U.S. citizen scientists; it seemed important to minimize the paperwork of applications and the time required for approval. With this urging, the Director took steps to investigate possibilities for reducing some of the more objectionable features of existing personnel security procedures. These steps have met with reasonatle success.

At the meeting on January 22-23, 1971, the Board bet with the new Direclur of CASL, Haruld Aignew, who welcomed four new members: Bruce Cork, Richard Garwin, Gerry Phillips, and Robert Stone, and took leave of four retiring members: Goodman, Hughes, Livingston, and Rau. Dr. Agnew gave the Board updated information on several of the policy problems considered earlier and requesied the $\mathrm{Bo}_{4}:$ 'd's assistance on otner LASL problems. The major problem for future years of operation still appeared to be chat of funding the research programs both at LASL and for the outside users. 


\section{CHAPTER 6}

\section{SCIENTIFIC USE AND RESEARCH FACILITIES}

\section{A. LAMPF Users Group}

The anticipated use of LAMPF as an open research laboratory in medium-energy physics required that new policies and procedures be developed to supply the needs of visiting scientists from the universities. LAMPF was expected to become both a national and regional facility to provide beams of particles and technical support for teams of user scientists and students from throughout the U.S. and abroad, and especially from institutions in the Rocky Molintain and Snuthwestern regions. The LASL scientific staff was expected to compete directly or in collaboration with the outside users. It was estinated that LASL scientists would use about $50 \%$ of the beam time.

Since 1950, LASL has provided opportunities to students and faculty from universities for thesis or postcloctoral research in various fields of science. Much of this research was unclassified but for convenience the outside personnel were usually processed for security clearance. LASL staff members frequently provided thesis advice and supervision. Arrangements were normally made directly with the individuals, with University agreement to accept a thesis with LASL supervision. In 1956, the University of New Mexico (at Albuquerque) established a graduate center at Los Alamos, with courses taught by UNM and LASL staff offered to boilt graduate and undergraduate students resident and working at LASL. All these arrangements have proved to be highly valuable, both to Los Alamos and to the University siaff and students.

However, the unique character of the meson facility and the magnitude of the government's investment required that broader and more formal arrangements be made for the unclassified research programs to be carried on by user scientists from the universities. This has been accomplished through the establishmer. of a "LAMPF Users
Group" with an urganization and an Executive Committee independent of LASL.

The initial move toward such an arrangement was a letter from Bradbury to the Presidents of 20 Southwestern and Rocky Mountain universities inviting them to send representatives (the Graduate Dean and Head of Physics Department were suggested) to a meeting at Los Alamos on December 17, 1963. The purpose was ro describe the proposed meson facility and to discuss its potential usefulness to the university scientific teaching and research programs. A,t the meeting, Rosen discussed the scientific motivation for LAMPF and Nagle described the accelerator design plans. ${ }^{7}$ Following this first meeting, Bradbury wrote letters to the participants summarizing the plans for LAMPF, the opportunities for the universitics, and reporting the formation of an ad boc committee of university representatives to work with LASL staff on plans for a more permanent organization.

An organization calling itself the Associated Rocky Mountain Universities (ARMU) was started in 1959. Its original purpose was to stimulate projects of a regional nature that required interuniversity cooperation for their achievement. Areas of interest ranged from humanistic and social to scientific and engineering. Later, in 1967, the ARMU charter was amended, the membership expanded, and the name changed to Associated Western Universities (AWU), with a more specific emphasis on cooperation with the $A E C$ and industrial laboratories throughout the western United States in the physica! sciences. The plans for LAMPF at Los Alamos were a prime stimulant to this refocusing of emphasis. This followed the pattern of university cooperation initiated following World War II by a group of east coast universities who formed Associated University, Inc. (AUI), to operate the Brookhaven National Laboratory.

A second conference on regional university cooperation for LAMPF was called jointly by LASL and 
ARMU for February 4-5, 1965. The status and progress of the LAMPF program was reported. Administrative representatives discussed procedures for implementing University-LASL cooperation. A small group of university scientists met with LASL staff members at this time to consider the equipment required and the problems involved in making effective research use of the facility.

Interest by the academic community increased sharply during 1966-1967. Many scientists visiting Los Alamos took an interest in the potential scientific uses of the mesor facility and joined in planning discussions with the LASL staff. A partial listing of these interested visitors would include Professors Gell-Mann of Cal Tech, Hughes of Yale, Phillips of Rice, Jakobson of Montana, and Telegdi and Anderson of Chicago. Medical scientists showed increasing incerest in the use of negative pion beams for cancer therapy, including Dr. Chaim Richman from Berkeley and Dr. Robert Stone of the Universiry of New Mexico.

The concept of a LAMPF Users Group crystallized out of the two conferences of regional university representatives described above, and the activities of Rosen and his staff in publicizing the scientific potential of LAMPF in visits to universities and in talks at scientific meetings. The group of potential users tvidened to include scientists from large universities of the east and west coasts and from other national laboratories, including many prominent scientists with experience in users groups at other large facilities. An ad boc committee chaired by Harry Palevsky of Brookhaven met at Los Alamos on January 17,1968 , and called for a meeting of potential users of LAMPF to be held on June 20,1968, following the American Physical Society Meeting at Los Alamos. At this first meeting, the general purposes and functions of the Users Group were discussed and committees were named to prepare a charter, nominate officers, and make plans for a second and more official meeting. A list of universities and laboratories whose representatives participated in this first LAMPF Users Group meeting is given is sppendix $B$.

At the second LAMPF Users Group Meeting on January 16, 1969, a Charter was adopted (Appendix C). It sets forth the regulations and bylaws for the Group and gives the procedures for electing officers and an Executive Committee. The initial slate of officers and Executive Committee elected were

$\begin{array}{ll}\text { Chairman: } & \begin{array}{l}\text { Harry Palevsky, Brookhaven } \\ \text { National Laboratory }\end{array} \\ \text { Chiairman-elect : } & \begin{array}{l}\text { David Lind, Univcrsity of } \\ \text { Colorado }\end{array}\end{array}$

Executive Committee: Roy Haddock, University of California, Los Angeles

Arthur Poskanzer, Lawrence Radiation Laboratory

Harvey Willard, Case Western Reserve University

Liaison Officer:

\section{Lewis Agnew, LASL (appointed} by Director, LAMPF)

The first task of the Executive Committee was to appoint a Technical Advisory Panel (TAP) to work closely with LASL scientists on plans for various features of the experimental program. The TAP was continued in succeeding years and became the major implement to transmit user's needs to the attention of the LAMPF staff. An important activity of the Liaison Otficer was to initiate a series of Newsletters reporting to the membership. The first Newsletter was published on March 21, 1969; others followed, repoiting actions of Users Group Mectings, meetings of Working Groups, and orher business. For example, during 1969-1970, working sessions of small groups of users were held on specific programs such as

a. pion beams (August 5-6),

b. stopped muon channel (August 4),

c. nucleon physics (August 4-8 and October 29),

d. high-resolution spectrometer (August 6-7 and Decernber 9),

e, medium-energy physics

f. biomedical applications (July 16, September 10, and October 28),

g. energetic pion channel and spectrometer (EPICS) (August 8 and January 19),

h. nuclear chemistry (January 14-15), and

i. isotope separator facility (January 14-15).

These activities continued and intensified during the next two years.

Annual Users Group Meetings were held on October 29, 1969, in Boulder, and on October 30-31, 1970, and November 8-9, 1971, at Los Alamos. New officers were elected each year and new members of the Technical Advisory Panel were appointed. The Users Working Groups continued their activities in consulting on plans for the major experimental facilities. As funds became available, the LASL staff started construction of the most critlial of these facilities. A preliminary version of a 
LAMPF Users Handbook ${ }^{70}$ was mailed to the Users in January 1971. The first call for rescarch proposals was issued by Rosen on October 30, 1970, at the Annual Ust:rs Meeting, and the first meeting of the Director's Program Advisory Committec was called for April 3-4, 1971. Users were informed that the scheduling of beam time for approved experiments would be announced at least six months before the anticipated date of initial operations.

The number of scientists in the Users Group toraled 830 in February 1972. A summary of the statistics of the Users Group as of that date is given in Table VI. In retrospect, the Users Group has provided an essential breadth and depth to the planning for experimental facilities and the research program in the years prior to operation. Experimental requirements developed in the working sessions supplied technical specifications for beam channels and for the initial array of beamhandling equipment. Much of the information developed by the working groups was used by the LASL staff responsible for equipment Jesign and construction. The Users organization has had, from the very beginning, a very strong influence on formulatiug policy governing experimental capabilities, as well as in the detailed design of equipment. A most important aspect affecting the morale of the users, as well as providing che best possible research facilities, has been the complete independence of the Users Group from the established LASL adninistration. This independence has brought general approval and support from the university scientists for the program at LAMPF and has enhanced the reputation of LASI.

\section{B. Research Facilities}

Planning for secondary beam lines and the associated research facilities started early and modifications have continued during accelerator construction. Most of the interests of the U.ers Group prior to operation lay in planning for research facilities. The first significant working meeting of the Usters Group was held in January 1969. when a charter was adopted and officers and an Executive Committee were elected. Bur a more important accomplishment was the decision to divide up the facilicies field between a number of small Working Groups, each involved in a specific program and to initiate cietailed studies. $A$ list of nine progranis on which Working Groups concentrated during 1969-1970 is given in the preceding secrion. Two orhers, Computing Facilities and Neutrino Research, have since been formed. This method of orgonizing users activities has been highly successful, making it possible for potential users from individual universities to work closely with other experts in their field. Many new ideas and important improvements have come from these working sessions. LAMPF has benefited through the detailed study of specifications and criteria used in the design of the :es:arcis fxcilities.

The L. APF staff nember most broadly involved in the Research Facilities field is Lewis Agnew. He caine to LASL in November 1968 from graduate training at Berkeley and an assignment as Head of the Physics Section of the International Atomic Energy Agency in Vienna, and joined Group MP-6, Experimental Areas. Rosen was acting as tempurary Group Leader at that time. Coch:an was Alternate Group Leader and later became Group Leader of MP-6.

Of: of Agnew's first asriguments was to ozganize the first Users Group Meering described above. He helped to impl:ment the working group sexsions that proved to be such a useful result of the Meeting. Rosen soon appointed Agnew to be LAMPF Liaison Officer to the Users Ciroup. In this capacity, he has published a series of Newsletrers reporting activities and progress to the users, and has carried out must of the routine business for the Users Group.

TABLE VI

STATISTICS OF USERS GROUP, FEBRUAKY 1972

\begin{tabular}{lr}
\multicolumn{2}{c}{ Kegional Breakdown } \\
\hline \\
East & 189 \\
Midwest & 94 \\
South & 29 \\
Southwest-Mountain & 177 \\
Far West & 117 \\
Foreign & 60 \\
LASL & 164 \\
& \\
User Memborship & $\mathbf{8 3 0}$
\end{tabular}

\begin{tabular}{lr}
\multicolumn{2}{c}{ Number of Institutions } \\
\hline Government & 30 \\
Universities & 113 \\
Hospitals and Medical Centers & 33 \\
Industry & 19 \\
Foreign & 33 \\
& \\
Total number of Instrtitutions & $\mathbf{2 2 8}$
\end{tabular}


Agnew was also assigned the specifie job of dereloping criteria for Beam Area B, the are tentatively assigned to be the nucleon physics taboratory. Ite was assisted by J. Simmors of $P$ Division, who has had a continuing interest in the nucleon-nucleon problem. especially that dealing with neutron besms. Out of this study came a report" that led to the final form of the Area B experimenial arrangerinent.

Another long-range research interest at LASL is the development of a beam to produce a pulsed source of neutrons for studies involving weapon's applicazions. Although LAMPF is open for unclussified research, this beam for possible military applicitions would be divered through a narrow underground chanael inzo a guarded laboratory. Those involved in the early planning wer: 1 . Agnew, J. R. Bcyster, A. Hemmindinger, and $R$. Fullwood. Present design studies are continuing. The first concept for a weapon's research besm was a fast-chopped stort pulse of protons at the start or end of the normal long linace pulse. It was modified to utilize the $\mathrm{H}$ beam when this alternate beam became possible. Nagle suapested that further plans include a small storage ring in which the $\mathrm{F}$ beam can be stored and ejected in a single turn to give an extremely short, high-intensity puise of neutrons. A channel stub-out for diverting the beam out of the main switchyard has been built, but constuction of a storage ring or a weapon's rescarch laboratory mast await future sllocations of tunds.

A new Group, MP-7. Secondary Spectrometers, was organized in June, 1970, witì $L$. Agnew as Group Leader. Agnew continued as Lizison Officer to the Users Groep and as the mijor contact for scientists from outside LASL. The new proup is responsible for the design and construction of tht beam handling equipment for secondary beam lines. When MP-7 was established, the planning and design work tor the beam channels was orgasized by appointing onc scientist and one coordinating enginter from LASL to be responsible for each beam. An important part of their assignment is to work directly witi: each of the Users Working Groups. Several incer-Group task forces have also been formed within MP Division to coordinate the design and development of major devices or services such as magnets, powe: supplies, vacuum systems, suppert and aligoment devices, and water cooling systeins.

l. the Fall of 1970,2 decision was inade (1) proceed with the design and construction of three beam systems in Areas A, B, and $C$, and for a number of specialized beam channels. $A$ list of the channe!s and tacilities is given in the Users Handbook ${ }^{\text {T0 }}$ published in January 1971. A brief summary follows.

1. Meson Plbysics (Area A). The main beam is sent successively through several targets in generate secondary pion (and nuon) beams. The objective is to provide for both ligh-precision experiments and a wide variety of meson research studies. Four chanuels are

1. Low-linergy Pion Channcl: Positive and negative pions from 20 to $300 \mathrm{MeV}$ with $\pi^{*}$ flux at $100 \mathrm{MeV}$ of $1.9 \times 10^{7}$ at a resolution $\Delta p / p$ of $\pm 0.05 \%$ or $1.5 \times 10^{\circ}$ at $\Delta p / p$ of $\pm 2 \%$.

b. Energesic Pion Channe: and Spectruincters (EPICS): Inciudes magnetic channel, spectronkecers, scattering chamber, and detection system; characterized by good energy resolution ( $50 \mathrm{keV}$ ) and good angular resolution (< 10 mrad). The channel will deliver $\pi^{ \pm}$up to $300 \mathrm{MeV}$ with a $\pi^{*}$ flux of $3 \times 10^{*} / \mathrm{sec}$ at $200 \mathrm{MeV}$ : the spectrometer has inaximum mor nentum of $680 \mathrm{MeV} / \mathrm{c}$.

c. Pion and Purticle Physics Channel $\left(\mathbf{P}^{\mathbf{3}}\right)$ : Provides a versatile $\pi^{ \pm}$beam of high energy ( 100 to $\left.600 \mathrm{MeV}\right)$ and high intensity $\left(>10^{10} / \mathrm{sec}\right)$. intended for elementary parsicle and nuclear reaction experinents.

d. Stopped Muon Channel: Provides $\pm \mu$ beams from 0 to $250 \mathrm{McV} / \mathrm{c}$ with intensities $\simeq 10^{7} / \mathrm{sec}-\mathrm{MeV} / \mathrm{c}$ for a variety of muon experiments including polarization studics.

2. Nucleon Pbysics Laboratory Ared B' The objective is to provide beams of protons, and neutrons from a liquid $D_{2}$ target, of low irtensity and good energy resolution ( $\pm 5 \mathrm{MeV}$ ) froin $300-$ to $800-\mathrm{MeV}$ energy, for nucleon-nucleon research. Plans also incluáe a polarized proton beam.

\section{IIigb-Resolintion Proton Spectrameter (IIRS)} (Area C). A high-momentum resolution $( \pm 0.01 \%)$ spectrometer at \pm 0.8 -mrad resolution in seatterite angle. Intended for studies of low-lying excitation states of nuclei. This important facility is so costly that the Users Working Group made a separate request ${ }^{69}$ for support from the AEC Rsearch Division. A fund of $\$ 2.5$ million was granted to be applied to construction of the HRS staring in Frisis?.

The Users Ilandboek gives detailed chatacteristics of each of the beam lines outlined above and the names of the appropriate LASL staff members to be contacted. It also gives instructions on how to prepare and submit proposals for rexearch experiments. A simplified sketch of the Experinental Areas is shown in Fig. 1. 


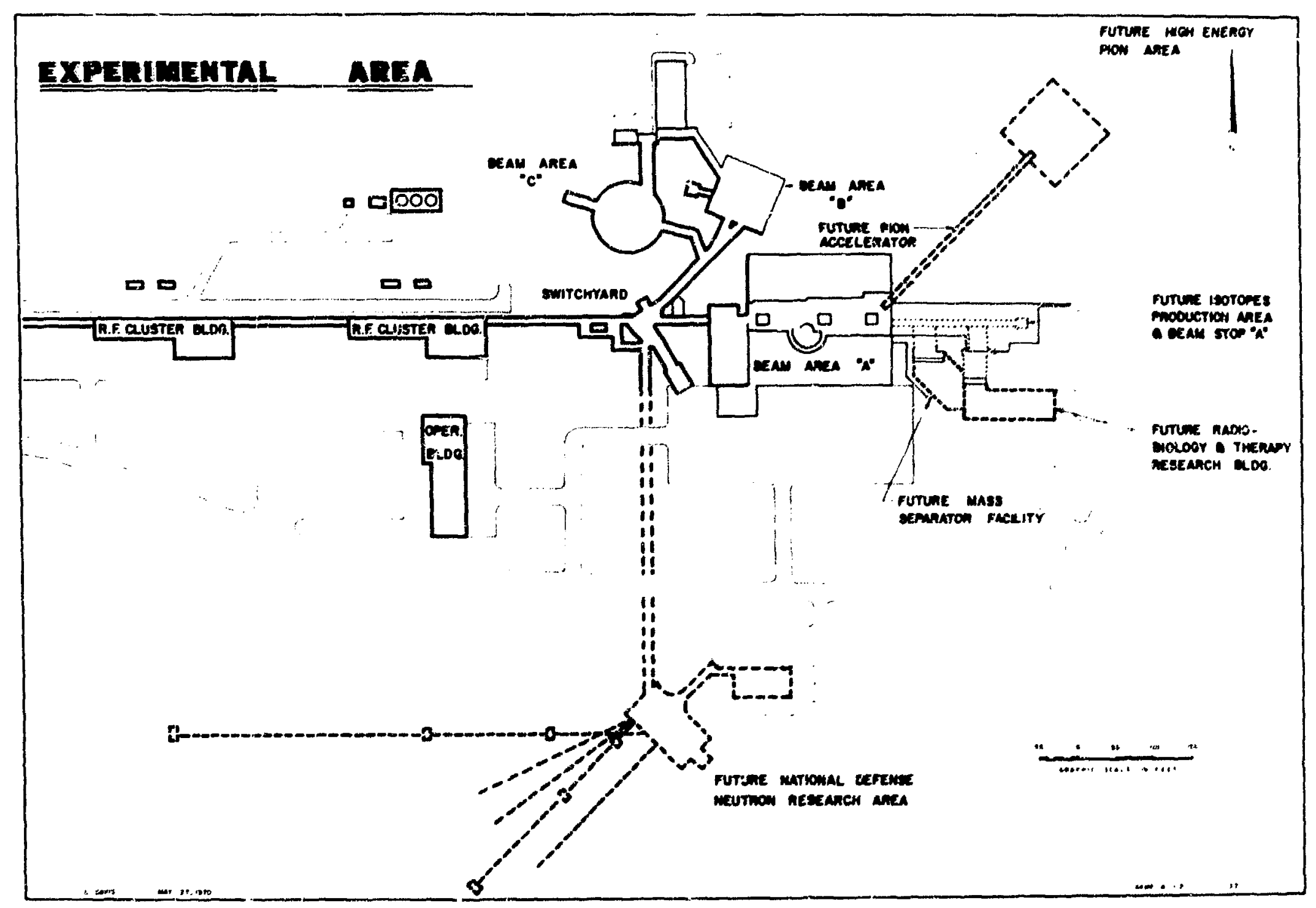




\section{c. Rexearch Progkzam}

The orighinal mosivation and prinary justification

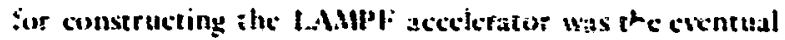
aciclopment of a brodal-ranging program of research in nucicur physics using the sciondary particle beams. The Hethe Puncl, so instruniental in persuading the Al:C: support IAN11!: cxpressed a strong conviction of the importance at the study of luclear stricsure using sulauckar particles such as mesons a projectiles. In 1904. the thethe Pancl listed the specific problems af interest to bc

1. Nuxclear fures
d. !ion-nucleon ctastic seattering
b. Pan-pion stattcring
c. Nuckeon-nucleon forces
d. Mlosun production

2. Nesclär structure, using strongly interacting parricles in lligin
c. H.iastic statrering by the nucleus
f. Various form tactors
s. Quasi-free scatucring
h. Ejection of clusters irom nucle us
i. Pickup reactors
3. Pion charge exehange
i. Mluon seartering

3. Rescarch with stopped pions:
l. Pion capture
m. Pi-nuesic atoms
n. Mu-music atums
o. Mtwor capiure

4. Woak interactions

$$
\begin{aligned}
& \text { p. Stopped pions } \\
& \text { y. Stopped muons } \\
& \text { r. Neutrinos }
\end{aligned}
$$

\section{Neurron sibure:}

\section{Possible czzčnsion to serange particles.}

The Bethe Pancl also identified the nost important experiments in the falds listed above and statce that intensities with factor: of 100 to 10,000 over those availabie from synchrocyclessons would be aceded. The very high intensity projected for a proton linac was one of the most important parameters that favored the linac over other meson producing accelerators.

With the authorization of iunds to build LAMPl: and with the growth of a Users Ciroup as described in an earlier section, the plans for a research program becane; more cxecnsive. Each sucetsive tisers lireap .tecting and IIP Divsion Progress Report cxpanded the sope and incteased the detail af the anticipatcel rescarch prongroni. In the definitive Propessel of Scptemler $196+$ to the AEC: Chap. IV on the "Scicntific Notistion" filled $26+$ pages - mure than half of the voluns. Many hours of discussion by Would-loc experimenters have explored the possilsilities, and reums of paper have been covered with ealeulations firg projected experinients. Olat of these studics have conk many changes in the original plans for cxpritikntal arcas and research facilitics. The number and varicty of boan lincs and of facilities for bean handling and andysis hate multiplicd. Cost estimates soñ totalied more than am conceivable budgex. It became necessary to ceurdinate the facilities planning prosram. How this was accomplished is testribed in preceling chapecrs. The initial resiarch proferam can best be appre. ciatcd by a study of the initial bayent of beam channels and rescareh facilitics as described in the precoding secrion un research facilitics.

\section{Prograu dulvistmy Commitete}

Furly in 1971, Kosen appisiotice a pancl af working stientists ro serte as a Program Acivisory Commitece (PAC). This griup studies the research proposals sub-

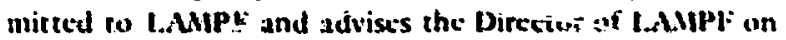
the priorities to bi assigned lased on

1. Scientific merit.

2. Tecinnicai forsibility, and

3. LAMPf: resources and running tink required.

The initial nentotrship of the l'sc: consisted of the following.
M. Buon. M.D.
K. II. Cronte
C. Hicilander
N. Hlinte.
V. Hughes
A. Kotman
D. lind

A. M. Poskinacr

H. Rait

I. 1.. Kathberg

J. Schifter

R. Taschek

ĩ. A. Tombretio

D. I:. Nizgle

The first meeting of the Program Advisory Commiztec was held on April $j+$, i₹rl, and a sceund metiny on July $5-6,1971$. The initial deadline for submission of propesals was April 1, but others were sent later. By July 5, nearly 80 proposils had been received and consiclered by the PAC. $A$ the second necting it becanke clear that the "case load" for the full Committec could be reduced by preliminary study of errain special ficlds in subcommiteces. Accordingly, two subeonmitrecs vere 
established: (1) Nuclear Chemistry-Gerhardt FriedInder, Chaimsan, and (2) Biomedical Applieations - Mtax Boone, Chairmun.

The PAC is aided in its stedies by preliminazy analysis and evaluation of propesols pertaining to the separate beam channels ot facilities by the several Users Working Groups responsible for organizing the programs for such channels or facilities. These singlefacility Working Groups alee serve a useful function in atranging for cellabomion between research groups whose jiopussits overlap. However, the relative balance and priority between all of the beam channel users is the respousibility of the PAC. PAC's recommendurions of itie prigram prioritics to the Directer of LAMPF have grear weight and go far toward establishing the working scheduks.

A third meeting of the PAC was heid on Oetobs: 21-23, by which time the number of proposals receivec had increased to over 100. Following their report to the Director, keters indisating aceeptance of proposals were sent out to about 60 scientific groups, indicating their place in the schedule for the particular beam channel following start of full-seale operations.

\section{E. Radivisutope Production}

A potentially valuable applization of LAWIPF is the utilization of the residual beam for the protuction of mdioisotopes. This opportunity was explored in a series of papers by isL statf presented to the AEC Division of Isotope Developinent on December 15, 1970, and published ther as a LASL Repert." The intent of elese studies was to extimate the eapabilities of the beam. calculate the yiclds of radionuctides, and justify support for constructing an isotope production facility at LAMPF. The funds requested svere needed to provide the target housing and rarger handling favilities at bAllpF. Chemical processing facilities for the radioisoropes that witl be produced aiready exist and are avaitable at LASL

The medical and scientific needs and uses of radioisotopes are well known. In the past they have justified s large AEC investment in equipment for the production of mdioisotopes from reactors and in chemical procescing plants. For example, turing 1966, AEC facilities produeed more than five million administraxions of radioisotopes for medieal parposes, involving more than thre miltion patients. It is safe to assume that this necd will not onty conainue sut will increase significantly. The protontich isotopes irom LAMPF should be especially valuable for medical dingnosis and localization.

When LAMPF reachs fult design eapability it will produce mote beam pawer than any oxher high-energy accelerator in the world, with an enery of $800 \mathrm{MeV}$ and 2 time average beam current of $1 \mathrm{~mA}$. The primary purpese is the production of axomentumaralyzed beams af protons and secondan radiations such as pions for nuckes structure resesteh. Following the beam sflitters and iagex that supply these beams for ssearch, the residual proton beam will still have an energit of $700 \pm 20 \mathrm{MteV}$ and an intensity of $400 \pm 100 \mathrm{pt}$. $\alpha$ a beam power approuching $300 \mathrm{~kW}$. If used for the preduction of radioisotopes, this 3 eam ean sield preater intensities than all other accelerators par rogether. It will result in radioisotopes lying forther from the srabilixy line than from laver-nergy jecekrators and of the protontich type that cannot be produced in resctors.

The principle rechanism for the proutuction of isotopes off the stability line is bigtrenerg: proxar induced spalthtion in which many nuckoss are knocked out of the necleus. The products will have a beond distibution in mass below the target mass, which simpinfics the problem of eargering, and will give useful intersities in the fission and low mas regions One papr in the study at LASL ${ }^{7}$ predicts the gields and describes the medical applications of a fong list of radionsclides. Anoxher paper ciescribes the ratyeting sysxem to be used at bahps including tagee cowling, a remokch controlled enyzer removal system, and the mechanisms for landives and rensporeing the eargets to the LASL. radiocheraisuy bboratory: Calculations of the thick arget penctrion for $700-$ llet protons sugest the adivisorope yields to be expected and atso predict the heat-dissiparion reguirsmonts in the targets

In 1971. LAMPF used $\$ 50,000$ of consacuction funds ta build a stub-out for a beam to be diverted obx of the moin beam at the beation of the isatope facilyy. And in FY 19:2, the AEC authonized LASL to dirx $\$ 100,000$ of Cencral Ptant Projecs funds to the contruction of basic varet facibices for the isocepe fecility at LAMIPF to enable a minimal program of isorope production to be stanted.

\section{F. Lionedical Fectin}

Fropl the caritest LAMPF planning dys, the use of

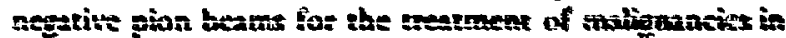

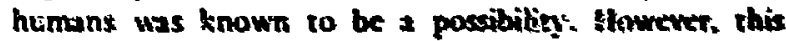
woukd require the develogenene of a bionctical ficibity at LAAPR, which was mot included in the original scope. and the couperation of competen biokyjul and mocdical staff to make the facility useful.

Nuclear physiciss bare known for years of the special property of nagative pions, on skowing down in mater, "keing atteacted to and absorbed by sromic nucki with the release of the surglus mass encts of the pion as a "star" of nuclear itryments. The ionizing purtictes in such stars (primarily peotons and alpha parictes) peoduct 
a concentration of ionization at the end of the range of pion beam that is considerably greater than the Bragg peak of ionization at the end of range of protons or light charged particles. Such a concentration of ionization was known to some physicists, as well as to some medical therapists, to be potentially useful in the treatment of deep-seated tumors. ${ }^{73}$ However, the use of pions for this purpose will become possible only when pion bearns of sufficient intensity become available.

In early 1962, Rosen calculated the yield of pions expected from a meson factory of the energy and intensity planned for LAMPF and convinced himseif that radiation doses of 50 to $100 \mathrm{rad} / \mathrm{min}$ over approximately $1000 \mathrm{~cm}^{3}$ would be achievable. This intensity is therapeutically valuable, and it gave him confidence to proceed with plans to exploit this property of the pion beams. However, the biomedical utilization of IAMPF was never claimed to be a major reason for building the facility.

Rosen took on himself the task, which extended over several years, of convincing the medical community that pions might provide a worthwhile method of cancer treatment. One of the first important steps was a publication of a paper ${ }^{74}$ by Rosen in December 1968 presenting his calculations of radiation dosage and discussing the favorable oxygen enhancement ratio for anoxic tumors. Some of his early supporters in the medical profession were Dr. Max Boone of the University of Wisconsin, Dr. Chaim Richman of the University of Texas, Dr. Robert Stone of the University of New Mexico, and Dr. Henry S. Kaplan of Stanford.

The AEC was informed at an early stage of the developing plans for a biomedical facility, and Rosen described the opportunities for such practical utilization of LAMPF to the Joint Committee on Atomic Energy at Hearings in Washington in February 1967 and again in April 1969 and March 1970. Discussions were held with Commissioners Seaborg, Thompson, and Johnson and also with Dr. John R. Totter, Director of the Division of Biology and Medicine. Early planning for the desired facility was supported under a Schedule 189 activity entitled "Applied Science - Development of Practical Applications of LAMPF" which was funued by the Division of Research. This study resulted in a preliminary proposal for the construction and operition of a biomedical facility. The proposal and an accompanying Schedule 44 were forwarded to the AEC in April 1969.

In early 1970, Dr. Totter wrote to Rosen and suggested that a group be set up in LASL's MP Division to continue planning activities for the biomedical facility. He strongly implied that eventual support for construction of the facility might be expected from the Division of Biclogy and Medicine. In response to Dr. Totter's letter, another Schedule 189 was prepared at LASL entitled "Biomedical Uses of Pions and Muons," dated August 3,
1970 , requesting supporting funds sufficient to pursue the planning and design of a suitable facility and to develop a biomedical program within MP Division.

In the Spring of 1970, Rosen testified before the JCAE on the status of LAMPF and dwelled on the biomedical capabilities. As a result of this testimony, the JCAE authorized the AEC to proceed with a "stub-out" for the biomedical facility within the base funding. Early construction of this stub-out and the basic target system in the maln beam was desirab!e to avoid a shut-down of operations at a later date. This start made it possible to construct the rest of the facility as funds became available without interference with the on-going operation of the acceleraror.

A formal proposal ${ }^{75}$ was prepared by Wright $H$. Langham, Associate $H$ Division Leader, for the Biomedical Research Group describing the broad cooperative interest in a facility at LAMPF capable of providing a pion beam and accommodations for its clinical utilization. A program of biological research and clinical trials was described. A cost estimate of the complete facility (in addition to the $\$ 300,000$ applied to the beam channei) came to $\$ 2,300,000$. Copies of the document were transmitted to the Division of Biology and Medicine of the AEC.

The policy developed during early discussions with AEC representatives was that LAMPF would provide the site and the pion beam, but that the responsibility for clinical meson therapy would be assigned to an organization experienced in medical techniques ard tradition and capable of handling large numbers of patients. Because the University of New Mexico Medical School was nearby, was interested and had a fine staff, it was the first choice to become this responsible organization. The LASL $\mathrm{H}$ Division formed a group under Dr. Chaim Richman, in 1971, to utilize the LAMPF biomedical facility. Dr. Morton Kligerman of the University of New Mexico Medical School was appointed Assistant Director of LASL for Radiation Therapy in October 1971; he is also Director of the Cancer Research Center at the Medical School.

The overall responsibility for support of the facility would appear to be within the province of the National Cancer Institute. The NCI has initiated support by a grant to the UNM Medical Schooi to develop plans for preclinical trials and an eventual patient management program. Also, the State of New Mexico has voted substantial funds to support some initial activities of the UNM Medical School in planning for their utilization of LAMPF.

As a result of the interest generated within the medical profession, a Biomedical Users Group evolved in 1969-1970 and was organized within the broader framework of the LAMPF Users Group. A "Biomedical 
Charter" was adopted at the Fourth LAMPF Users Group Meeting on October 30-31, 1970. A Users Steering Committee for biomedical applications and six standing subcommittees were established to carry on the planning. The initial Biomedical Applications Steering Committee (1970) consisted of

Chairman: Chaim Richman (then University of Texas)

Alternate Chairman: W. H. Langham (H-4, LASL)

Assistant to Chairman: David E. Groce (JRB Associates, La Jolla)

Subcommittees:

Cellular Radiation Biology:

Chairman: Paul Todd (Pennsylvania State University)

Alternate Chairman: Donald F. Peterson (LASL)

Therapy:

Chairman: Max Boone (University of Wisconsin)

Facility and Beam Line:

Co-Chairman: Paul Franke (MP-6, LASL)

Co-Chairman: Richard Hutson (MP-7, LASL)

Whole Animal Radiation Biology and Pathology:

Chairman: Charles Key (University of New Mexico Medical School)

Alternate Chairman: J. F. Spalding (H-4, LASL)
Physical and Biological Dosimetry:

Chairman: M. R. Raju (LRL, Berkeley)

Alternate Chairman: Phillip N. Dean, (H-4, LASL)

Isotopes and Diagnostic Applications:

Chairman: Jon Shoop (University of New Mexico Medical School)

Alternate Chairman: Harold O'Brien, (MP-7, LASL)

A full meeting of the Biomedical Applications Steering Committee was held November 11-12, 1970, at the University of Texas, Dallas, and a following meeting vias held at the University of New Mexico on January 22-23, 1971. Subcommittee meetings were scheduled and planning activities started for each of the working groups. At the time of writing (1971), the major problem appears to be that of obtaining funds to start construction of the housing for the basic Biomedical Facility at the LAMPF site.

Just before his departure from the Atomic Energy Commission, when it became clear that the AEC was not going to be able to include funds for the desired biomedical facility in the FY 1972 budget request, Chairman Seaborg arranged for a meeting involving Rosen, AEC staff, and National Cancer Institute staff on the question of AEC/NCI joint support for the biomedical facility. From this meeting emerged a tentative agreement whereby NCI will provide $\$ 1,000,000$ for construction of the pion channel portion of the LAMPF Biomedical Facility and associated controls. AEC is seeking funds for the remainder of the facility in its FY 1973 budget request. 
APPENDIX A

\section{LAMFF CONSTRUCTION STAFF, JULY 1971}

\section{Name}

MP Division Office

Staff Members:

$$
\text { Job Description }
$$

Degree

Start

Date

$\begin{array}{lll}\text { Division Leader } & \text { Ph.D. Phys } & 9 / 62 \\ \text { Alt Div Ldr } & \text { Ph.D. Phys } & 2 / 63 \\ \text { Magnet Task } & \text { B.S. ME } & 7 / 70 \\ \text { Force Ldr } & & \\ \text { Assoc Div Ldr } & \text { Ph.D. Phys } & 6 / 65- \\ & & 6 / 68\end{array}$

Admin Asst \&

$7 / 65$

Div Sec

Ed Asst

Alt Div Ldr Sec

Sec

Receptionist

Sec

$\begin{array}{ll}\text { B.A. } & 2 / 66 \\ & 1 / 66 \\ \text { B.A. } & 1 / 66 \\ & 6 / 70 \\ \text { B.S. } & 1 / 70\end{array}$

MP-1 - Controls and Instrumentation - R\&D Staff

Putnam, Thomas $M$.

Butler, Harold S.

Gore, Raymond A.

Machen, Donald R.

Thomas, Richard F.

Staff Members:

$\begin{array}{ll}\text { Bergstein, Joe } & \text { Elec Engr } \\ \text { Biswell, Lavon B. } & \text { Elec Engr } \\ \text { Criscuolo, Alph. L. } & \text { Elec Engr } \\ \text { Elkins, Edgar P. } & \text { Elec Engr } \\ \text { Hill, Robert E. } & \text { Elec Engr } \\ \text { Little, James D. } & \text { Physicist } \\ \text { Lundy, Arvid S. } & \text { Elec Engr } \\ \text { Parker, Joseph R. } & \text { Safety Sy'st } \\ \text { Schultheis, Tom } & \text { Elec Engr } \\ & \\ \text { Simmonds, Dennis D. } & \text { Physicist } \\ \text { Rogers, W. Vern } & \text { Elec Engr }\end{array}$

Group Leader \&

Ph.D. Phys

$2 / 64$

Div Safety Ofc

Alt Grp Ldr

Ph.D. Phys

$9 / 63$

Assoc Grp Ldr

Ph.D. EE

$5 / 67$

Asst Grp Ldr

M.S. EE

$10 / 67$

Asst Grp Ldr

M.S. Phys

$10 / 70$

M.S. EE

$7 / 70$

B.S. EE

$6 / 69$

M.S. EE

$1 / 69$

B.S. EE

$2 / 70$

B.S. EE

$4 / 70$

B.S. Phys

$6 / 67$

B.S. EE

$7 / 67$

M.S. Engr

$9 / 63$

B.S. EE

7/65-

$3 / 67$

$1 / 71$

B.A. Phys

$7 / 69$ 
Admin, Sec, \& Clerical:

Gutierrez, Cleo

Harris, Robert E.

Holterman, Danie!

Ungnade, Pauline

Wallis, Phyllis A.

Skilled Craft Personnel:

Conley, Andrew P.

Easley, James D.

Ekeroth, Gustaf A.

Garcia, David L.

Lederer, Harold $M$.

Potter, Jerry $M$.

Smith, Wayne L.

\section{MP-1 - Construction Staff}

Staff Members:

Hartway, Bobby L.

Plopper, Clifford M.

Sharp, John B.

Shlaer, Sally D.

Admin, Sec, \& Clerical:

Chavez, R. M.

France, Stephen W.

Labadour, Benedict

Martinez, Elvira

Vigil, Herman J.

Skilled Crafts Personnel:
Steno

Draftsman

Storesmian

Grp Sec

Data Analyst

Sr Tech

Elec Tech

Elec Tech

Elec Tech

Elec Tech

Elec Tech

Elec Tech
$10 / 70$

$2 / 66$

$5 / 70$

$3 / 66$

$10 / 67$
$3 / 66$

$3 / 70$

Jr. College $\quad 3 / 67$

$3 / 67$

$5 / 68$

Tech Inst

Tech Inst
Elec Engr

Programmer

Elec Engr

Elec Engr

Draftsman

Draftsman

Draftsman

Clerk III

Draftsman
B.S. EE

B.S. Math

M.S. EE

B.S. Mith
Elec Tech

Tech Inst

$1 / 70$

Elec Tech

Elec Tech

Elec Tech

Elec Tech

Elec Tech

Elec Tech

Elec Tech

Elec Tech

Elec Tech

Elec Tech

Safety Tech

Elec Tech

Safety Tech

Elec Tech

Tech Inst

Tech Inst

Tech Inst

MP-2 - Radiofrequency Systems - R\&D Staff

Hagerman, Donald
Boyd, Thomas J.
Jameson, Robert A.

Group Leader \&

Ph.D. Phys 
Staff Members:

$\begin{array}{ll}\text { Cady Robert L. } & \text { RF Engr } \\ \text { DeHaven, Russel A. } & \text { RF Engr } \\ \text { Doss, James D. } & \text { RF Engr } \\ \text { Faulkner, J. Ross } & \text { RF Engr } \\ & \\ \text { Hoffert, William J. } & \text { RF Engr } \\ \text { Kandarian, Robert } & \text { Mech Engr } \\ \text { Liska, Donald J. } & \text { Mech Engr } \\ \text { Newell, Robert H. } & \text { RF Ergr } \\ \text { Tallerico, Paul J. } & \text { RF Engr } \\ \text { Turner, Thomas } & \text { RF Engr } \\ \text { Wallace, Jerry D. } & \text { RF Engr }\end{array}$

M.A. Phys

$1 / 66$

B.S. EE

$11 / 67$

M.S. EE

$2 / 64$

M.S. EE 5/69-

7/71

M.S. EE $\quad 4 / 66$

M.A. Mech. $\quad 12 / 65$

M.S. ME $\quad 11 / 65$

B.S. EE $\quad 8 / 64$

Ph.D.EE 2/68

B.S. EE $8 / 64$ -

$9 / 70$

M.S. EE $\quad 7 / 67$

Admin, Sec, \& Clerical:

Eutsler, Margaret
French, Garrison H.
Ray'burn, Lois
Thisrn, Wayne K.

Steno

Draftsman

Grp Sec

Draftsman

Elec Tech

Elec Tech

Elec Tech

Elec Tech

Elec Tech

Elec Tech

Elec Tech

Elec Tech

Elec Tech

Elec Tech

Elec Tech
$7 / 69$

$2 / 66$

$5 / 70$

$10 / 66$

B.S.

$7 / 65$

Tech Inst

$3 / 67$

$7 / 69$

Tech Inst

$4 / 65$

Tech Inst

$3 / 66$

$10 / 66$

$7 / 70$

4./67

$9 / 67$

$4 / 64$

$7 / 67$

\section{MP-2 - Construction Staff}

Staff Members:

Ferguson, Harold D.

Mech Engr

B.S. ME

$7 / 67$

Hardwick, Jack N.

RF Engr

Kelly, Maxie $M$.

Morris, Duard 1.

Tubb, George E.

Mech Engr

M.S. Math

$7 / 67$

RF Engr

B.S. ME

$6 / 68$

RF Engr

B.S. ME

$9 / 67$

Riedel, Jack

RF Engr

B.S. Phys

$8 / 66$

Phys

$1 / 71$

Admin, Sec, \& Clericill:

Baran, Edward J.

Draftsman

Gallegos, Jose

Drartsman

Helland, William R.

Elec Tech

Mills, Rene

Data Analyst

$10 / 69$

Roller, Theodore

Hawkins, Walter L.

Draftsman

Katcher, Joe G.

Elec Tech

Ridlon, Rae N.

Zastrow, John A.

Elec Tech

Elec Tech 
MP-j - Accelerator Structures - R\&D Staff

\begin{tabular}{|c|c|c|c|c|}
\hline & Knapp, Edward A. & $\begin{array}{l}\text { Group Leader \& } \\
\text { Asst Div Ldr }\end{array}$ & Ph.D. Phys & $2 / 63$ \\
\hline & Swenson, Donald & Assoc Grp Ldr & Ph.D. Phys & $12 / 64$ \\
\hline & Worstell, Hairston & Assoc Grp Ldr & B.S. ME & $9 / 63$ \\
\hline \multirow[t]{17}{*}{ Staff Members: } & Bush, Edgar D. & Design & M.S. ME & $6 / 65$ \\
\hline & Busick, John F. & Accel Oper & B.S. & $8 / 68$ \\
\hline & Gillis, Robert C. & Design & B.S. ME & $6 / 65$ \\
\hline & Goplen, Bruce C. & Beam Dynamics & M.S. Phys & $7 / 70$ \\
\hline & Hart, Valgene E. & Install \& & M.S. ME & $3 / 64$ \\
\hline & & Alignment & & \\
\hline & Kelly, L. Michael & Design & B.S. ME & $6 / 66$ \\
\hline & Koczan, Steven P. & Fabrication & B.S. ME & $1 / 66$ \\
\hline & Martin, E. Ray & R\&D & Ph.D. Phys & $10 / 67$ \\
\hline & Paciotti, Michael & Beam Dynamics & Ph.D. Phys & $1 / 70$ \\
\hline & Rislove, Seth E. & Cooling Systems & M.S. NE & $4 / 66$ \\
\hline & Ruhe, Janes R. & Vacuum & M.S. NE & $7 / 65$ \\
\hline & Schneider, Edward & Elec Design & B.S. EE & $11 / 66$ \\
\hline & Shlaer, William & R\&D & Ph.D. Phys & $8 / 65$ \\
\hline & Swain, George R. & R\&D & Sc.D. EE & $10 / 65$ \\
\hline & Tregellas, Ri،hard & R\&D & B.S. EE & $8 / 67$ \\
\hline & Trump, Michael & R\&D & B.S. EE & $6 / 68$ \\
\hline
\end{tabular}

Adimin, Sec, \& Clerical:

Garcia, Steve F.

Harrison, Ronald

Miller, Kaye

O'Neal, Melvin K.

Smith, Chester R.

Stroik, Paul J.

Skiller Crafts Personnel:

Adams, Edwin L.

Armijo, Valerio

Manger, Charles E.

Mynaugh, Charles

Ortega, Jose P.

Sherwood, Jerald

Studebaker, Jan K.

Suazo, Gilbert

MP-3 - Construction Staff

Staff Members:

$$
\text { Colston, Elbert W. }
$$

Rhorer, Richarard

Schamaun, Roger $\mathbf{R}$.

Stovall, James E.

Van Dyke, W. Joseph
Draftsman

Draftsman

Grp Sec

Draftsman

Draftsman

Draftsman

Accel Oper

Mech Tech

Elec Tech

Phys Tech

Elec Tech

Mech Tech

Elec Tech

Mech Tech
$12 / 69$

$1 / 69$

$7 / 71$

$8 / 65$

$5 / 64$

$8 / 65$

$2 / 70$

$12 / 66$

$3 / 66$

$11 / 65$

$1 / 70$

$6 / 64$

Tech Inst

$9 / 65$

$10 / 66$
Install \&

Alignment

Design

Design

R\&D

Design
B.S. ME

$1 / 69$

M.S. ME

M.S. ME

B.S. Phys

B.S. ME 
Skilled Crafts Personnel.

Arquero, Eligio
Bricễo, Eugene W.
Canfield, Craig T.
Chellis, Kenneth
Clayton, Richard
Clayton, Ronald D.
Cordova, Justo F.
Espinoza, Alfred
Gonzales, Gilbert
Harrison, Robert F.
Herman, Lloyd J.
Johnson, Jerald L.
Jones, David F.
Jones, David M.
Lopez, Eugene J.
Martinez, Richard
Martinez, Vidal
McClellan, Patrick
Mills, Ennis
Ortiz, Benjamin F.
Poe, Bobby F.
Rector, Bobby
Rivera, Oliver M.
Romero, Jerry
Roybal, Gustavo
Sandoval, Daniel A.
Trujillo, Faustin
Weiler, Edward R.
Welch, Carl L.
West, Dennis K.

Mech Tech

Mech Tech $\quad 1 / 67$

Mech Tech $\quad 5 / 70$

Mech Tech $\quad 1 / 70$

Mech Tech

$1 / 69$

Mech Tech

$5 / 70$

Mech Tech

$7 / 69$

Mech Tech

$2 / 69$

Mech Tech

$12 / 67$

Mech Tech

$11 / 67$

Elec Tech

$7 / 70$

Mech Tech

$11 / 70$

Mech Tech

$5 / 70$

Mech Tech

$11 / 68$

Mech Tech

$2 / 70$

Mech Tech

$9 / 69$

Mech Tech

$7 / 69$

Mech Tech

$5 / 67$

Mech Tech

$2 / 69$

Mech Tech

$5 / 69$

Mech Tech $\quad 5 / 70$

Mech Tech $\quad 5 / 70$

Mech Tech $\quad 1 / 70$

Mech Tech $\quad 4 / 69$

Mech Tech $\quad 7 / 69$

$\begin{array}{ll}\text { Mech Tech } & 10 / 67\end{array}$

Mech Tech $\quad 5 / 69$

MP-4 - Injector - R\&D Staff

Nagle, Darragh E.
Emigh, C. Robert

Staff Members:

Allison, Paul W.
Crandall, Kenneth
Meyer, Earl A.
Mueller, Donald W.
Oostens, Jean M.
Potter, James E.
Stevens, Ralph R.

Admin, Sec, \& Clerical

Trussell, Patsy

Grp Sec

4/71

Skilled Crafts Personnel:
Group Leader Alt Div Ldr Assoc Grp Ldr

Ion Source

Beam Dynamics Accelerating

Column

Ion Source

Spectrometer

R\&D

Beanı Transport
Ph.D. Phys

$2 / 63$

Ph.D. Phys

$3 / 65$

B.S. Phys

M.S. Phys

A.B. Phys

M.S. Phys

M.S. Phys

Ph.D. Phys

$5 / 66$

$10 / 65$

$10 / 67$

$7 / 63$

$7 / 70$

$7 / 70$

$9 / 66$
Ph.D. Phys
Mech Tech

Instr Dev

Accel Oper
Tech Inst 
Rajala, Robert F.

Scoti, Leonard

MP-4 - Construction Staff

Adnuin, Sec, \& Clerical

Leavitt, John $\mathrm{N}$.

Vasquer, Joe E.

Skilled Crafts Personnel:

Dalton, Charlice

Lemoins, Wayne $W$.

Milder, Martin

Rodriguez, Joe E.

MP-5 - Building and Site Construction - R\&D Staff

lidwards, Paul D.

Claiborne, Eddic

Tesche, Frederick

Admin, Sec, \& Clerical:

Burdette, Robert $\mathbf{S}$.

Cutler, Louis

Riggs, Mary $\mathrm{V}$.

Vigil, Epitacio

Skilled Crafts Personnel:

Gonzales, Pablo A.

MP-5 - Construction Staff

Staff Members:

Wilhelm, Richard

Y'srk, Don A.

Programimer

Engr

Liaison Engr

Prop Supv

Grp Sec

Prop Rep

Driver

M.S. Phys

B.S. Engr

Ph.D. Phys

$12 / 69$

$6 / 65-$

$6 / 68$

B.S. Eingr

$3 / 66$

$2 / 66$

$7 / 68$

$7 / 69$

$3 / 70$

B.S. ME 7/65-

Admin, Sec, \& Clerical:

Garreffa, Larry
Ryan, Bernard L.
Whittemore, Pat
Comp Analyst

Procurement

Clerk
$5 / 67$

$7 / 67$

$5 / 68$

\section{MP-6 - Experimental Areas - R\&D Staff}

$\begin{array}{lllll} & \text { Cochran, Donald R.F. } & \text { Group Leader } & \text { Ph.D. Chem } & 2 / 64 \\ \text { Wilson, Mahlon T. } & \text { Assoc Grp Ldr } & \text { Ph.D. ME } & 5 / 67 \\ & \text { Franke, Paul R. } & \text { Asst Grp Ldr } & \text { B.S. Phys } & 5 / 67 \\ \text { Gram, Peter A.M. } & \text { Beam Diagnostics } & \text { Ph.D. Phys } & 1 / 68 \\ & \text { Harvey, Alexander } & \text { Magnet Design } & \text { B.S. EE } & 2 / 70 \\ \text { Hassenzahl, William } & \text { Magnet Mcasurc } & \text { Ph.D. Phys } & 9 / 67 \\ \text { Roeder, Dennis } & \text { Computation } & \text { A.B. Phys } & 6 / 69 \\ & \text { Shively, Frank T. } & \text { Beam Transport } & \text { Ph.D. Phys } & 9 / 69\end{array}$


Admin, Sec, \& Clerical:

Grote, Freda $A$.

Thorn, Linas l..

Shilled Crafts Personnel:

Uher, Joseph 1 ..

MP-6 - Construction Staff

Staff Members:

Bridge, James $A$.

King, Charles R.

Meier, Karl

Turner, Robert D.

Admin, Sec, \& Clerical:

Christiansen, R.

Davis, Lawrence

Havens, James $\mathrm{H}$.

Martinez, Ricardo

Mclnteer, Carlotza

Michaud, Francis

Montoya, William

Roybal, Phillip

Sharp, Nancy

Skilled Crafts Personnel:

Caine, James $C$.

Leydig, Robert

Martinez, Lonjino

Montoya, Tecdosio

Mueller, Charles

Roberts, Maynard

Voss, Hans J.

Grp Sec

$9 / 69$

Sr Designer

$11 / 67$

Mech Tech

$10 / 69$
Switchyard Dev
Exper Area Oper
Target Dev
Magnet Design

B.S. ME

$7 / 70$

M.S. EE

$5 / 71$

M.S. ME

$7 / 70$

B.S. ME

$7 / 70$

\begin{tabular}{|c|c|c|}
\hline Designer & & $11 / 68$ \\
\hline Draftsman & & $1 / 70$ \\
\hline Draftsman & & $7 / 70$ \\
\hline Draftsman & & $12 / 68$ \\
\hline Data Analyst & $\begin{array}{l}\text { B.S. Math } \\
\text { (Eq) }\end{array}$ & $6 / 71$ \\
\hline Designer & & $3 / 68$ \\
\hline Draftsman & & $1 / 70$ \\
\hline Draftsman & & $5 / 70$ \\
\hline Data Analyst & B.S. Math & $\begin{array}{l}10 / 70- \\
6 / 71\end{array}$ \\
\hline
\end{tabular}

Elec Tech

Elec Tech

Mech Tech

Mech Tech

Mech Tech

Mech Tech

Elec Tech

Tech Inst

$9 / 69$

$4 / 70$

$7 / 70$

$1 / 68$

$7 / 70$

$7 / 70$

$7 / 70$

MP-7 - Secondary Beam Lines and Spectrometers - R\&D Staff

Agnew, Lewis E.

Thiessen, H. A.

Staff Members:

Amato, James J.
Burman, Robert $\mathbf{L}$.

Cowan, Helen D.

Dunwoody, Wade E.

Hutson, Richard L.

Hwang, Chester F.

Macek, Robert J.

Nuvak, Jan K.

Schiliaci, Mario

Tanaka, Nobuyuki
Group Leader

Assoc Grp I.dr

f ow Lnergy Pion

Channel

Low Energy Pion

Channel

Pion Channels

EPICS

Bio Med

Nucleon Phys

$\mathrm{P}^{3}$ Pion Channel

Nucleon Phys

Raa Isotope Prod

HRS
Ph.D. Phys

$11 / 68$

Ph.D. Phys

$10 / 66$

Ph.D. Phys

$9 / 69$

Ph.D. Phys

$9 / 68$

B.S. Chem

$10 / 69$

B.S. ME

$6 / 70$

Ph.D. Phys

$10 / 69$

Ph.D. Phys

$2 / 71$

Ph.D. Phys

$2 / 69$

M.S. ME

$4 / 70$

$1 / 70$

Ph.D. Phys

Ph.D. Phys 
Thompson, Patrick

Vogel, Herbert F.

Admin, Sec, \& Clerical:

Thorn, Patricia

Weinbrecht, Nancy

MP-7 - Construction Staff
Muon Channel

Muon Channel

Ph.D. Phys

$4 / 71$

Dipl Engr

$5 / 66$

Yourd, Roland B.
Grp Sec

Data Analy'st

B.A.

$6 / 70$

$4 / 69$

M.S. ME

$12 / 70$
Magnet Design 


\section{APPENDIX B}

UNIVE RSITIES AND LABORATORIES PARTICIPATING IN FIRST LAMPF USERS MEETING,

JUNE 20, 1968

Virginia Associated Research Centel

Chalk River (AECL)

Columbia University

Texas A \& $\mathbf{M}$

Carleton University

University of California, Berkeley

University of Wisconsin

Ames Laboratory

Catholic University

University of Toledo

Michigan State University

University of Wyoming

Brigham Young University

Ncw Mexico State University

University of South Carolina

University of Utah

Uriversity of Oregon

University of Southern California

Brookhaven National Laboratory

University of Houston

Virginia Polytech

College of William \& Mary

Rice University

Northeastern University

University of Victoria

Lawrence Radiation Laboratory

University of Denver

Oak Ridge National Laboratory

Florida State University

Montana State University

California Institute of Technology

University of Texas

Sarnegie-Mellon University

University of Iowa

Associated Western Universities
Colorado College

University of Maryland

Massachusetts Institute of Technology

University of Alberta

Duke University

Yale University

USAEC-Washington \& Idaho Falls

Arizona State University

University of Montana

Northwesterr. University

University of Idaho

University of California, Los Angeles

University of Rochester

Los Alamos Scientific Laboratory

University of Arizona

Argonne National Laboratory

Colorado State University

University of New Mexico

University of Colorado

University of Illinois

University of Washington

Stanford Linear Accelerator Cenier

University of Georgia

University of North Carolina

University of Minnesota

Texas Institute of Technology

University of Chicago

Texas Nuclear Corporation

University of Manitoba

University of Virginia

Purdne University

Univorsity of British Columbia

Case Western University

University of Indiana

University of Maryland 


\title{
APPENDIX C
}

\section{USERS GROUP}

\author{
Los Alamos Meson Physics Facility
}

\section{CHARTER}

The Los Alamos Meson Physics Facility (LAMPF) Users Group is an organization of active scientists and engineers with a special interest in LAMPF and, in particular, its research prograin. The purpose of this group is two-fold:

a) To provide a formal channel for the exchange of information between the LAMPF administration and scientists of other laboratories who will utilize this facility fur their research.

b) To provide a means for involving scientists and engineers from user groups in specific projects at LAMPF and for offering advice and counsel to the LAMPF management on LAMPF operating policy and facilities.

Through a wide representation of scientists the group will make known to the LAMPF administration the needs and desires of those scientists actively engaged in research projects. As an example of the relationship between the users community and the LAMPF administration, it is understood that some members of the Program and Scheduling Cummittee will be selected from candidates proposed by the Users Group.

1. Membership. The membership of the Users Group is repen to practicing scientists and engineers. The LASL-appointed Director of LAMPF and University and National Laboratory Scientific Administrators shall be

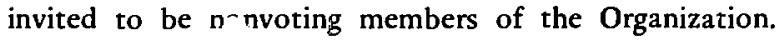
Following the drawing up of an original membership list, new members will be added by action of the Executive Committee of the Users Group upon receipt of a written request. In addition, each member will indicate in writing at the time of each general election his desire to remain on the membership list for the coming year.

2. Officers and Executive Committee. The officers of the Users Group shall consist of a Chairman, Chairman-elect, Liaison Officer, and three other elected members. The Chairman, Chairman-elect, and three elected members will constitute the Executive Committee of the LAMPF Users Group. The Liaison Officer will be an ex officio member of the Executive Committee. The Chairman-elect and the three committee members will be elected annually by mail ballot. The first slate of officers shall be elected by a plurality of the users attending the initial organization meeting held at Los Alamos on January 16, 1969 , and thereafter elections st.all be held as described in 2a, b, c, and d.

a. A Chairman-elect shall be elected annually by members of the Users Group by written ballot, distributed prior to October 1 to the membership as of September 1 , and shall take office on January 1 of the following year. A plurality of votes cast is sufficient for election.

b. The Chairman-elect will succeed to the office of Chairman at the end of one year.

c. The term of the Chairman of the Users Group for LAMPF is for a period of one year.

d. The three other members of the Executive Committee will be elected annually. 
e. A Liaison Officer of the Users Group is to be appointed by the LAMPF Director in consultation with the Chairman and Chairman-elect of the Users Group. It will be the duty of the Liaison Officer to act as secretary of the meetings and keep the minutes. He will request nominations, send and tally mail ballots, and generally serve as secretary to the Users Group. It is further the duty of the Liaison Officer to keep the Users Group informed by means of frequent news letters of new developments at the LAMPF and other matters of interest to the users. The Liaison Officer shall serve for a period of two years and can be reappointed for an additional two. He should not serve three consecutive terms.

f. A person who has served as Chairman cannot be nominated as Chairman-elect for a period of three years.

3. Meetings. The LAMPF Users Group shall meet at least once each calendar year at a time and place designated by the Chairman, upon advice of the Executive Committee. Notice of the meeting should be sent to the members of the Users Group at least a month in advance and shall include the agenda for the meeting. The Secretary-Liaison Officer will prepare summaries of all meetings, which will be mailed to all members, arrange details of meetings and other necessary work of the Committee.

\section{Procedures.}

a. The Executive Committee may, on its own initiative, and shall, upon instruction of a majority of the members attending a general meeting, submit questions for consideration to the full membership. Results of the deliberations of the Users Group shall be communicated to the Director of LAMPF.

b. The Executive Committee shall recommend to the LAMPF administration names of user scientists for consideration as members of LAMPF's Program and Scheduling Committee.

c. The Executiv: Comnittee will appoint a Technical Advisory Panel (TAP) from the membership of the
Users Group. The Chairman of the Executive Committee will act also as Chairman of TAP. This Committee shall consist of twelve (12) members appointed for two years in such a way that six (6) new members are added each year to take office on January 1. The duties of the TAP will be to collaborate with the staff of the LAMPF in devising new experimental facilities and evaluating future developments. The TAP will meet at least twice a year, and the Chairman-elect and the Liaison Officer are to be members ex officio.

d. The Executive Committee shall appoint a Nominating Committee consisting of five members of the Users Group, but not including any officers, who are charged with the duty of nominating a slate of candidates for the Chairman-elect and the three other elective positions of the Executive Committee. The Nominating Committee may meet in person if it wishes or may transact its business by mail or by telephone. The Chairman of the Nominating Committee will be designated by the Chairman of the Users Group. Direct nominations, for each of the positions, from the membership can be made by a petition from at least ten (10) members, sent to the Chairman of the Executive Committee prior to September 15 .

5. This Charter shall be adopted, if approved, by two-thirds of the prospective members attending the initial meetings.

6. This Charter may be amended by a written vote of the members. A proposed amendment shall be introduced at a general meeting. A two-thirds majority of the members voting is required for passage of the amendment. The vote must be taken within a month of the time the amendment was introduced.

Adopted at Second LAMPF Users Meeting Los Alamos, New Mexico January 16, 1969 


\section{REFERENCES}

1. "Long-Range Program for Updating Low-Energy Nuclear Physics Facilities at Los Alamos." Memo from $L$. Rosen to J. M. B. Kellogg, May 16, 1962.

2. "Conference on Sector-Focussed Cyclotrons, Proceedings," Nucl. Inst. \& Meth. 18-19, 387-478 (1962).

3. "Preliminary Proposal for a Meson Facility at Los Alamos," Los Ajamos Laboratory of the University of California, Nec. 28, 1962. Prepared by: E, Bemis, L. Burdge, E. Claiborne, D Cochran, C. Critchfield, C. R. Emigh, P. Franke, J. Gammel, D. Hagerman, N. Jarmie, A. Kerman (Consultant), E. Knapp, A. Lyle, L. Marshall (Consultant), J. Marshall, A. McGuire, D, Nagle, L. Rodberg (Consultant), L. Rosen, D. Venable, S, Whetstone, and J. E. Young.

4. P-11 Progress Reprirts, D. E. Nagle, Group Leader, June 1963 to June 1965 .

5. Outline of Proposal for a Meson Facility at Los Alamos, L. Rosen, LAMS-2935, July 16, 1963.

6. Work Schedule, Organization, and Budget of LAMPF, by McGuire, Nagle, Hagerman, and Knapp, ENG-1; April 1963.

7. Introduction to Proposed Meson Project, L. Rosen and D. Nagle, LAMS-3025, Dec. 1963.

8. Proposed Los Alamos Meson Project; Ad Hoc Advisory Comm. to the U. S. Atomic Energy Commission (G. A. Kolstad, Chairman) March 17, 1964.

9. Report of the GAC/PSAC Panel (Ramsey Report), U.S. A.E.C. Division of Tech ical Information, TID-18363, April 26, 1963.

10. Meson Factories, "Bethe Panel Report," Office of Science and Technology, March 1964, p. 11. Panel members: H. A. Bethe, H. Feshbach, H. Gove, W. W. Havens, R. Christy, G. Phillips, and R. R. Wilson.

11. Proposal for a High-Flux Mexon Facility at Los Alamos, LASL, Sept. 1964. (The definitive proposal known locally as the "Blue Book.")

12. High-Energy Physies Research - Hearings before Subcommittee of JCAE, U.S. Government Printing Office Doc. No. 46-982, March 2-5, 1965.

13. "A Decade of Nuclear Progress," Chap. 4, "The AEC's LAMPF," AEC Document in preparation, 1071.

14. G. Ising, Arkiv fur Matematik, Astronomi och Fysik, 18, 1 (1924).

15. R. Wideroe, archiv fur Elektrotechnic 21, 387 (1928).

16. D. H. Sloan and E. O. Lawrence, Phys. Rev, 38, 2021 (1931).

17. D. H. Sloan and W. M. Coates, Phys. Rev. 46, 539 (1934).
18. B. B. Kinsey, Phys. Rev. 50, 386 (1936).

19. "Design of a Proton Linear Accelerator," L. W. Alvarez, Phys. Rev. 70, 799 (1946).

20. C. S. Taylor, Proton linacs; Alvarez Structure; p. 879-889. Linear Accelerators, Lapostolle \& Septier, Eds., North Holland Publ. Co., Amsterdam, 1970.

21. Private Communication: W. Walkinshaw to $M$. S. Livingston, Sept. 15, 1970 .

22. Letter: T. G. Pickavance (Harwell) to W. Walkinshaw (T.R.E., Great Malvern), Nov. 21, 1950.

23. Letter: T, G. Pickavance to D. W. Fry, Sept. 5, 1951.

24. Minutes: Meeting to discuss Future Migh-Energy Accelerator Program, $O c^{*}, 23,1951$.

25. Memo: "British Accelerator Policy and the European Nuclear Physics Scene" ca. early 1953. (Probably by T. G. Pickavance.)

26. "Design Study for a 600-MeV-Proton Linear Acceleratur," $L$. B. Mullett, AERE-G/M 151, April 1953.

27. E. C. Courant, M. S. Livingston, and H. S. Snyder, Phys. Rev. 88,1190 (1952).

28. "Design for Structure for Acceleration of Protons to 600 GeV," P. D. Dunn and D. J. Thompson, Harwell, AERE-GP/R 2000,1957 .

29. "Coupling of Resonant Cavities by Resonant Coupling Devices," P. D. Dunn, C. S. Sabel, and D. J. Thompson, AERE (Harwell) Report GP/R-1966, Dev. 1956.

30. "Notes on Coupled Pill Box Resonators Operating on the $\pi$-iMode," J. H. Adlam and P. D. Dunn, October 1954

31. Private Communication: G. Wheeler to M. S. Livingston, August 13, 1970 .

32. "A Very High Intensity Linear Accelerator for Protons of 750 MeV," by the Design Study Staff, Yale Internal Report Y-6, Octobe: 30, 1962.

33. Yale study on High Intensity Proton Acceterators, Design Staff, Yale Internal Report Y-12, October 1964.

34. L. H. Thomas, Phys. Rev. 54, 580, 588 (1938).

35. "Sector Focused Cyclotrons," Conference at Sea Island, Georgia, F. T. Howard, Ed., Nat'l. Acad. Sci.-Nat. Res. Coun. Publ. 656, 1959.

36. "Oak Kidge Relativistic Isochronous Cyclotron," R. S. Livingston and F. T. Howard, Eds., ORNL-2648, Sept. 1958. 
37. "Proposal for $\mathrm{Mc}^{2}$ Isochronous Cyclotron," ORNL-3540, Nov. $1,1963$.

38. "Conference on SF Cyclotrons, Proceedings," Nucl. Instr. Meth. 18-19, 387-478, 1962.

39. "A Strong Focusing Cyclotron with Separated Orbits," F. M. Russell, ORNL-3431, Jan. 1963.

40. Private Communications: J. R. Richardson to $M . S$. Livir.gston, Oct. 14, 1970, and Dec. 10, 1970.

41. Proposal to the U.S. AEC for a Conceptual Design and Preliminary Engineering Study of a Cyclotron for the Production of Large Fluxes of Mesons," J. Reginald Richardson, Kenneth R. MacKenzie, Byron T. Wright, Donald H. Stork, and Roy P. Haddock, July 1960.

42. "700 MeV Negative Hydrogen Ion Facility," J. R. Richardson, UCLA Report, 1963.

43. Pion Facility - A High Energy Cyclogron for Negative lons, J. R. Richardson, UCLA Report, 1964.

44. "Tri University Meson Facility - TRIUMF," Proposal, Eds: E. W. Vogt and J. J. Burgerjon, U. of British Columbia, Vancouver, Nov. 1966.

45. "Proposal for Sector-focused Cyclotron for 450-MeV," ETH Report, Zurich, Jan. 1964.

46. Villigen, Progress of SIN Cyclotron Project, CERN Courier, Vol, 11, June 1971 .

47. "Modification Program for the Nevis Synchrocyclotron," J. Rain water, Columbia U. Dept. of Physics Report, R-536, Jan. 1966.

48. Proceedings: Particle Accelerator Conference, IEEE Trans., NS-16, No. 3, June 1969 and IEEE Trans. (to be published) 1971.

49. "The AECL Study for an Intense Neutron Generator," Eds: G. A. Batholomew and P. R. Tunnicliffe, AECL-2600, July 1966.

50. Private Communication: E. W. Vogt to M. S. Livingston, Nov. 27, 1970 .

51. Proton Linac Conference Minutes, Yale, Oct. 21-25, 1963.

52. Minutes: Proton Linear Accelerating Conference, MURA, July 20-24, 1964, MURA-714 and UC-28 and TID 45 (37th Ed.).

53. "Electron Analog Tests of Proton Linac Structure," John E. Brolley, Jr, E. Robert Emigh, and Donald Mueller. Proceedings Nat'l. Accel. Conf., 1965, IEEE Trans., June 1965.

54. "The Pierce Geometry Accelerating Column Design," C. Robert Emigh, Oct. 1966.

55. "On the Feasibility of $\mathrm{H}^{-}$-Ion Acceleration at LAMPF," Paul W. Allison and C. R. Emigh, MP-4/PWA, CRE-1, July 2, 1968.

56. "Source of Polarized Negative Hydrogen Ions," G. P. Lawrence, G. G. Ohlsen, and J. L. McKibben, Physics Letters, 28B, 594 (March 3, 1969).
57. Generation of Geometrical Dimensions for Drift Tube Linacs, D. A. Swenson, MP-3/DAS-1, June 29, 1967.

58. "An 805 Mc 1-1/4 Mw Amplifier for Accelerator Service," IEEE Trans. on Nucl. Sci., D. C. Hagerman, J. D. Doss, R. W. Freyman, and J. R. Parker, Vol. NS-12, No. 3, p. 96, June 1965.

59. "Design of RF Phase and Amplitude Contro' for a Proton Linac," R. A. Jameson, T. F. Turner, and N. W. Lindsay, IEEE Trans. of Nucl. Sci. NS-12, No. 3, p. 138, June 1965.

60. "805-MHz Power Sources for the LAMPF Accelerator," D. C. Hagerman, Proton Linac Conference, Brookhaven, 1968.

61. Memo to D. E. Nagle from R. A. Jameson and H. S. Butler, "Process Computer Control of the LAMPF Linac," Oct. 14, 1963.

62. T. M. Putnam, R. A. Jameson, and T. M. Schultheis, "The Application of a Digital Computer to the Control and Monitoring of a Proton Linear Accelerator," IEEE Trens. on Nucl. Sci., Vol. NS-12, No. 3, June 1965, pp. 21-26.

63. H. S. Butler and J. J. Smith (of EG\&G), "LAMPF DataAcquisition and Control System," LAMPF Internal Report MP-1-803, Nov. 1965.

64. T. M. Putnam, "LAMPF Control System Design and Construction," LAMPF Internal Report MP-1-121, Nov. 1967.

65. H. S. Butler, "Proposal for the LAMPF Computer," LAMPF Internal Report MP-1-910, Dec. 1968.

66. "Status of LASL Monte Carlo Intra-nuclear Cascade Calculations," S. L. Whetstone, LA-3206-MS, March 3, 1965.

67. Memo: M. Wilson to L. Rosen, "Remote Handling Philosophy for LAMPF," July 18, 1968.

68. "Proposal for HRS for Proton Reactions near $800 \mathrm{MeV}$," Princ. Invest., L. Rosen, plus 15 Users, August 16, 1968.

69. Proposed Organization for the Management of LAMPF as a National Facility. G. A. Kolstad, August 10, 1966.

70. LAMPF Users Handbook, LA-4586-MS, Jan. 1971.

71. Proposal for Nucleon Physics Lab at LAMPF, J. E. Simmons and L. Agnew, plus a Users Working Group, Dec. 9, 1969.

72. "Use of LAMPF for Isotope Production," L. Rosen, M. E. Shillaci, B. J. Dropesky, and H. A. O'Brien, LA-4587-MS, Dec. $15,1970$.

73. "Possibilities of Therapeutic Application of Beams of Negative Pi-Meons," P. H. Fowler and D. H. Pet ins. Nature 189. 525 (1961).

74. "Possibilities of Using Negative Pions in Rudiotherapy," $L$. Ros'n, Nuclear Applications 5, 379, Dec. 1968.

75. "Proposal for a Biomedical Addition to LAMPF," LA-4490-P, July 1970. 